\title{
Exploration of Linkages between Nickel Speciation and Toxicity to Aquatic Biota in Mining and Municipal Aqueous Effluents
}

\author{
by \\ Yamini Gopalapillai \\ (B.Sc., Carleton University)
}

\author{
A thesis submitted to the Faculty of Science \\ in partial fulfillment of the requirements for the degree of \\ Master of Science \\ Department of Chemistry \\ Carleton University \\ Ottawa, Ontario
}

Copyright (C) 2007

Yamini Gopalapillai 


$\begin{array}{ll}\begin{array}{l}\text { Library and } \\ \text { Archives Canada }\end{array} & \begin{array}{l}\text { Bibliothèque et } \\ \text { Archives Canada }\end{array} \\ \begin{array}{l}\text { Published Heritage } \\ \text { Branch }\end{array} & \begin{array}{l}\text { Direction du } \\ \text { Patrimoine de l'édition }\end{array} \\ \begin{array}{l}\text { 395 Wellington Street } \\ \text { Ottawa ON K1A ON4 }\end{array} & \begin{array}{l}\text { 395, rue Wellington } \\ \text { Ottawa ON K1A ON4 } \\ \text { Canada }\end{array}\end{array}$

Your file Votre référence ISBN: 978-0-494-36845-9 Our file Notre référence ISBN: 978-0-494-36845-9

NOTICE:

The author has granted a nonexclusive license allowing Library and Archives Canada to reproduce, publish, archive, preserve, conserve, communicate to the public by telecommunication or on the Internet, loan, distribute and sell theses worldwide, for commercial or noncommercial purposes, in microform, paper, electronic and/or any other formats.

The author retains copyright ownership and moral rights in this thesis. Neither the thesis nor substantial extracts from it may be printed or otherwise reproduced without the author's permission.
AVIS:

L'auteur a accordé une licence non exclusive permettant à la Bibliothèque et Archives Canada de reproduire, publier, archiver, sauvegarder, conserver, transmettre au public par télécommunication ou par l'Internet, prêter, distribuer et vendre des thèses partout dans le monde, à des fins commerciales ou autres, sur support microforme, papier, électronique et/ou autres formats.

L'auteur conserve la propriété du droit d'auteur et des droits moraux qui protège cette thèse. $\mathrm{Ni}$ la thèse ni des extraits substantiels de celle-ci ne doivent être imprimés ou autrement reproduits sans son autorisation.
In compliance with the Canadian

Privacy Act some supporting forms may have been removed from this thesis.

While these forms may be included in the document page count, their removal does not represent any loss of content from the thesis.
Conformément à la loi canadienne sur la protection de la vie privée, quelques formulaires secondaires ont été enlevés de cette thèse.

Bien que ces formulaires aient inclus dans la pagination, il n'y aura aucun contenu manquant.

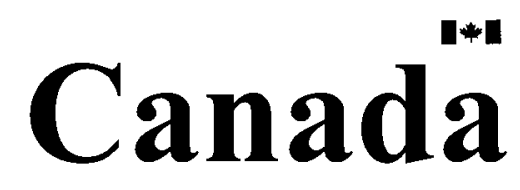


In memory of my loving father 
The undersigned hereby recommended to the Faculty of Graduate Studies and Research acceptance of the thesis,

"Exploration of Linkages between Nickel Speciation and Toxicity to Aquatic Biota in Mining and Municipal Aqueous Effluents"

\author{
submitted by \\ Yamini Gopalapillai \\ B.Sc. (Carleton University)
}

in partial fulfillment of the requirements for

the degree of Master of Science

Chair, Department of Chemistry

Thesis Supervisor

2007, Carleton University

2007, Carleton University

iii 


\begin{abstract}
Metal speciation and its relationship to toxicity are critical concepts for understanding the effect of metals on the natural environment. This study explores the speciation of nickel and its relationship to algal toxicity (Pseudokirchneriella subcapitata) in mining and municipal aqueous effluents. Ion Exchange Technique (IET) was applied to determine free nickel ion concentration, $\left[\mathrm{Ni}^{2+}\right]$, which was compared with the predictions of Windermere Humic Aqueous Model (WHAM) VI. Labile [Ni] and [Cu] were measured using Competing Ligand Exchange Method (CLEM), for comparison. Only half of the samples showed agreement between the IET and the WHAM VI results. Good consistency was found between the measured $\mathrm{IC}_{25}$ (concentration causing $25 \%$ growth inhibition) and the labile [Ni], but not the IET-measured $\left[\mathrm{Ni}^{2+}\right]$. The results of this study suggest that labile metal concentrations may be better indicators of bioavailability in complex effluent samples, and further development of IET for applications to such samples is necessary for the method validation.
\end{abstract}




\section{Acknowledgements}

I should like to take this opportunity to acknowledge all those who have contributed to my intellectual growth during this M.Sc. study. I extend a special appreciation to my supervisor, Professor C.L. Chakrabarti, for gently encouraging me to do my best and for helping me to achieve my initial dream of working on a multidisciplinary project combining the disciplines of Chemistry and Biology. Chak's ceaseless dedication to research is truly inspirational.

I wish to also express my appreciation to Dr. David R. S. Lean from the University of Ottawa for providing the resources to complete my algal bioassay study and for his invaluable help and support. My special thanks to Dr. Emmanuel Yumvihoze for measuring the phosphate levels in the Sudbury effluent samples and for all his help and support throughout the project.

Many thanks to the entire Chakrabarti research group, past and present, for their role in enriching my graduate experience: Ismail Fasfous, Partha Chakraborty, Jian Fu (Andrew) Deng, Joya (Rong) Wang, Min Yang, Tahir Yapici, and Jiujiang (JJ) Zhao. Finally, I wish to express my sincere gratitude and love to my family and my fiancé, for their continued love and support.

I gratefully acknowledge the financial support provided by the Ontario Graduate Scholarship in Science and Technology and the Emmett Dunne Scholarship. 


\section{Table of Contents}

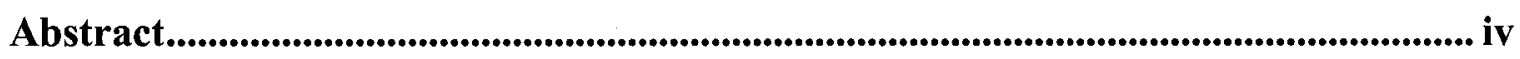

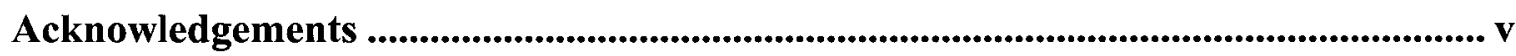

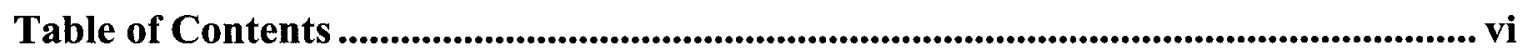

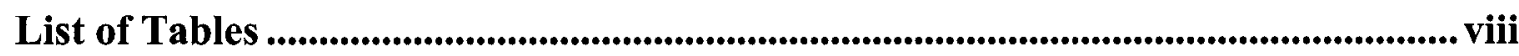

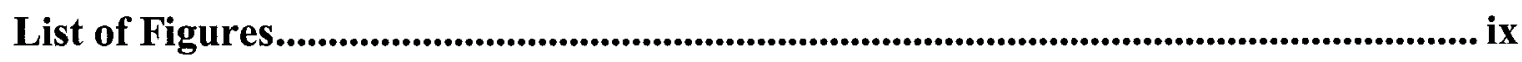

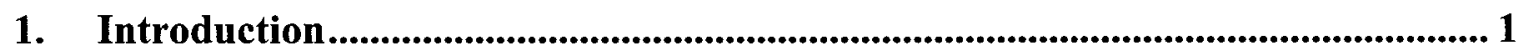

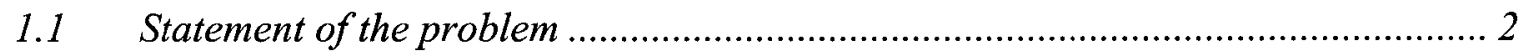

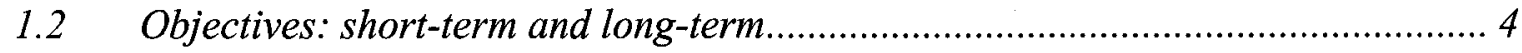

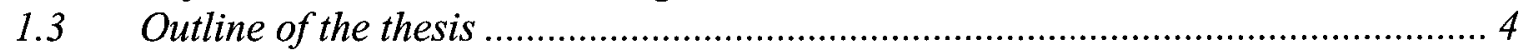

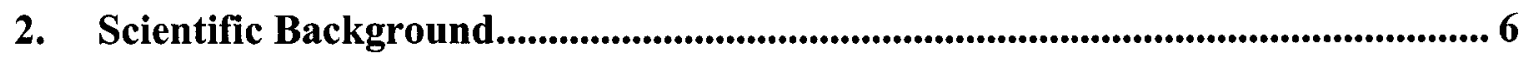

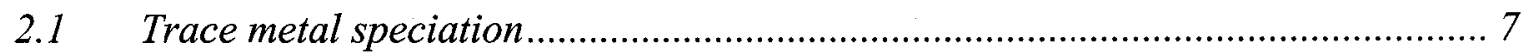

2.2 Nickel in the environment ........................................................................ 8

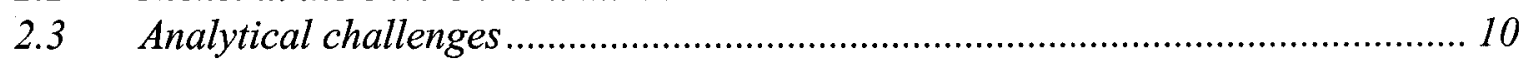

2.4 Interactions between trace metals and aquatic organisms............................... 13

2.5 Predicting metal speciation: Windermere Humic Aqueous Model...................... 16

2.6 Predicting metal toxicity: Biotic Ligand Model (BLM) .................................. 18

3. Determination of free nickel ion concentrations using the Ion Exchange Technique (IET) in aqueous mining and municipal effluents: Comparison of the IET results with the WHAM VI predictions................................................. 23

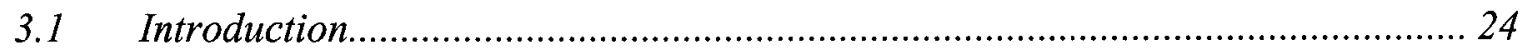

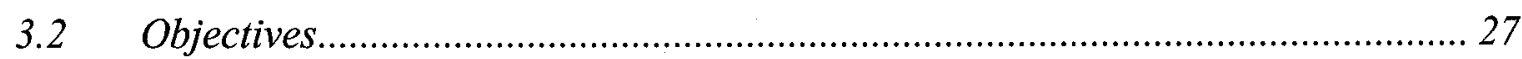

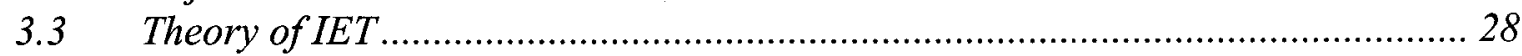

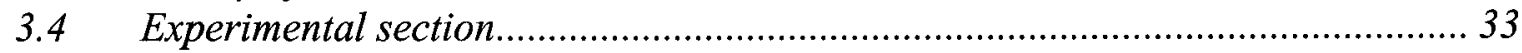

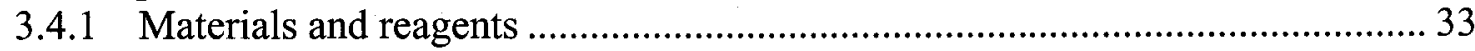

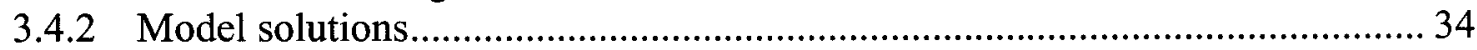

3.4.3 Mining and municipal aqueous effluent samples...................................... 35

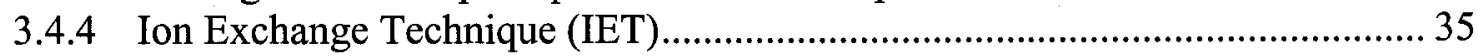

3.4.5 Graphite Furnace Atomic Absorption Spectrometry ................................... 37

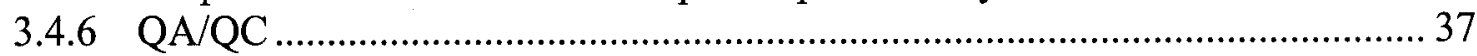

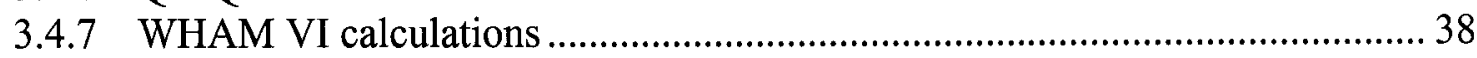

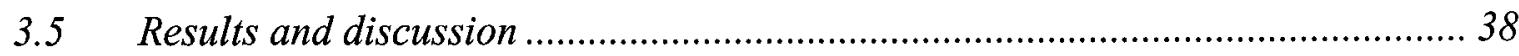

3.5.1 GFAAS: Optimization of the graphite furnace program for nickel

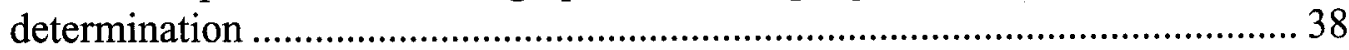

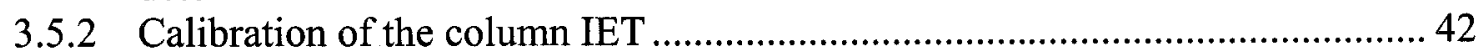

3.5.3 Effect of ionic strength and $\mathrm{pH}$ on the $\mathrm{Ni}$ (II)-binding affinity of the resin ...... 46

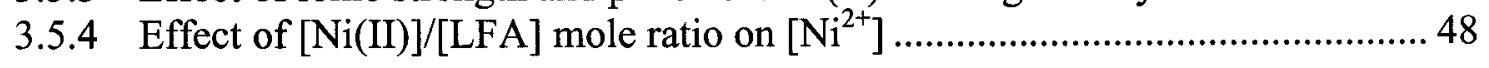


3.5.5 Sudbury mining and municipal aqueous effluents........................................ 50

3.5.6 Comparison of the IET results with WHAM VI predictions ........................... 52

4. Relationships between equilibrium- and kinetics-based estimates of nickel speciation to algal toxicity in aqueous mining and municipal effluents.................. 61

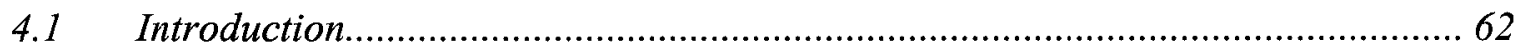

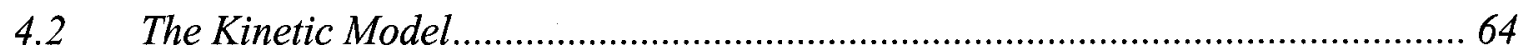

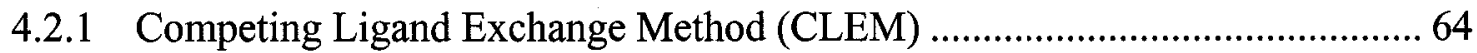

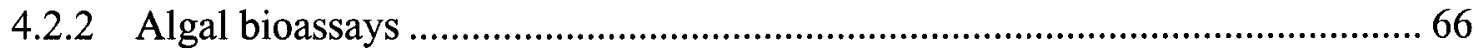

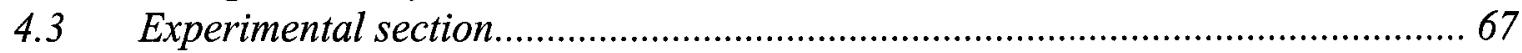

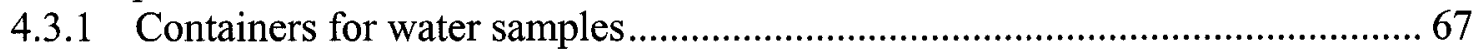

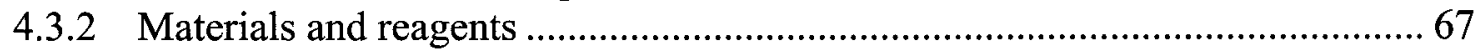

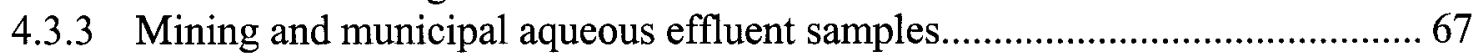

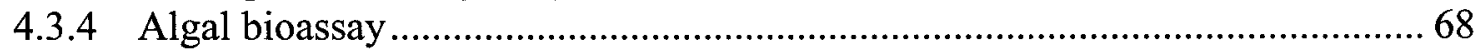

4.3.5 Competing Ligand Exchange Method (CLEM) .........................................6 69

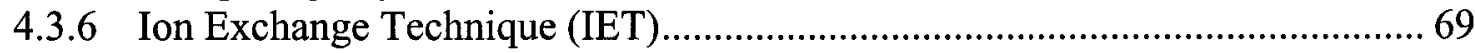

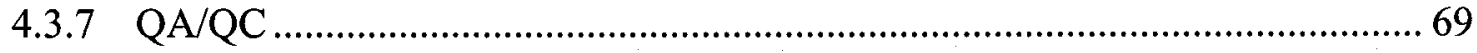

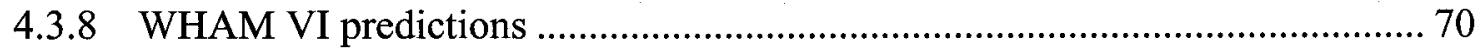

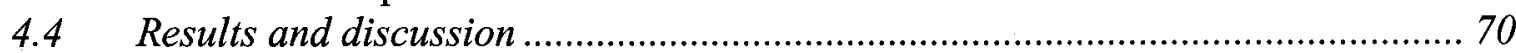

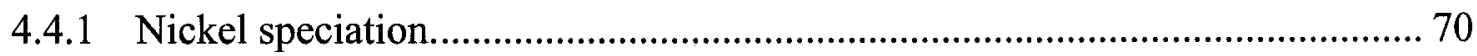

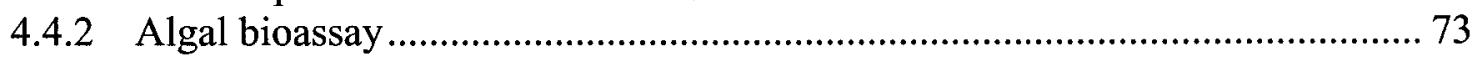

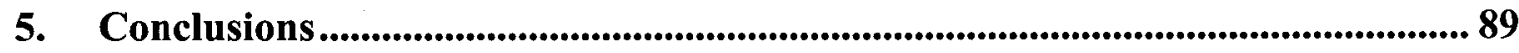

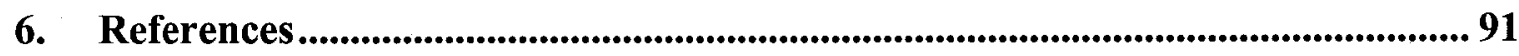

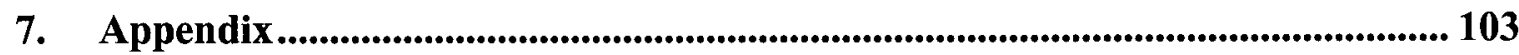




\section{List of Tables}

Table 3.1 Properties of Dowex ${ }^{\mathrm{TM}} 50 \mathrm{~W}-\mathrm{X} 8$, a widely-used cation-exchange resin for determination of free metal ion concentration.

Table 3.2 Formation constants used to calculate free nickel ion concentration.

Table 3.3 Optimized furnace instrumental operation program for determination of nickel in acidic solutions of high ionic strength (up to $0.2 \mathrm{M}$ ) by graphite furnace atomic absorption spectrometry (Perkin Elmer AAnalyst 600).

Table 3.4 Effect of [Ni(II)]/[LFA] mole ratio on the percentage of free $\mathrm{Ni}(\mathrm{II})$ (with respect to total nickel concentration) determined by column IET.

Table 3.5 Concentrations of major anions, major cations and other trace metals in the mine and municipal aqueous effluent water samples, collected from Sudbury, Ontario, in May 2006.

Table 3.6 The IET determined free nickel ion concentration compared with the predictions of WHAM VI (assuming $40 \%$ of Dissolved Organic Carbon as "active") and the nickel-to-DOC mole ratio as a parameter.

Table 4.1 Composition of the modified algal growth medium used for the algal culture and the exposure medium used for the test experiments (AAP medium; modified from Environment Canada (1992) [75]

Table 4.2 Ligand exchange kinetics of $\mathrm{Ni}$ (II)-DOC and $\mathrm{Cu}$ (II)-DOC complexes in mining and municipal effluent water samples collected from Sudbury, Ontario (May 2006), determined by Competing Ligand Exchange Method/Graphite Furnace Atomic Absorption Spectrometry (CLEM/GFAAS), using Chelex 100 as the competing ligand. Temperature $23 \pm 2^{\circ} \mathrm{C}$.

Table 4.3 IET measured free nickel ion concentrations and predictions of WHAM VI (assuming $40 \%$ of dissolved organic carbon as "active"), and labile nickel concentrations measured by CLEM/GFAAS, and the effect of nickel/DOC ratios.

Table 4.4 Growth inhibition at the $25 \%$ level $\left(\mathrm{IC}_{25}\right)$ for P. subcapitata in mining and municipal effluent water samples collected from Sudbury, Ontario, in May 2006 and in reference toxicity tests using nickel and copper standards. 


\section{List of Figures}

Figure 2.1 Interactions of a metal $\left(\mathrm{Cu}^{2+}\right.$ as an example $)$ in natural waters..................

Figure 2.2 Tentative structure of humic acid as proposed by Schulten and Shnitzer (1993) ............................................................................... 15

Figure 2.3 The BLM design for metal speciation in solution and at the biotic ligand. Adapted from Niyogi and Wood (2004)

Figure 3.1 Illustration of the experimental design for the micro-column Ion Exchange Technique.

Figure 3.2 Volume of sample solution required for $\mathrm{Ni}$ to equilibrate with approx. $7.8 \mathrm{mg}$ of the resin at $5 \mathrm{~mL} / \mathrm{min}$ flow rate. Samples contained $4.40 \times 10^{-7} \mathrm{M} \mathrm{Ni}$ and $0.2 \mathrm{M} \mathrm{NaNO}_{3}$ at $\mathrm{pH} 5.5 \pm 0.1$ and were buffered using $0.01 \mathrm{M}$ acetic acid - sodium acetate buffer. Vertical bars represent \pm 1 standard deviation (visible only when larger than the symbol). (A) The change in distribution coefficient with volume of sample solution loaded onto the column where each load volume was conducted as a separate experiment. (B) Monitoring the change in [Ni] in the effluent fractions with respect to the influent (original sample) in a single experiment.

Figure 3.3 The effect of ionic strength on the distribution coefficient $\left(\lambda_{\mathrm{Ni}}\right)$ at various $\mathrm{pH}(\square, \mathrm{pH} 5.5 ; \circ, \mathrm{pH} 7.5 ; \bullet, \mathrm{pH} 8.5)$. The sample solutions contained $4.40 \times 10^{-7} \mathrm{M}$ nickel and the $\mathrm{pH}$ buffer of $0.01 \mathrm{M}$ acetic acid - sodium acetate buffer ( $\mathrm{pH} 5.5$ ) or $0.01 \mathrm{M}$ Tris (hydroxymethyl) aminomethane hydrochloride ( $\mathrm{pH} 7.5$ and 8.5).

Figure 3.4 Relationship between total nickel and free nickel concentration determined by optimized IET in model solutions containing varying concentrations of Laurentian Fulvic Acid $(\bullet, 1 \mathrm{mg} / \mathrm{L} ; \nabla$, $10 \mathrm{mg} / \mathrm{L} ; \square, 20 \mathrm{mg} / \mathrm{L})$. Samples had an ionic strength of $0.2 \mathrm{M}$ sodium nitrate at $\mathrm{pH} 5.5$ (buffered with $0.01 \mathrm{M}$ acetic acid sodium acetate buffer). Total nickel concentration in the samples varied between $2.00 \times 10^{-8}$ and $2.00 \times 10^{-7} \mathrm{M}$

Figure 3.5 Using pre-equilibrated (72 hours) model solutions: (A) study of the effect of [LFA] on the nickel speciation, $100 \mathrm{nM} \mathrm{Ni}(\bullet), 200$ nM nickel (o); (B) study of the effect of [Ni(II)]/[LFA] mole ratio on the $\% \mathrm{Ni}$ (II) found as free. Ionic strength was $0.2 \mathrm{M}$ (sodium nitrate) and pH 5.5 (buffered with $0.01 \mathrm{M}$ acetic acid - sodium acetate buffer). The vertical error bars represent \pm 1 standard deviation, of three replicate determinations.

Figure 3.6 Comparison on a log scale of free nickel concentrations measured by optimized IET and that predicted by WHAM VI in model 
solutions containing the following concentrations of the Laurentian Fulvic Acid; $1 \mathrm{mg} / \mathrm{L}(\boldsymbol{\Delta}), 10 \mathrm{mg} / \mathrm{L}(\mathbf{\square})$, or $20 \mathrm{mg} / \mathrm{L}$ $(\bullet)$. The solutions had an ionic strength of $0.2 \mathrm{M}$ (sodium nitrate) and $\mathrm{pH} 5.5$ (buffered with $0.01 \mathrm{M}$ acetic acid - sodium acetate buffer). Total nickel concentration in the samples varied between $2.00 \times 10^{-8}-2.00 \times{ }^{10-7} \mathrm{M}$

Figure 4.1 Percentage of Ni(II) released from Ni(II)-DOC complexes in mining and municipal effluent water samples, determined by CLEM/GFAAS. Chelex 100 was the competing ligand

Figure 4.2 Effect of Ni/DOC ratio on the free (filled symbols) and labile (unfilled symbols) nickel species in mining and municipal effluent water samples collected from the Sudbury area, Ontario, Canada

Figure 4.3 Algal bioassays ( $P$. subcapitata) as function of percent water sample for the mining effluent samples diluted with Reference River water (unfilled symbols) and laboratory water (filled symbols). a) Garson Mine effluent b) Copper Cliff WWTP

Figure 4.4 Algal (P. subcapitata) bioassay curve for Sudbury Waste Water Treatment Plant effluent sample as a function of percent sample.

Figure 4.5 Effect of additional nutrients on algal (P. subcapitata) growth with respect to the control. a) Effect of an additional 10, 100 and $200 \mathrm{ug} / \mathrm{L}$ of $\mathrm{Zn}$ in the algal growth media b) Effect of an additional $1.5 \mathrm{mg} / \mathrm{L}$ nitrate, $30 \mathrm{mg} / \mathrm{L}$ nitrate, $0.05 \mathrm{mg} / \mathrm{L}$ phosphate, or $0.3 \mathrm{mg} / \mathrm{L}$ phosphate in the algal growth media.

Figure 7.1 Optimization of pyrolysis temperature for determination of $[\mathrm{Ni}(\mathrm{II})]_{\text {total }}$ in samples of high ionic strength and low $\mathrm{pH}$ by GFAAS. The sample solution contained $4.40 \times 10^{-7} \mathrm{M} \mathrm{Ni}$ (II) and $0.2 \mathrm{M} \mathrm{NaNO}_{3}$ at pH 5.5 (0.01 $\mathrm{M} \mathrm{C}_{2} \mathrm{H}_{3} \mathrm{O}_{2} \mathrm{Na} \mathrm{pH}$ buffer $)$. The atomization temperature was kept at $2250^{\circ} \mathrm{C}$ 104

Figure 7.2 Optimization of atomization temperature for determination of $[\mathrm{Ni}(\mathrm{II})]_{\text {total }}$ in samples of high ionic strength and low $\mathrm{pH}$ for GFAAS. The sample solution contained $4.40 \times 10^{-7} \mathrm{M} \mathrm{Ni}$ (II) and $0.2 \mathrm{M} \mathrm{NaNO}_{3}$ at $\mathrm{pH} 5.5$ (0.01 $\mathrm{M} \mathrm{C}_{2} \mathrm{H}_{3} \mathrm{O}_{2} \mathrm{Na} \mathrm{pH}$ buffer $)$. The pyrolysis temperature was kept at $1200^{\circ} \mathrm{C}$

Figure 7.3 The effect of $\mathrm{pH}$ on the $\lambda_{\mathrm{Ni}}$ at various ionic strength $(\varpi, 0.001 \mathrm{M}$; $\square, 0.01 \mathrm{M} ; \bullet, 0.1 \mathrm{M} ; \circ, 0.2 \mathrm{M})$ using the same $\mathrm{pH}$ buffer. The sample solutions contained $4.40 \times 10^{-7} \mathrm{M} \mathrm{Ni}$ (II) and a $\mathrm{pH}$ buffer $0.01 \mathrm{M}$ tris- $\mathrm{HCl}$ 106

Figure 7.4 The effect of $\mathrm{pH}$ buffer on $\lambda_{\mathrm{Ni}}$ as a function of ionic strength $(\bullet$, $0.01 \mathrm{M} \mathrm{C}_{2} \mathrm{H}_{3} \mathrm{O}_{2} \mathrm{Na} ; \circ, 0.01 \mathrm{M}$ tris- $\mathrm{HCl}$ ). The sample solutions 
contained $4.40 \times 10^{-7} \mathrm{M} \mathrm{Ni}(\mathrm{II})$ at a $\mathrm{pH}$ of 5.5 (a) and at a $\mathrm{pH}$ of 6.5 (b)

Figure 7.5 Comparison on a log scale of $[\mathrm{Ni}(\mathrm{II})]_{\text {free }}$ measured by optimized

IET and that predicted by WHAM VI in mining and municipal effluent water samples collected from the Sudbury area, Ontario, Canada.

Figure 7.6 Percentage of $\mathrm{Cu}$ (II) released from $\mathrm{Cu}$ (II)-DOC complexes in mining and municipal effluent water samples as function of time, determined by CLEM/GFAAS. Chelex 100 was the competing ligand

Figure 7.7 Growth curve for the algal stock culture.

Figure 7.8 Growth curve (72-hour) for algae in the control microplate.

Figure 7.9 Growth curve (72-hour) for algae in the control $50 \mathrm{~mL}$ Erlenmeyer test flasks.

Figure 7.10 Standard calibration curve for algal concentration measured by fluorescence using a microplate spectrofluorometer.

Figure 7.11 Comparison on a log scale of $[\mathrm{Ni}]_{\text {labile }}$ measured by CLEM and that predicted by WHAM VI in mining and municipal effluent water samples collected from the Sudbury area, Ontario, Canada.

Figure 7.12 Comparison on a log scale of $[\mathrm{Ni}]_{\text {labile }}$ measured by CLEM and the $[\mathrm{Ni}(\mathrm{II})]_{\text {free }}$ measured by optimized IET in mining and municipal effluent water samples collected from the Sudbury area, Ontario, Canada

Figure 7.13 Algal bioassay as a function of percent water sample for Crean Hill Mine effluent collected in May 2006.

Figure 7.14 Algal bioassay as a function of percent water sample for Nolin Creek Waste Water Treatment Plant effluent collected in May 2006 .

Figure 7.15 Algal bioassay as a function of percent water sample for Whistle Mine effluent collected in May 2006.

Figure 7.16 Inhibition test for standard nickel solution diluted with laboratory water.

Figure 7.17 Inhibition test for standard nickel solution diluted with Reference River water.

Figure 7.18 Inhibition test for standard copper solution diluted with laboratory water.

Figure 7.19 Inhibition test for standard copper solution diluted with Reference River water. 


\section{Introduction}




\section{Introduction}

\subsection{Statement of the problem}

Trace metal concentrations in natural waters are regulated by processes such as atmospheric precipitation and weathering of soils and bedrocks. However, these processes have been considerably altered by anthropogenic activities which have resulted in increased flux of toxic metals and their distribution in freshwater systems $[1,2]$. Large contributions to metal pollution in the aquatic environment are made by toxic species in industrial and domestic wastewaters, sewage discharges, and urban water run-off. Such contaminations often originate from point sources and may result in excessive metal burden in local waters. Mine aqueous effluents, which are composed of multiple metal mixtures, are a persistent threat to human and environmental health. Since trace metals (e.g. $\mathrm{Ni}, \mathrm{Cu}, \mathrm{Pb}, \mathrm{Cd}$ ) can play the role of either essential micronutrients or toxicants depending on their concentrations and chemical speciation, their regulation in natural waters is critical [3].

In Canada, the new Metal Mining Effluent Regulations (MMER) require mines to assess the possibility for chronic effects of effluents via Environmental Effects Monitoring (EEM) studies and a set of lab-based chronic toxicity tests [4]. Although EEM and mesocosm studies (simplified but reliable substitutes for EEM) can indicate environmental effects, a key knowledge gap is our inability to identify the causes of toxicity. In addition, field studies have several disadvantages including exposure to confounding factors in natural waters, inherent variability, high cost, and results that are not always comprehensible. Thus, it would be beneficial and cost effective to build 
mechanistic geochemical models that could provide reliable predictions of chronic impacts of mine effluents based on laboratory-based determination of metal speciation. Further research in this field is necessary to reduce uncertainties associated with measuring long-term impacts of mine effluents. One of the vital steps to the above approach is the exploration of the link between geochemical speciation of metals and their bioavailability and toxicity in mining aqueous effluents. Bioavailability refers to the amount of metal that is available for absorption or uptake at the physiologically active sites of the aquatic biota with respect to the actual exposure amount (i.e. it accounts for the difference between exposure and dose).

The approach taken in this work consisted of a parallel method of experimental determination of nickel species based on different physico-chemical principles: Ion Exchange Technique (IET) [5-6] and Competing Ligand Exchange Method (CLEM) [78]), and also by using a computational method (a computer-based speciation code) based on discrete electrostatic binding called Windermere Humic Aqueous Model (WHAM) [911]. Comparison of the experimentally determined values of free nickel ion concentration (by IET) and labile nickel concentration (by CLEM), i.e. free nickel plus weak dissociating nickel complexes with those of the theoretically predicted values (by WHAM VI) for the Sudbury mining and municipal waters should bring out both the strengths and weaknesses of the respective methods. Investigation into linkages, if any, between metal speciation and the toxicity to aquatic biota was made by studying algal toxicity in the same effluent samples and comparing the results with those of the chemical speciation. 


\subsection{Objectives: short-term and long-term}

The free metal ion concentration is generally considered to be linked to metal bioavailability and toxicity. However, this relationship has mostly been studied in model solutions or pristine natural waters. The short-term objective of this research is to study linkages, if any, between the metal speciation (free and labile) and its toxicity in mining aqueous effluents using modern analytical techniques and algal toxicity testing. The longterm objective of this research is to build the scientific foundation for a predictive model, such as the Biotic Ligand Model (based on WHAM), for metals toxicity in complex natural waters such as mining and municipal effluents.

\subsection{Outline of the thesis}

This thesis comprises seven sections. Section 1 presents the introduction which includes statement of the problem, the main objectives and an outline of the thesis. Section 2 presents the current scientific knowledge in metal speciation and toxicity. Section 3 presents the determination of free $\mathrm{Ni}$ ions using IET, its application to mining aqueous effluent samples and a comparison of WHAM VI predictions with the experimental results. Section 4 illustrates the algal toxicity tests of the Sudbury mining aqueous effluent samples, the determination of labile nickel and copper using CLEM, and a comparison of the results with the IET-determined and the WHAM VI-predicted free nickel concentrations presented in Section 3. Some highlights of this study, the final conclusions drawn from them, and their overall significance are described in Section 5. 
Section 6 includes a list of references. Section 7 is an appendix of figures not included in the previous sections. 


\section{Scientific Background}




\section{Scientific Background}

\subsection{Trace metal speciation}

Previously, it has been generally held that the total metal concentration is related to the metal's toxic effects. With the available technology, direct determination of total metal concentration is a relatively simple task. For example, analytical techniques, such as Inductively Coupled Plasma-Mass Spectrometry (ICP-MS) and Graphite Furnace Atomic Absorption Spectroscopy (GFAAS), provide reliable determinations combined with suitable low detection limits for trace metal analysis [12]. However, a consensus has developed, suggesting that total metal concentration is not a good predictor of toxicity, and this has presented a new challenge for environmental scientists [3].

The following factors are involved in metal toxicity to freshwater biota: 1) metal speciation in the exterior environment of the organism; 2) metal interactions with the biological membrane that separates the organism from its external environment; and 3) metal partitioning within the organism [3]. These interactions are the main focus of environmental scientists today. This thesis focuses on metal speciation in the exterior environment and how that may relate to toxicity to aquatic biota.

Metal speciation is defined as the distribution of an individual metal between different chemical forms (e.g. free (hydrated) metal ion, inorganic and organic complexes) [13]. Surface waters (freshwaters, estuarine and seawaters), especially the ones in the neighbourhood of metal smelters, are representative media of the chemical complexities that can exist in the environment which make the task difficult for environmental 
chemists. To name just a few, complexities include: wide range of metal concentrations, dissolved organic matter of mainly unknown structure, inorganic and organic colloidal material, and the presence of microorganisms which consume and excrete dissolved chemicals, which are sometimes metal-complexants. Figure 2.1 illustrates the nonbiological processes that determine metal speciation and that are used in mathematical calculations for speciation modeling [14].

\subsection{Nickel in the environment}

In the earth's crust, nickel is found in very low quantities (approximately 0.0099\%), mainly in the form of sulfide, oxide and silicate materials [15]. However, nickel is now one of the most common metals found in natural waters as a result of its heavy use in industry. A well-known example of such a source in Canada is the nickel smelter in Sudbury (Ontario). Background nickel concentrations in the open ocean water range from $0.2 \mu \mathrm{g} / \mathrm{L}$ to $0.7 \mu \mathrm{g} / \mathrm{L}$, and from $1 \mu \mathrm{g} / \mathrm{L}$ to $50 \mu \mathrm{g} / \mathrm{L}$ in unpolluted water supplies [15]. However, this could increase by several orders of magnitude in water sources near rural and urban environments affected by industrialization. Nickel is currently used in alloys (stainless steel), electroplating, catalysts, foundries, welding rods and coinage. It is also employed in electronic equipment, construction materials, aerospace equipment and consumer goods such as batteries, paints and ceramics [15]. Anthropogenic sources of nickel (i.e. manufacturers of the above listed products) may expose nickel to the environment through air, soil or water. 


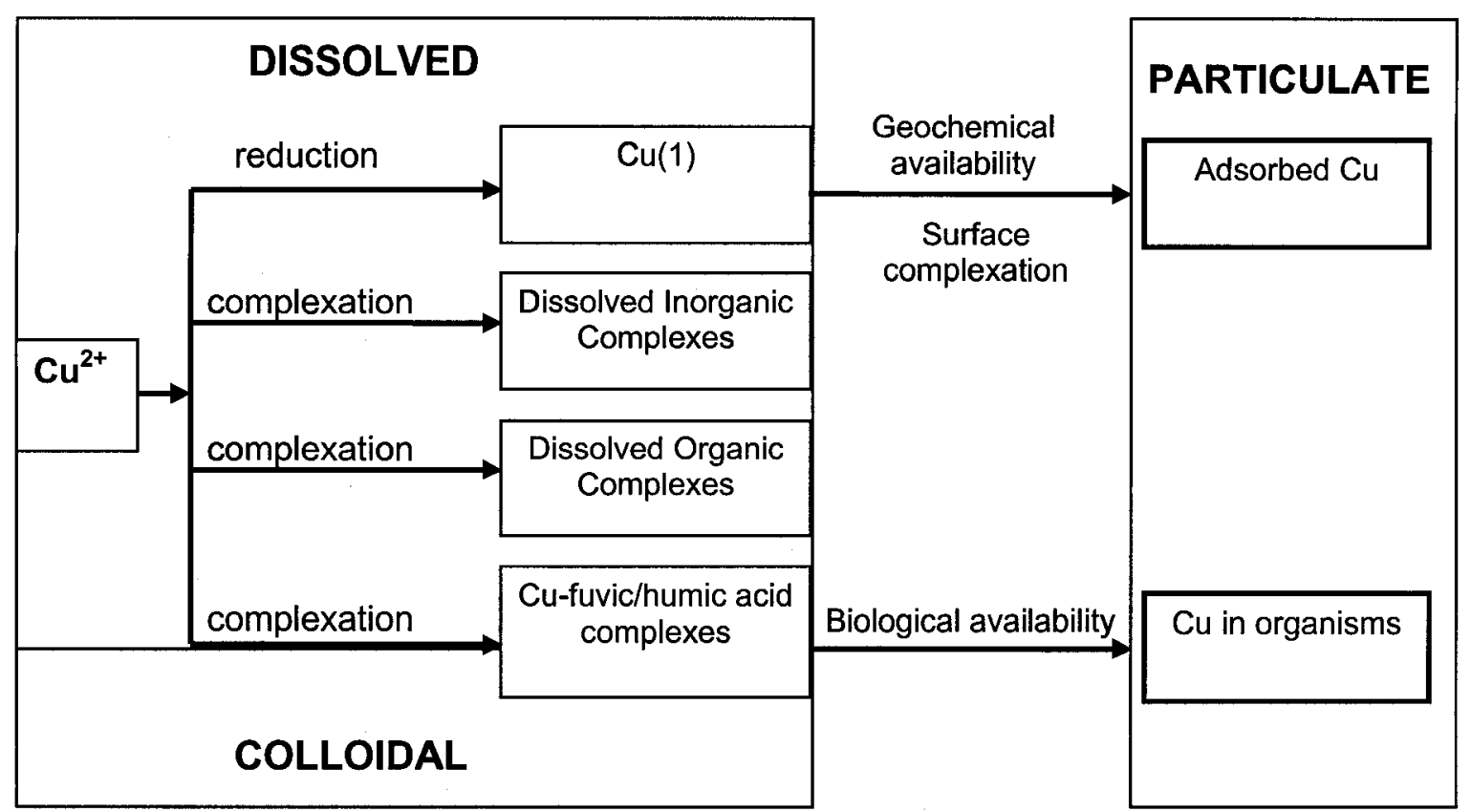

Figure 2.1 Interactions of a metal $\left(\mathrm{Cu}^{2+}\right.$ as an example) in natural waters.

Adapted from Turner (1995) [14]. 
The essentiality of nickel to aquatic organisms has been studied recently and nickel has been shown as an essential element for several animals and plants [15-16]; however, its toxicity is not well known. This is mainly due to lack of knowledge of Ni(II) bioavailability which has been deterred by the absence of convenient, sensitive methods for determining concentrations of bioavailable nickel species in the presence of natural organic matter. It is safe to say that the majority of environmental scientists regard the hydrated free ion (e.g. $\mathrm{Ni}^{2+}$ ) as the bioavailable nickel species because of its ability to pass through the external membrane of the aquatic biota [17]. In aquatic systems, nickel is usually present as the free ion $\left(\mathrm{Ni}^{2+}\right)$, or complexed with other ions such as hydroxyl $\left(\mathrm{OH}^{-}\right)$, sulfate $\left(\mathrm{SO}_{4}{ }^{2-}\right)$, chloride $\left(\mathrm{Cl}^{-}\right)$, carbonate $\left(\mathrm{CO}_{3}{ }^{2-}\right)$, or nitrate $\left(\mathrm{NO}_{3}{ }^{-}\right)$[15]. The presence of inorganic and organic compounds in the surrounding environment increases complexation of $\mathrm{Ni}^{2+}$, which may cause it to precipitate out of solution or adsorb onto surfaces of particulate matter, thereby reducing its bioavailability. The physico-chemical parameters that determine the fate of $\mathrm{Ni}^{2+}$ include: $\mathrm{pH}$, redox potential, temperature, ionic strength, $\mathrm{Ca}^{2+}$ concentration, complexing and precipitating organic and inorganic ligands, other cations that compete with binding sites on ligands, insoluble organic or inorganic matter, and cation exchange capacity [15]; the majority of these parameters are accounted for in the WHAM VI, resulting in WHAM VI's predictive capability.

\subsection{Analytical challenges}

Quantitative determination of metal speciation is much more challenging than determination of total metal concentration for several reasons, including difficulties in isolating compounds of interest from complex matrices; existing analytical techniques 
disturb the chemical equilibrium in the sample solutions; many analytical techniques are not sensitive enough to measure ultra-trace levels of metals; and standard reference material suitable for the complex matrices under study are not available [1]. However, the increased hazards of trace metals caused by heavy industrialization have promoted research and development of improved analytical methods that measure metal speciation.

Several studies in the past two decades have concluded that the bioavailability of a metal to an aquatic organism is directly related to the metal's speciation [17]. Most often, the metal species that correlated with bioavailability was the free metal ion. Thus, in order to study the toxicity of a metal, it is important to determine the free metal ion activity (or concentration) and any other relevant species such as labile metal complexes [14]. Labile metal complexes are important because they contribute to free metal ion concentration by rapid dissociation of the metal complexes. In fact, some techniques, such as CLEM, are limited to measuring 'labile species' (free-metal ions + weak metal-ligand complexes) versus 'non-labile species' (strong metal-ligand complexes). Concentration of labile species is a critical parameter that can be related to toxicity [9].

Measuring free metal ions has proved to be more difficult. In most experiments, free metal ion activity is calculated based on the known total metal concentration and the measured variables of water chemistry (e.g. pH, ionic strength, hardness and DOC). Currently, techniques that are able to directly determine free metal ion concentration at trace concentrations are Ion Exchange Technique (IET) combined with ICP-MS or GFAAS, and Square Wave Anodic Stripping Voltammetry with a Rotating Disk 
Electrode (RDE). Ion-Selective Electrode (ISE) potentiometry can measure free ions directly; however, it has a very limited range of sensitivity that makes it inappropriate for low concentrations of trace metal analysis in natural waters [18]. In this work, the use of IET for determining free metal ion concentration was investigated because of the simplicity of the approach and the high analytical sensitivity.

A common problem of speciation analysis is the disturbance of the chemical equilibrium state. The greatest potential for this disturbance is during sampling. The various chemical forms of a metal (e.g. simple hydrated ions (free), ion pairs, organic/inorganic complex ions, sorbed on colloidal/particulate material, etc.) co-exist in an equilibrium or quasiequilibrium state. Thus, during sampling, preparation and storage, the equilibrium may be disturbed causing a change in the species distribution. For example, during filtration, the removal of particulate matter may cause disturbance of the equilibrium. Also, the internal surfaces of all glass vessels have ion-exchange properties and tend to adsorb dissolved metals. Acidification of the samples minimizes the adsorption by the internal surface of the vessels because the $\mathrm{H}^{+}$ions of the acidified water cover all the internal surface of the storage vessels, resulting in their surface charges being completely satisfied by the $\mathrm{H}^{+}$ ions of the acidified water; however, it may also cause dissociation of certain complex species [19]. Consequently, it is important to combine speciation analysis with toxicity studies for a better understanding of their relationship. Since bioassay toxicity study has its own challenges and can be relatively time consuming and expensive, predictive computer speciation models, such as the Biotic Ligand Model (BLM) [17], are useful tools in the assessment and are attracting the interests of many environmental scientists. 


\subsection{Interactions between trace metals and aquatic organisms}

One of the challenges faced in studying toxicity of metals in natural waters are the laboratory bioassay tests. Results of bioassay tests for a metal can vary widely between different biota species. Hence, this complicates the establishment of water quality standards and deters confident application of the set criteria. Organisms used for the bioassay tests are usually cultured in standard waters with a chemical composition that may be significantly different from the test water. Thus, the organism is then forced to adapt to a completely new environment presented by the test water and this adaptation has been shown to affect the observed toxicity. In fact, toxicity tests performed in laboratory waters were observed to vary greatly from those done in natural waters [20]. Many times, this is due the level of DOC in natural waters. Natural waters tend to contain higher DOC levels than the laboratory water, thereby increasing metal complexation and reducing bioavailability and toxicity.

Studies show that water chemistry has a major effect on the toxicity of a metal. The toxicity of the dissolved metals is mainly affected via two pathways: either by blocking physiologically relevant $\mathrm{Ca}^{2+} / \mathrm{Na}^{2+}$ uptake or by affecting metal speciation. Some of the factors of water chemistry found to affect bioavailability of a metal are water hardness, $\mathrm{pH}$ and dissolved organic carbon (DOC) [21]. Hardness is a measure of the presence of major cations such as calcium and magnesium. Calcium ions are special in that they are physiologically essential to aquatic biota. An increase in the calcium ion concentration (i.e. hardness) will allow calcium ions to dominate the competition with metals for the 
binding sites on the organism (surface functional groups that act as ligands) [17]. Thus, it will interfere with the organism's uptake of potentially toxic metals, resulting in a decreased toxicity for the same total metal concentration. Many metals such as $\mathrm{Cd}$ and $\mathrm{Zn}$ are toxic to aquatic biota because of their interference with the organism's ability to uptake calcium. Metals such as $\mathrm{Al}, \mathrm{Cu}$, and $\mathrm{Ag}$ can cause toxicity by interfering with sodium uptake of the organism. For fish, this interference with ionic regulation occurs in the gills [20].

High $\mathrm{pH}$ levels favour the formation of metal hydroxides. When hydrolysis does not occur, the binding of metals with humic substances (HS) and carbonates is enhanced at high $\mathrm{pH}$, because more functional acidic groups of $\mathrm{HS}$ are ionized at higher $\mathrm{pH}$, creating more negative sites on HS for binding metal cations. This is consistent with the fact that metal cations and protons compete with ligands for bindings sites. At high $\mathrm{pH}$, protons bound to humic substances will dissociate, creating an increased availability of binding sites for metal cations [11]. Overall, the effects of high $\mathrm{pH}$ result in reduced activity (concentration) of free cupric ion, and hence, bioavailability and toxicity to biota is decreased.

Dissolved organic carbon (DOC) in freshwaters mainly includes HS. HS are produced either by leaching of soil organic matter or by excretion of organic material from aquatic biota. In addition to their large size, HS contain multi-functional binding sites, most importantly, carboxylic and phenolic functional groups, which lose protons at $\mathrm{pH} \geq 7$, and/or bind metal ions (Figure 2.2) [22]. Caboxylic groups are commonly more prevalent 


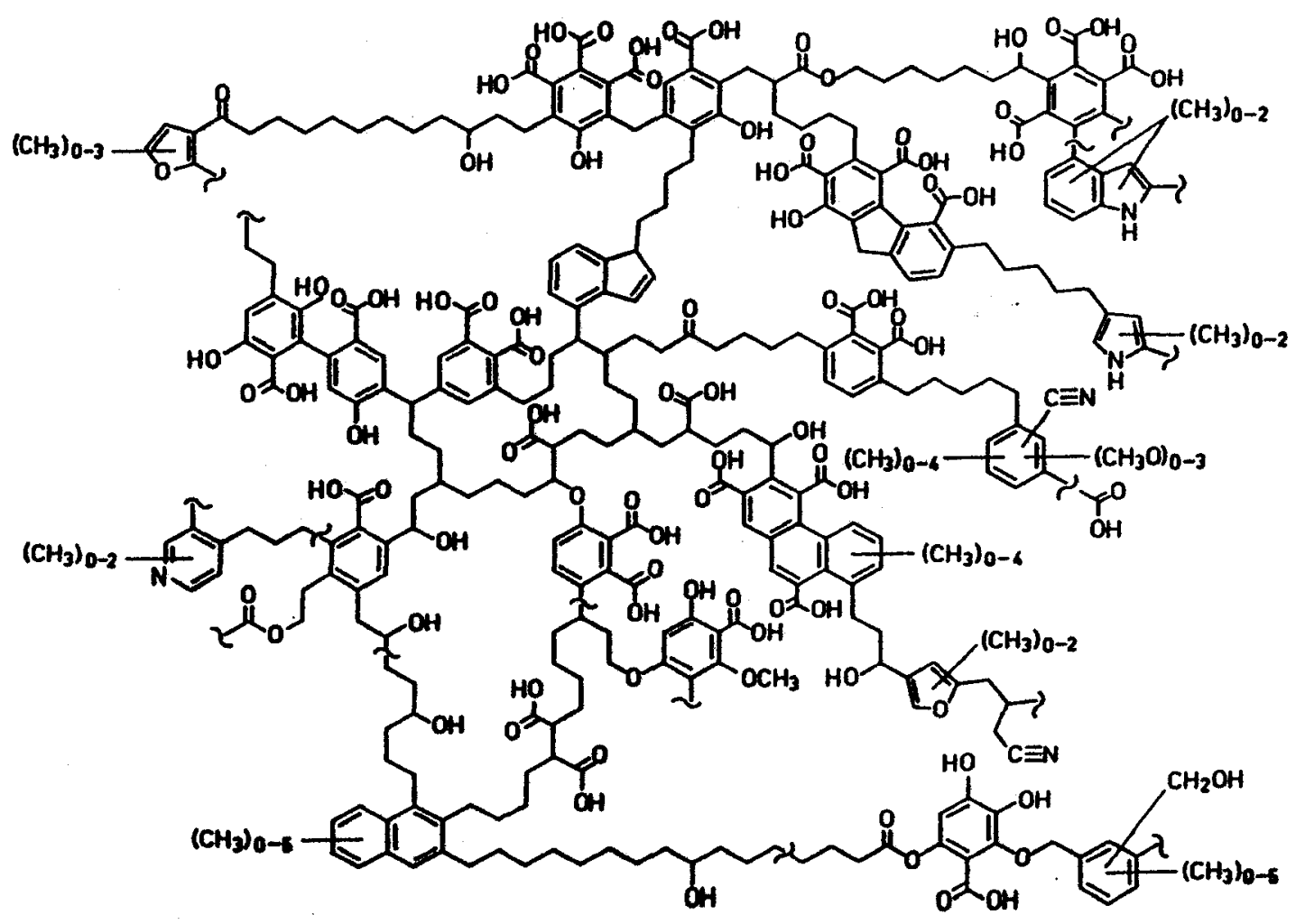

Figure 2.2 Tentative structure of humic acid as proposed by Schulten and Shnitzer (1993) [22]. 
than phenolic ones in HS [14]. Humic substances (HS) can be divided into three operationally-defined fractions; fulvic acid (FA), humic acid (HA), and humin. FA is soluble in acidic and alkaline solutions; HA is soluble in alkaline solutions but precipitates at $\mathrm{pH}$ lower than 2; and humin is insoluble in water at any $\mathrm{pH}[2]$. Generally, FA and HA are the humic substances that are active in aquatic systems. FAs are smaller in size than HAs. The importance of HS is that they can bind trace metals and help decrease their bioavailability and toxicity to aquatic biota. Hence, an increase in $\mathrm{LC}_{50}$ (defined as the sample concentration to kill $50 \%$ of the biota) values will be observed with the increase in [DOC].

\subsection{Predicting metal speciation: Windermere Humic Aqueous Model}

Modeling chemical speciation is a critical step in understanding metal speciation and bioavailability in freshwater systems. Earlier, speciation models only considered the effect of hardness. Later, $\mathrm{pH}$, ionic strength, humic substances and other critical factors were also included. Several speciation models exist today (e.g. MINTEQA2, GEOCHEM, and the Consistent Non-Ideal Competitive Adsorption (NICCA)-Donnan Model). However, one of the most popular models is the equilibrium-based computer speciation model, Windermere Humic Aqueous Model (WHAM), versions V and VI, which was specifically designed to account for metal interactions with humic substances [11]. WHAM correctly describes FA and HA while models such as GEOCHEM and MINTEQA2 do not and are hindered by limited databases used for the predictions. WHAM and the NICCA-Donnan Model have been tested on numerous datasets from various scientists and are widely used chemical speciation models. WHAM is the 
preferred model of the two because of its comprehensive approach for modeling ion binding in freshwaters [9].

The history of WHAM began in 1994, when Tipping developed the model using assumptions of site-specific electrostatic binding and a collection of sub-models that were calibrated with the literature data $[10]$. A relatively recent comparison of the measured labile metal concentration and the WHAM predicted $\left[\mathbf{M}^{\mathrm{n}+}\right]$ in metal-impacted natural waters of Quebec, Canada, by Guthrie et al. [9] showed good correlation between the WHAM predictions and the measured values. Use of the model involves a data file that is entered into the model, which includes total concentrations of all reactants involved. The WHAM database comprises a set of reaction stoichiometries and equilibrium constants from reliable literature sources. There also exists an option to update the dataset to match up-to-date standards such as the log K values established by NIST [11]. Using the given information (e.g. pH, total metal concentrations, dissolved anions and cations, and "active" DOC), the model could calculate the concentration of individual species such that the mass balance of each element is satisfied. If not known, the $\mathrm{pH}$ could be calculated by WHAM such that the charge balance is satisfied. WHAM achieves adequate predictions for interactions involving high cation concentrations. However, it likely underestimates the extent of cation binding to rare, strong sites in humic matter [11].

One of the major problems of WHAM is the need to input "active DOC" concentration (i.e. the portion of HS that forms complexes with the metals under the investigation). 
This is a critical parameter since it determines the number of binding sites available to metals. However, the value of "active DOC" is rarely known and must be estimated to get the best fit (e.g. 50-80\%). Another important point to keep in mind is that WHAM was designed to calculate speciation at chemical equilibrium for metals in complex systems such as surface and ground waters, sediments, and soils [9], which are not really at chemical equilibrium. Additional source of error in WHAM may be the information in the database or the input data, which are both subject to analytical and experimental errors. Nevertheless, WHAM is one of the most useful predictive tools available today for metal speciation. Its popularity had initiated its incorporation in a predictive model for toxicity, the Biotic Ligand Model (BLM). The BLM will be discussed further in the next section.

\subsection{Predicting metal toxicity: Biotic Ligand Model (BLM)}

During the past two decades, environmental scientists have made considerable progress in improving our understanding of metal speciation and its relationship to toxicity, and in developing models that accurately predict trace metal toxicity. Much effort has been made to test the hypothesis that the free metal ion is directly related to bioavailability. A critical review by Campbell (1995) [3] reported that the majority of the studied cases conform to the Free Ion Activity Model (FIAM) hypothesis, and this has promoted global interest in this topic [23].

Progress towards the free metal ion concept began in the seventies, when scientists demonstrated that the free metal ion activity, specifically of the cupric ion, was a better 
indicator of toxicity than the dissolved total metal concentration [24]. Reduction in toxicity as a result of competition of hardness cations $\left(\mathrm{Ca}^{2+}\right.$ and $\left.\mathrm{Mg}^{2+}\right)$ with metal ions for binding sites on the organism was also identified [25-26]. These studies, along with those of Pagenkopf et al. [27] resulted in the formulation of a chemical equilibrium model to describe the effect of water chemistry on metal speciation and toxicity and marked the advent of the metal bioavailability era.

A significant advancement was made in 1983, when Morel proposed a theoretical scheme by his FIAM [28] which incorporates interactions between the metal and organism based on a general chemical equilibrium principle. FIAM also incorporates binding of free metal ions and other metal complexes to cellular binding sites in competition with other cations such as protons and hardness cations $\left(\mathrm{Ca}^{2+}\right.$ and $\mathrm{Mg}^{2+}$ ions). The major shortcoming in Morel's depiction of FIAM was the lack of details on how it may be applied in practice. This was satisfied by Pagenkopf and colleagues who proposed the Gill Surface Interaction Model (GSIM) at about the same time as FIAM was proposed [29]. The GSIM allowed for an interpretation of toxicity test results for both individual metals (e.g. $\mathrm{Cd}, \mathrm{Cu}, \mathrm{Pb}$, and $\mathrm{Zn}$ ) and metal mixtures in fish. Approximately 10 years later, Playle et al. [30-32] provided additional information on the effect of anionic complexation and competition with other cations on trace metal binding to fish gills. These data were later integrated with toxicity data by Di Toro et al. [33], who developed an early version of the Biotic Ligand Model (BLM) to predict the acute toxicity of copper and silver to several freshwater biota. 
The BLM's popularity has been extended to freshwater resources regulatory systems. Recently, the U.S. EPA has incorporated the BLM into their Water Quality Criteria (WQC) development for copper [34]. Prior to BLM's integration, the freshwater copper criteria recommendations involved a hardness-dependent value. The BLM's role was to improve the criterion by including other critical water chemistry factors that are known to affect toxicity. Most importantly, BLM includes the metal complexation role of dissolved organic carbon (DOC) and inorganic ligands, the competitive interactions at the site of toxicity (i.e. biotic ligand), and the effect of $\mathrm{pH}$, all of which were not accounted for in the hardness correction method. However, the use of BLM means that a single WQC cannot be used for comparison purposes. Thus, it will depend on the judgment of the regulatory agency's personnel to decide if the criteria will provide the expected level of protection [34]. Other countries are following suit. For example, regulators in Australia and New Zealand, and the European Union (EU) have approved the incorporation of the BLM in their regulatory system. In addition, Environment Canada and the Canadian Council of Ministers of the Environment (CCME) have decided to integrate the BLM approach into the development of Canada's water quality guidelines for metals [35].

Figure 2.3 illustrates the water chemistry factors that are considered in BLM to affect bioavailability, using fish as an example. As is evident in the diagram, hardness directly affects bioavailability by competing with the free metal ion $\left(\mathrm{Me}^{2+}\right)$ for the binding site in organism (e.g. gill in fish). Note that $\mathrm{H}^{+}$ions also directly compete with the metal ion for binding at the gill. Thus, at very low $\mathrm{pH}$ levels, significant competition between $\mathrm{H}^{+}$and $\mathrm{Me}^{2+}$ may exist, resulting in reduced bioavailability. However, a very low $\mathrm{pH}$ level such 
as $\mathrm{pH}$ of 2 is not relevant for natural waters because natural waters usually have $\mathrm{pH}$ of 68. The more probable case is $\mathrm{pH}$ levels above 5 where an increase in $\mathrm{pH}$ reduces the bioavailability of the metal because of increased formation of metal hydroxides, and enhanced metal complexation with humic substances and carbonates [17]. Other factors such as presence of organic and inorganic ligands, indirectly affect bioavailability by binding free metal ions, thereby preventing them from binding to the fish gill.

The initial stages of BLM testing were focused on its application for $\mathrm{Cu}$ toxicity in fish (e.g. Fathead Minnow). BLM accurately predicted $\mathrm{Cu}$ toxicity for various studies performed in different laboratories with different water chemistry [17]. BLM was also tested on Ag toxicity in various fish species [17]. BLM proves to be promising for future use as a toxicity model for water quality regulation.

In summary, BLM is a mechanistic biogeochemical model which is applied for setting site-specific acute water quality criteria [21]. However, not much is known about the relationship between the metal speciation and its toxicity. Also, the current BLM does not account for impacts of multiple metal exposure systems, such as mining and municipal aqueous effluents, where the mode of action differs, nor does it account for the effects of anthropogenic ligands. Thus, integrating the ability of chemical speciation and BLM modeling to identify cause will help focus mitigation efforts for reducing environmental impacts and will be a significant advance for environmental risk assessment. 


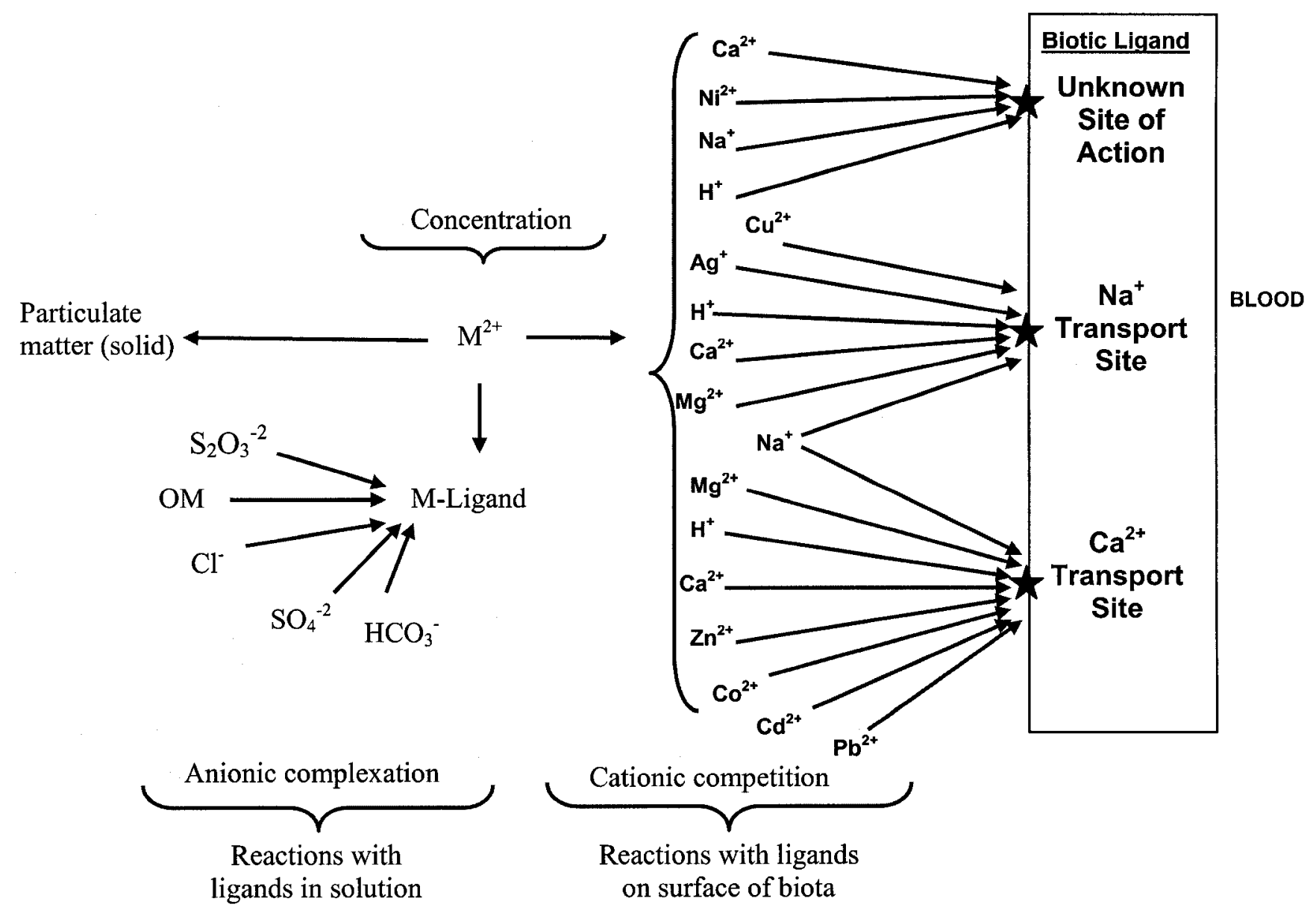

Figure 2.3 The BLM design for metal speciation in solution and the biotic ligand. Adapted from Niyogi and Wood (2004) [36]. 
3. Determination of free nickel ion concentrations using the Ion Exchange Technique (IET) in aqueous mining and municipal effluents: Comparison of the IET results with the WHAM VI predictions 


\section{Determination of free nickel ion concentrations using the Ion Exchange Technique (IET) in aqueous mining and municipal effluents: Comparison of the IET results with the WHAM VI predictions}

\subsection{Introduction}

Nickel and other trace metal concentrations in natural waters are regulated by processes such as atmospheric precipitation and weathering of soils and bedrocks. However, these processes have been considerably altered by human activities, which have resulted in increased flux and distribution of trace metals in most freshwater systems [1]. Largely, these changes are contributed by industrial and domestic wastewaters, sewage discharges, and municipal water run-off. A well-known example of a nickel contamination source is the nickel smelter in Sudbury (Ontario, Canada). The essentiality of nickel to aquatic organisms has been studied recently [16]; however, its toxicity is not well known. This is mainly due to lack of convenient, sensitive methods for determination of the nickel speciation in environmental samples containing appreciable concentrations of dissolved organic matter.

Metal speciation, defined as the quantitative distribution of an element (e.g. a metal) amongst its free and complexed forms, profoundly affects metal bioavailability and toxicity to aquatic organisms $[13,37]$. Over the past two decades, many papers have been published on metal speciation in aquatic systems. These publications have mainly focused on the measurement of labile metals using methods such as Diffusive Gradients in Thin Films Technique (DGT) [38-41], Competing Ligand Exchange Methods (CLEM) $[1,7,8,42]$, and, with the exception of the Donnan membrane technique [43], which also measures free metal ion concentration. Although labile metal species may be indicators 
of metal bioavailability [8], the free metal ion concentration is generally considered to be a better predictor of bioavailability [28]. The core assumption of the Free Ion Activity Model (FIAM) is that metal bioavailability is under thermodynamic control. This chemical equilibrium basis assumes that the rate of metal uptake across a cell surface is comparatively slow relative to the rate of diffusion to the cell surface, and the surfacebound metal rapidly comes into pseudo-equilibrium with the metal in the bulk solution [44]. Exceptions to this assumption were rare; in fact, 52 out of 59 cases conformed to the assumption [3] and validated the applicability of FIAM. This initiated a global interest in computer speciation models that predict bioavailability based on FIAM concepts.

Recently, the Gill Surface Interaction Model (GSIM) [29] has been combined with FIAM concepts to form the Biotic Ligand Model (BLM). The BLM proposes that toxicity is due to accumulation of metal at physiologically active sites such as the gill in fish. A comprehensive study by MacRae and co-workers [45] with rainbow trout (Oncorhynchus mykiss) clearly illustrated a direct relationship between copper accumulation at the fish gill and mortality. This work demonstrated that BLM is a better indicator of toxicity than FIAM alone, especially when water hardness varies. In any case, it is the free metal ion that binds to physiologically active sites and hence, when determined along with other water chemistry factors such as hardness and $\mathrm{pH}$, the free metal ion concentration is an important indicator of metal bioavailability in aquatic systems.

Dissolved Organic Carbon (DOC) is ubiquitous in the aquatic environment. In general, the major component of DOC is humic substances (HS) (approx. $50-90 \%$ of DOC). HS play a significant role in metal bioavailability by complexing metals and constraining 
their availability to aquatic biota. HS, by forming dissolved complexes of metals, prevent precipitation of metals and control their speciation and transport [47]. HS-metal complexation is affected by factors such as charge, binding sites distribution, variable reaction stoichiometry and competitive nature of the ion binding [39]. According to a new view of humic substances recently proposed by Sutton and Sposito [48], humic substances are collections of diverse, relatively low molecular mass components forming dynamic associations stabilized by hydrophobic interactions and hydrogen bonds. These associations are capable of organizing into micellar structures in suitable aqueous environment. In general, metal complexation depends on the metal, the nature of the DOC, and on competition between all metals. Hence, there is a need to investigate metalDOC complexation using different analytical techniques and the need for rapid and accurate determination of free metal ion concentrations.

Previous reports indicate that the Ion Exchange Technique (IET) provides an estimate of free metal concentrations of $\mathrm{Cd}, \mathrm{Cu}, \mathrm{Pb}$ and $\mathrm{Zn}$ in controlled solutions and in the presence of dissolved organic matter [6,49-50]. Ge and co-workers [50] have also found that the results of the IET were comparable with those of Ion Selective Electrode (ISE) potentiometric measurements of copper, and with those of Anodic Stripping Voltammetry (ASV) measurements of $\mathrm{Cd}$ and $\mathrm{Pb}$ in lysimeter soil solutions from forest floors contaminated by trace metals. In addition, IET determinations have been related to toxicity tests. For example, Vigneault and Campbell [51] used free cadmium ion concentrations determined by IET to study the effects of $\mathrm{pH}$ and humic substances on the uptake of $\mathrm{Cd}^{2+}$ by freshwater algae. Worms et al. [52] used IET to study nickel uptake by 
algae in the presence of various ligands forming hydrophilic and amphiphilic nickel complexes. However, the applicability of IET to real freshwater samples containing dissolved organic matter, particularly mining and municipal aqueous effluents, has seldom been studied. With its high analytical sensitivity and lack of lengthy, complex sample preparations [50], IET offers advantages over other methods. Additionally, IET

measurements are less likely to be affected by interference from absorption of Dissolved Organic Carbon (DOC) [6]. Since IET measures free ion concentrations directly, it is more reliable than interpretive methods that calculate free metal ion concentration based on models and alternative speciation parameters such as stability constants. However, like other analytical techniques, IET also has its disadvantages. It must be used in combination with an analytical instrument and as a result, is limited by the instrument's sensitivity and detection limit. Also, the system reagents must be ultrapure in order to minimize errors when working in trace level conditions (e.g. $\left.10^{-9}-10^{-10} \mathrm{M}\right)[36]$. There have also been some reports of interferences caused by adsorption of neutral and other cationic species to the ion-exchange resin $[6,54]$. However, because of the simplicity of the IET approach, it offers possibilities of wider and better applicability to freshwaters.

\subsection{Objectives}

The objective of this work was to study nickel speciation using IET in mining and municipal aqueous effluent samples and in model solutions containing natural organic matter. In addition, a comparison of experimentally validated values of free metal ion concentration by IET with those of the theoretically predicted values by WHAM VI was undertaken. The purpose was to validate both the IET determination and the WHAM VI 
prediction of free nickel ion concentration, primarily because WHAM VI is a major component of the BLM, and the latter is being considered for inclusion in regulatory framework in North America and Europe.

\subsection{Theory of IET}

IET involves a simple theory in which the ions in the sample solution exchange with ion exchangers of complex-forming resins. For cation exchange, the most selective resins are composed of sulphonic acid anion $\left(\mathrm{SO}_{3}{ }^{-}\right)$binding sites (a strong acid type resin). Table

3.1 presents the properties of a widely used strong acid type cation resin, Dowex ${ }^{\mathrm{TM}} 50 \mathrm{~W}-$ $\mathrm{X} 8[55]$.

It is well known that a resin has affinity for higher charge (i.e. bivalent ions versus monovalent ions). However, selectivity is also a function of ionic strength and $\mathrm{pH}$. Aside from the selectivity, another factor that affects the effectiveness of ion exchanger resin is the number of binding sites available on the resin in which the distribution coefficient (distribution of metal between resin and sample) increases proportionally with the surface area of resin beads [1].

In general, the process of IET involves passing the sample solution through a strongly acidic cation exchange resin in the sodium form until the metal ions in sample reach equilibrium with the resin (i.e. influent and effluent concentrations of the test metal are 
Table 3.1 Properties of Dowex ${ }^{\mathrm{TM}} 50 \mathrm{~W}-\mathrm{X} 8$, a widely-used cation-exchange resin for determination of free metal ion concentration*.

\begin{tabular}{ll}
\hline Properties & Description \\
\hline Resin & Dowex ${ }^{\mathrm{TM}} 50 \mathrm{~W}-\mathrm{X} 8$ \\
Usual form when purchased & Aryl- $\mathrm{SO}_{3}-\mathrm{H}^{+}$ \\
Thermal stability & Good up to $150^{\circ} \mathrm{C}$ \\
pH range & $0-14$ \\
Exchange capacity & 4.8 mequiv $/ \mathrm{g}$ of dry resin \\
Resin selectivity for cations & $\mathrm{H}^{+}>\mathrm{Na}^{+}>\mathrm{Mg}^{2+}>\mathrm{Zn}^{2+}>\mathrm{Cu}^{2+}>\mathrm{Cd}^{2+}>\mathrm{Ni}^{2+}>\mathrm{Ca}^{2+}>\mathrm{Pb}^{2+}$ \\
\hline
\end{tabular}

* adapted from Sigma-Aldrich Corporation (2007) [55] 
equal). As a result, the concentration of metal adsorbed to the resin can be related to the free metal ion concentration [53].

In order to apply IET, three assumptions are made; 1) the sample and the standard are swamped with the same "electrolyte" (e.g. $\mathrm{NaNO}_{3}$ ) to achieve the same bulk ionic strength; 2) trace conditions are met (i.e. the number of resin binding sites are much greater than the $\mathrm{M}^{\mathrm{n}+}$ in sample, which occupies less than $1 \%$ of the resin sites); 3) $\mathrm{M}^{\mathrm{n}+}$ species are the only species of the sample metal that will bind to the resin [5]. Assumption 1 can be ignored if samples are of high ionic strength since the method can be calibrated for a matrix of varying salt composition [56]. The second assumption can be easily fulfilled by analyzing the eluant for the counter-ions (e.g. $[\mathrm{Na}] \gg[\mathrm{M}]$ ).

Deviations from assumption 3 are possible because cationic complexes of nickel possessing equal or lower charge than the free-metal ion, such as $\mathrm{NiL}+$ and $\mathrm{Ni}\left(\mathrm{NH}_{3}\right)_{\mathrm{x}}{ }^{2+}$, will undergo ion exchange. However, assumption 3 is common to all ion exchange speciation methods when applied to real samples, which usually have a composition that is difficult to define in its entirety. Also, the assumption is likely to lead to fairly small errors for two reasons. First, in complex aqueous samples such as mining effluents, the principal ligands are likely to be polydentate and/or to carry a multiple negative charge at $\mathrm{pH}$ levels greater than 7. Examples of such ligands include humates, nitrilotriacetate, phosphate, carbonate, and peptides, which are all common in aqueous effluent samples. Consequently, cationic metal-ligand species are unlikely to represent a significant fraction of the measured free metal concentration, except in unusual samples containing 
high concentrations of neutral ligands such as $\mathrm{NH}_{3}$. Typically, $\mathrm{NH}_{3}$ in natural waters are $<10^{-5} \mathrm{M}$ and should not affect IET determinations (46). Second, the resin binding site generally has a lower affinity for species of lower charge (e.g., for $\mathrm{NiL}^{+}$compared to $\mathrm{Ni}^{2+}$ ), especially at low ionic strength [5]. In fact, evidence exists in the literature demonstrating the resin's (sulphonic acid group) higher selectivity for free ion in the presence of other cation-chloride complexes [6,54]. Assumption 3 is important in IET because it allows the use of a simple mass balance equation.

A normal ion exchange reaction of a free metal in solution with a resin site saturated with sodium can be represented as:

$$
M^{n+}+n R N a \longleftrightarrow R_{n} M+n N a^{+}
$$

where $M^{\mathrm{n+}}$ represents free metal ion in solution (aqua complex), $\mathrm{n}$ is its charge; and $\mathrm{R}$ is the resin binding site. $\mathrm{K}_{\mathrm{IE}}$, the ion exchange reaction constant, is defined as:

$$
\mathrm{K}_{\mathrm{IE}}=\frac{\left[\mathrm{R}_{n} \mathrm{M}\right]\left[\mathrm{Na}^{+}\right]^{n}}{\left[\mathrm{M}^{n+}\right][\mathrm{RNa}]^{n}}
$$

The square brackets [], indicate that concentration units of the various species will be used in the calculation rather than the thermodynamic activities (based on assumption 1 of constant ionic strength).

Based on the above equilibrium and $\mathrm{K}_{\mathrm{IE}}$ (Equations 1 and 2), the distribution of the metal between resin and sample, known as the distribution coefficient $(\lambda)$, is as follows:

$$
\lambda_{0, i, p H}=K_{I E} \frac{[R N a]^{n}}{\left[N a^{+}\right]^{n}}=\frac{\left[R_{n} M\right]}{\left[M^{n+}\right]}
$$


where a standard of known $\left[\mathrm{M}^{\mathrm{n}+}\right]$ without the ligands is used, at constant ionic strength and $\mathrm{pH}$. The distribution coefficient can be considered constant if $\mathrm{Na}^{+}$or another counter-ion is maintained at suitably high concentrations. The result will then be a simple relationship between the free-ion concentration in the original solution and the total metal adsorbed on the resin.

The concentration of metal bound to resin, $\left[R_{n} M\right]$, with a resin mass $\left(m_{r}\right)$ can be determined experimentally by eluting the metal bound by the resin with a volume (V) of strong acid (1.5 $\left.\mathrm{M} \mathrm{HNO}_{3}\right)$ and measuring $[\mathrm{M}]_{\text {Eluant, }}$, the concentration $(\mathrm{M})$ of metal in the eluant. The equation is as follows;

$\left[R_{n} M\right]=\frac{\left[M_{\text {Eluent }}\right] \times V}{m_{r}}$

Combining and rearranging of equations 3 and 4 will give the free metal ion concentration, $\left[\mathrm{M}^{\mathrm{n+}}\right]$ as follows;

$$
\left[M^{n+}\right]=\frac{\left[M_{\text {Eluent }}\right] \times V}{\lambda_{0, i, p H} \times m_{r}}
$$

The distribution coefficient is easily determined for a constant resin mass and elution volume by running a standard solution of known $\left[\mathrm{M}^{\mathrm{n}+}\right]$ through the column until steadystate is reached (i.e. $\left.[\mathrm{M}]_{\mathrm{in}}=[\mathrm{M}]_{\mathrm{out}}\right)$. At that point, the total metal concentration in solution remains the same during the passage of any additional volume of sample through the ion exchange resin bed which means that the chemical equilibrium has been established. This same concept can be applied to the sample solution being passed through the column until steady-state is reached. The concentration of metal adsorbed by 
the resin can be determined, and $\lambda$ can be calculated for the specific $\mathrm{pH}$, ionic strength and counter-ion used for the above determination:

$$
\lambda_{0, i, p H}=\frac{\left[M_{\text {Eluent }}\right] \times V}{\left[M^{n+}\right] \times m_{r}}
$$

Once a distribution coefficient specific to the metal of interest has been determined, for the relevant concentration and nature of the electrolyte and for the $\mathrm{pH}$ of the solution, one can easily calculate $\left[\mathrm{M}^{\mathrm{n}+}\right]$.

\subsection{Experimental section}

\subsubsection{Materials and reagents}

All solutions were prepared with ultrapure water (resistivity $18.2 \mathrm{M} \Omega-\mathrm{cm}$ ) which was obtained direct from a Nanopure Diamond purification system (Barnstead, USA) fitted with a purifying column to remove organic matter. A standard solution of Ni(II) was prepared by dilution of $1000 \mathrm{mg} / \mathrm{L}$ high-purity nickel aqueous standard (ICP grade, SCP Science). This standard was used to prepare working standards by serial dilution and acidification of the diluted standards to contain $1 \%(\mathrm{v} / \mathrm{v})$ ultrapure nitric acid (Baseline, Seastar Chemicals) in order to prevent metal loss by adsorption on the container walls. A stock solution of $2 \mathrm{M}$ sodium nitrate (supporting electrolyte) was prepared by dissolving sodium nitrate (puriss. p.a. Reag. ACS, Riedel-de Haën) in ultrapure water. This sodium nitrate solution was further purified by the following procedure [6]: $40 \mathrm{~g}$ of Chelex-100 resin in the sodium form (Bio-rad) was added to $1 \mathrm{~L}$ of $2.0 \mathrm{M} \mathrm{NaNO}_{3}$ solution (pH 7), and the mixture was left to stir gently for at least 48 hours for equilibration before filtering through a $0.45 \mu \mathrm{m}$ (Millipore) cellulose filter paper. The filtrate was stored at room temperature. A stock solution of $2 \mathrm{M}$ sodium acetate solution was prepared by 
dissolving sodium acetate trihydrate (ANALAR, EMD) in ultrapure water. A $0.1 \mathrm{M}$ sodium hydroxide solution was prepared by dissolving sodium hydroxide pellets (puriss. p.a. Reag. ACS, Riedel-de Haën) in ultrapure water. Ultrapure nitric acid (Baseline, Seastar Chemicals) was used to prepare a $1.5 \mathrm{M} \mathrm{HNO}_{3}$ solution for elution of metals from the resin.

The Laurentian Fulvic Acid (LFA) was purchased from Fredriks Research Products (The Netherlands) in the freeze-dried form. The LFA was derived from a podzol collected from the Laurentian Forest Preserve of Laval University, Quebec, Canada. This well characterized fulvic acid (LFA) has been certified to contain $11.6 \mathrm{mmol} / \mathrm{g}$ of carboxylate and phenolate groups and its elemental analysis is C $45.14 \%, \mathrm{H} 4.11 \%$ and $\mathrm{N} 1.07 \%$ [57]. The cationic resin was purchased from Sigma (Dowex ${ }^{\mathrm{TM}} 50 \mathrm{~W}-\mathrm{X} 8,50-100 \mathrm{mesh}$, analytical grade). The $\mathrm{pH}$ of samples was measured using an Accumet 20 $\mathrm{pH} /$ conductivity meter (Fisher).

\subsubsection{Model solutions}

A $1.0000 \mathrm{~g} / \mathrm{L}$ stock solution was prepared by dissolving $1.0000 \mathrm{~g}$ of freeze-dried LFA in ultrapure water. Model solutions of combinations of $1 \times 10^{-3}, 1 \times 10^{-2}$, or $2 \times 10^{-2} \mathrm{~g} / \mathrm{L}$ of LFA with $2 \times 10^{-8}, 1 \times 10^{-7}$, or $2 \times 10^{-7} \mathrm{M} \mathrm{Ni}$ (II) were prepared individually (separately) in ultrapure water. The ionic strength of the model solutions were adjusted to $0.2 \mathrm{M}$ using $2 \mathrm{M}$ sodium nitrate supporting electrolyte solution. The solutions were $\mathrm{pH}$-buffered with $0.01 \mathrm{M}$ sodium acetate using the $2 \mathrm{M}$ sodium acetate stock solution. The $\mathrm{pH}$ was adjusted to $5.5 \pm 0.1$ with $2 \mathrm{M}$ nitric acid and $2 \mathrm{M}$ sodium hydroxide. These solutions were left 
standing for a minimum of 3 days to allow for equilibration of $\mathrm{Ni}$ (II) with LFA because this reaction is slow to reach equilibrium; finally, the $\mathrm{pH}$ was re-adjusted to $5.5 \pm 0.1$, if necessary. All tests were done in triplicate and changes in $\mathrm{pH}$ of the test solutions between the beginning and the end of the experiment were found to be $< \pm 0.5 \mathrm{pH}$ units.

\subsubsection{Mining and municipal aqueous effluent samples}

The mining and municipal aqueous effluent samples were collected in May 2006 from several sampling sites in the Sudbury area. The aqueous effluent samples were collected from discharge points of Crean Hill Mine, Garson Mine, Whistle Mine, Copper Cliff Waste Water Treatment Plant, Nolin Creek Waste Water Treatment Plant, and Sudbury Municipal Waste Water Treatment Plant. A $0.45-\mu \mathrm{m}$ membrane filter (AquaPrep ${ }^{\mathrm{TM}} 600$ Capsules, Pall Corporation) was used to separate particulates from dissolved species in the water samples. This filter is made of mixed cellulose esters and has the advantage of providing filtrates having low blanks for the metals. Before the beginning of the test, the $\mathrm{pH}$ of the samples was re-checked. If a $\mathrm{pH}$ was significantly different from its original $\mathrm{pH}$ (the $\mathrm{pH}$ measured at the time of the sample collection), it was re-adjusted to the original pH using $2 \mathrm{M}$ nitric acid and $2 \mathrm{M}$ sodium hydroxide.

\subsubsection{Ion Exchange Technique (IET)}

A column ion exchange technique was used to determine the $\left[\mathrm{Ni}^{2+}\right]$. The micro-column was composed of Teflon tubing ( $3 \mathrm{~mm}$ internal diameter, $3 \mathrm{~cm}$ long), in which 7.8-8.0 mg (dry weight) of resin (Dowex ${ }^{\mathrm{TM}} 50 \mathrm{~W}-\mathrm{X} 8$ ) was trapped by two pieces of porous polyethylene discs that was fitted into polypropylene Luer tips (both supplied by Kimble 
Kontes). The miniature column was fitted within the Biologic LP Chromatography System (Bio Rad). Figure 3.1 shows an illustration of the general experimental design that was used for IET.

The following is a step-by-step description of the optimized procedure that was used for every sample; (Note: Steps 1-6 were entered into the automated system and all steps were run at a flow rate of $5 \mathrm{~mL} / \mathrm{min}$ unless indicated otherwise); 1) The resin was washed for 4 minutes with nanopure water; 2) The resin was converted from protonated form to sodium form by running $0.1 \mathrm{M} \mathrm{NaOH}$ for 2 minutes ( $\mathrm{Na}$ form is highly selective for divalent cations); 3) To remove excess $\mathrm{NaOH}$ from system, the resin was washed with nanopure water for 4 minutes; 4) The system was pumped for 3 minutes with a supporting electrolyte solution of concentration and $\mathrm{pH}$ matching that of the sample solution; 5) The sample solution was passed through for 18 minutes to equilibrate the sample with the resin; 6) The excess sample solution was washed out with nanopure water for 1 minute; 7) The metal bound to the resin was eluted with $2 \mathrm{~mL}$ of $1.5 \mathrm{M}$ nitric acid at $0.50 \mathrm{~mL} / \mathrm{min}$ flow rate (preliminary studies had shown that $2 \mathrm{~mL}$ was sufficient to elute all metal bound to resin if the mass of resin was between $7.8-8.0 \mathrm{mg}$ ); 8) Finally, the $[\mathrm{Ni}(\mathrm{II})]_{\text {total }}$ in eluant (representing $\left[\mathrm{Ni}^{2+}\right]$ bound to resin) was analyzed. Note that at the beginning of each experiment, a blank solution (matrix components) was run through the system and its value was subtracted from the subsequent samples only if any significant levels of nickel were found in the blank solution. 
All sample containers were made of Teflon and were pre-cleaned by soaking in $10 \%$ $\mathrm{HNO}_{3}$ (AR grade) for 1 week at room temperature, followed by a 5 time rinse with ultrapure water. The containers were kept filled with ultrapure water until used [58].

\subsubsection{Graphite Furnace Atomic Absorption Spectrometry}

Graphite Furnace Atomic Absorption Spectrometry (GFAAS) was used for quantitative determination of $[\mathrm{Ni}]_{\text {total }}$ because of the high sensitivity, accuracy and applicability of GFAAS to samples of high ionic strength (i.e. containing large amounts of solids), and low pH. Perkin-Elmer AAnalyst 600, fitted with Zeeman background correction system and transversely-heated graphite atomizer (THGA), was used. The instrument was equipped with an AS-800 autosampler and THGA graphite furnace; THGA graphite tubes (Perkin-Elmer) which were pyrolytically coated and contained integrated L'vov platforms were used. Each determination included a clean-up step where the graphite tube was heated at $2450^{\circ} \mathrm{C}$ for $5 \mathrm{sec}$. During the drying, pyrolysis and clean-up steps, the internal argon gas was passed through the furnace at $250 \mathrm{~mL} / \mathrm{min}$, but was interrupted during the atomization step. The signal was measured in the peak area mode and the concentrations were determined by using an analytical calibration curve.

\subsection{6 $Q A / Q C$}

To achieve quality control, the analysis schedule included a blank for every fifth sample, and a Certified Reference Standard (NIST \#1640) was run at midway and near the end of the run. If a difference of $>10 \%$ from certified value was observed, the selected set of samples were re-analyzed. All samples were analyzed in quadruplicate and the mean was 
used in the data analysis. The relative standard deviation among replicate determinations was typically $\leq 5 \%$.

\subsubsection{WHAM VI calculations}

The computer program, WHAM version 6.0, was used to calculate the speciation of $\mathrm{Ni}(\mathrm{II})$ in model solutions containing Laurentian Fulvic Acid. WHAM had been designed to calculate equilibrium speciation of metals in complex systems such as sediments, soils as well as surface and ground waters [10]. It was found to be useful for systems containing humic substances, such as humic acid (HA) and fulvic acid (FA), which had a major effect on metal speciation. The thermodynamic formation constants in the WHAM program were updated with the recent NIST Standard Reference Database [59] and listed in Table 3.2. The ionic strength correction was carried out in WHAM VI for metal standards used to calibrate IET (determination of distribution coefficient).

\subsection{Results and discussion}

\subsubsection{GFAAS: Optimization of the graphite furnace program for nickel determination}

GFAAS was chosen for quantitative determination because GFAAS was least affected by matrix effects. GFAAS is well-known for tolerating samples of high ionic strength (such as $0.2 \mathrm{M}$ sodium nitrate) and is applicable to highly complex samples like aqueous mining effluents [12]. The furnace program for GFAAS was optimized for each sample. Table 3.3 summarizes the optimized graphite furnace program for samples having a $\mathrm{pH}$ as low as 5.5 and an ionic strength as high as $0.2 \mathrm{M}$. The pyrolysis temperature $\left(1200^{\circ} \mathrm{C}\right)$ and the 


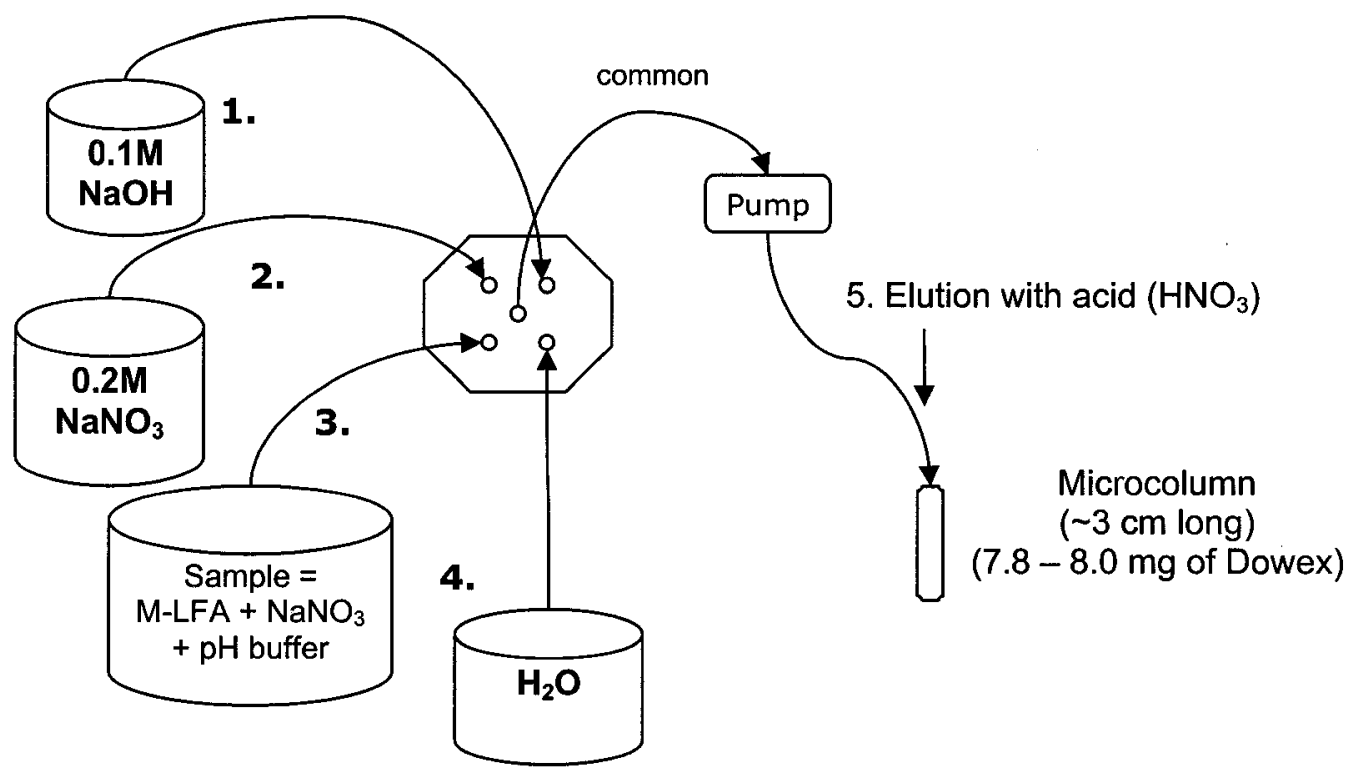

Figure 3.1 Illustration of the experimental design for the micro-column Ion Exchange Technique. 
Table 3.2 Formation constants used to calculate free nickel ion concentration.

\begin{tabular}{lc}
\hline Reaction & Log $\mathrm{K}^{*}$ \\
\hline $\mathrm{Ni}^{2+}+\mathrm{H}_{2} \mathrm{O} \leftrightarrow \mathrm{NiOH}^{+}+\mathrm{H}^{+}$ & 4.1 \\
$\mathrm{Ni}^{2+}+2 \mathrm{H}_{2} \mathrm{O} \leftrightarrow \mathrm{Ni}(\mathrm{OH})_{2}+2 \mathrm{H}^{+}$ & 9 \\
$\mathrm{Ni}^{2+}+3 \mathrm{H}_{2} \mathrm{O} \leftrightarrow \mathrm{Ni}(\mathrm{OH})_{3}^{-}+3 \mathrm{H}^{+}$ & 12 \\
$4 \mathrm{Ni}^{2+}+4 \mathrm{H}_{2} \mathrm{O} \leftrightarrow \mathrm{Ni}_{4}(\mathrm{OH})_{4}^{-}+4 \mathrm{H}^{+}$ & 28.3 \\
$\mathrm{Ni}^{2+}+\mathrm{NO}_{3}{ }^{-} \leftrightarrow \mathrm{NiNO}_{3}^{+}$ & 0.4 \\
$\mathrm{Ni}^{2+}+2 \mathrm{NO}_{3}{ }^{-} \leftrightarrow \mathrm{Ni}^{2}\left(\mathrm{NO}_{3}\right)_{2}^{+}$ & $-0.5(2 \mathrm{M})$ \\
$\mathrm{Ni}^{2+}+\mathrm{Cl}^{-} \leftrightarrow \mathrm{NiCl}^{+}$ & -0.45 \\
$\mathrm{Ni}^{2+}+\mathrm{CH}_{3} \mathrm{COO}$ & $\leftrightarrow \mathrm{NiOOCCH}_{3}^{+}$ \\
$\mathrm{Ni}^{2+}+2 \mathrm{CH}_{3} \mathrm{COO}^{-} \leftrightarrow \mathrm{Ni}\left(\mathrm{OOCCH}_{3}\right)_{2}$ & 2.44 \\
$\mathrm{CH}_{3} \mathrm{COOH} \leftrightarrow \mathrm{CH}_{3} \mathrm{COO}+\mathrm{H}^{+}$ & 4.757 \\
\hline
\end{tabular}

* Ionic strength $=0 \mathrm{M}$; and the formation constants were corrected for the effect of the ionic strength using WHAM VI. 
Table 3.3 Optimized furnace instrumental operation program for determination of nickel in acidic solutions of high ionic strength (up to $0.2 \mathrm{M}$ ) by graphite furnace atomic absorption spectrometry (Perkin Elmer AAnalyst 600).

\begin{tabular}{ccccccc}
\hline Step & $\begin{array}{c}\text { Description of } \\
\text { step }\end{array}$ & $\begin{array}{c}\text { Temp } \\
\left({ }^{\circ} \mathbf{C}\right)\end{array}$ & $\begin{array}{c}\text { Ramp } \\
\text { Time } \\
(\mathbf{s})\end{array}$ & $\begin{array}{c}\text { Hold } \\
\text { Time } \\
(\mathbf{s})\end{array}$ & $\begin{array}{c}\text { Internal } \\
\text { Flow }\end{array}$ & Gas Type \\
\hline 1 & Initial Drying & 110 & 5 & 30 & 250 & Normal \\
2 & Second Drying & 130 & 5 & 30 & 250 & Normal \\
3 & Final Drying & 350 & 15 & 20 & 250 & Normal \\
4 & Pyrolysis & 1200 & 10 & 30 & 250 & Normal \\
5 & Atomization & 2300 & 0 & 5 & 0 & Normal \\
6 & Cleanout & 2450 & 1 & 5 & 250 & Normal \\
\hline
\end{tabular}


atomization temperature $\left(2300^{\circ} \mathrm{C}\right)$ were chosen based on the best signal-to-noise ratio (see Figures 7.1 and 7.2 in Appendix) and the completeness of atomization. The high ionic strength of the IET samples (i.e. high solid contents) created a new problem, resulting in very spiky, disfigured Ni peaks. The spiky peaks were indicative of multiple deposition of material on the graphite tube caused by either poor positioning of the sampler or splattering (the latter was the more likely cause). Since the boiling point of $\mathrm{NaNO}_{3}$ is $380^{\circ} \mathrm{C}$, it decomposes explosively when heated at temperatures greater than $538^{\circ} \mathrm{C}[60]$. The "explosions" are likely to occur during the pyrolysis step, splattering the solution on the graphite tube, hence the spikes in the transient readout. In order to control the removal of the Na compounds, a step at $350^{\circ}$ degrees (hold time of $20 \mathrm{sec}$ ) was added. In addition, the clean-out step was increased from 3 to $5 \mathrm{sec}$ in order to ensure complete removal of the residue.

\subsubsection{Calibration of the column IET}

An essential step in calibration of IET is determining the volume of sample needed for the metal (or metals) of interest to equilibrate with resin. This can be determined in two ways: Method 1 is to conduct individual IET experiments, in which varying volumes of sample solution of known total metal concentrations are run (Figure 3.2a); Method 2 is to conduct a single experiment, in which the sample solution of known total metal concentrations is passed through the column and subsequent fractions of the direct effluent are collected for total metal analysis (Figure 3.2b). In Method 1, chemical equilibrium is attained when the concentration of metal extracted from the resin for the various sample volumes reaches a plateau (i.e. ion-exchange equilibria). When Method 2 
is used to determine steady-state, theoretical equilibrium is reached when the effluent concentrations is similar to the influent and is also indicated by a plateau in the metal concentration [5]. The plateau is indicative of equilibrium between the resin and the unperturbed sample solution since the sample in contact with the resin will not have any further free metal ions removed from its labile complexes. Thus, passage of more sample solution through the resin will make no additional change. Both experiments indicated that a plateau was reached at a sample volume of $80 \mathrm{~mL}$. Hence, all IET experiments in this study were run with $90 \mathrm{~mL}$ of sample loading onto column. However, the last $15 \mathrm{~mL}$ of effluent for each sample were collected and tested to ensure that equilibrium was attained as expected. It is interesting to note that literature on IET, using similar conditions (especially resin mass) but testing metals other than nickel, reports that only $20 \mathrm{~mL}$ of sample volume is required to reach steady-state [6,50]. Nickel may be special as it has been known to have slow kinetics to attain equilibrium in natural waters [61]. Slow kinetics may also affect the equilibration of nickel with the resin in IET. This is a critical consideration for IET studies that involve multi-metal composition such as mining aqueous effluents which may require even greater volumes to attain steady-state.

The equilibrium curve (Figure 3.2a) revealed that a steady-state was achieved at a distribution coefficient $\left(\lambda_{\mathrm{Ni}}\right)$ of approximately $0.65 \mathrm{~L} / \mathrm{g}$. However, repeated testing was necessary to calibrate IET and determine the $\lambda_{\mathrm{Ni}}$ specific for the resin mass, ionic strength, $\mathrm{pH}$ and the $[\mathrm{Ni}(\mathrm{II})]_{\text {total }}$ range to be used in the study. For the purpose of the model solution investigation, IET was calibrated with a standard $\mathrm{Ni}\left(\mathrm{NO}_{3}\right)_{2}$ solution $(0.2$ M sodium nitrate, $\mathrm{pH}$ 5.5) for which the initial free nickel ion concentration was 

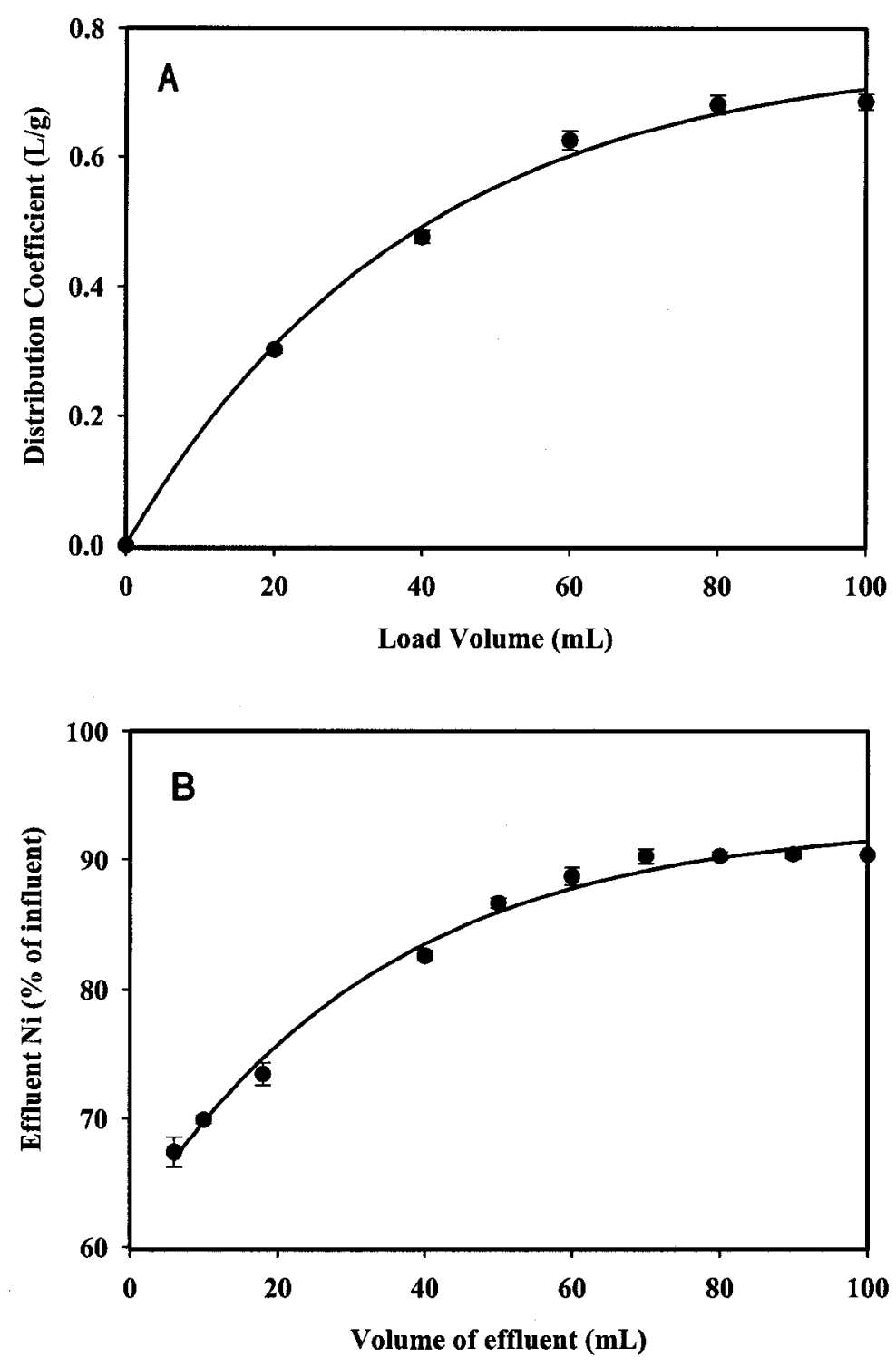

Figure 3.2 Volume of sample solution required for $\mathrm{Ni}$ to equilibrate with approx. 7.8 $\mathrm{mg}$ of the resin at $5 \mathrm{~mL} / \mathrm{min}$ flow rate. Samples contained $4.40 \times 10^{-7} \mathrm{M} \mathrm{Ni}$ and $0.2 \mathrm{M} \mathrm{NaNO}_{3}$ at $\mathrm{pH} 5.5 \pm 0.1$ and were buffered using $0.01 \mathrm{M}$ acetic acid - sodium acetate buffer. Vertical bars represent \pm 1 standard deviation (visible only when larger than the symbol). (A) The change in distribution coefficient with volume of sample solution loaded onto the column where each load volume was conducted as a separate experiment. (B) Monitoring the change in $[\mathrm{Ni}]$ in the effluent fractions with respect to the influent (original sample) in a single experiment. 
calculated using WHAM VI to correct for the high ionic strength. This is because a high salt concentration of nitrate may cause significant complexation of $\mathrm{Ni}^{2+}$ by nitrate. Note that the conditions of the model solutions do not necessarily match the conditions of the aqueous mining effluent samples tested. This is because the investigation in model

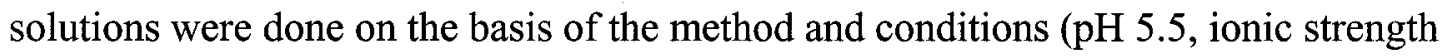
$0.20 \mathrm{M} \mathrm{NaNO}_{3}$ ) used by Fortin and Campbell (1998) [6], for comparison purposes. In addition, the effluent samples were collected from Sudbury (ON, Canada) after completion of the investigation in model solutions. Based on available literature information, it was concluded that it was unnecessary to repeat the study of model solutions at the $\mathrm{pH}$ and ionic strength matching the effluent samples. However, because of the difference in conditions ( $\mathrm{pH} 7-8$, ionic strength adjusted to $0.01 \mathrm{M}$ ), the IET determinations were re-calibrated to determine the new applicable distribution coefficient. See Section 3.5.4 for further discussion of IET application to the aqueous mining and municipal effluents.

For the investigation of model solutions, the distribution coefficient was repeatedly tested (minimum three times) for $[\mathrm{Ni}(\mathrm{II})]_{\text {total }}$ ranging between $20-200 \mathrm{nM}$ at a $\mathrm{pH}$ of 5.5 and ionic strength of $0.2 \mathrm{M}$. The average $\lambda_{\mathrm{Ni}}$ was determined to be $0.62 \pm 0.04 \mathrm{~L} / \mathrm{g}$. Cantwell et al. [5], using a larger mass of resin $(0.30 \mathrm{~g})$ and $1000 \mathrm{~mL}$ of sample volume, found $\lambda_{\mathrm{Ni}}$ $=0.48 \pm 0.01 \mathrm{~L} / \mathrm{g}$ at $\mathrm{pH} 7$ and $\lambda_{\mathrm{Ni}}=0.54 \pm 0.03 \mathrm{~L} / \mathrm{g}$ at $\mathrm{pH} 8$ [5]. In addition, they used a standard solution having approximately 4 times higher nickel concentration ( $852 \mathrm{nM})$. The above difference in the distribution coefficient between this study and that of Cantwell et al. (1982) [5] was probably due to operational parameters such as $\mathrm{pH}$, mass 
of resin, volume of the sample loaded and different laboratories. However, the results are close regardless of differences in the experimental conditions.

For the investigation of the aqueous mining effluent samples, the distribution coefficient was determined for $[\mathrm{Ni}(\mathrm{II})]_{\text {total }}$ ranging between $20-440 \mathrm{nM}$, and a $\mathrm{pH}$ of 7.5 or 8.5 . The average $\lambda_{\mathrm{Ni}}$ determined for $\mathrm{pH} 7.5$ and $8.5(2.04 \pm 0.08 \mathrm{~L} / \mathrm{g})$ was utilized in the free nickel ion calculations.

\subsubsection{Effect of ionic strength and $p H$ on the Ni(II)-binding affinity of the resin}

Figure 3.3 illustrates the effect of ionic strength on the binding affinity of Ni(II) with the resin (i.e. distribution coefficient) at different $\mathrm{pH}$ values (see also Figures 7.3 and 7.4 in Appendix for effects of $\mathrm{pH}$ and $\mathrm{pH}$ buffers). Increasing the ionic strength generally

decreases the $\lambda_{\mathrm{Ni}}$ at all $\mathrm{pH}$ 's tested ( $\mathrm{pH} 5.5,7.5,8.5$ ). Thus, greater ionic strength generally lowers the binding affinity of $\mathrm{Ni}^{2+}$ with Dowex ${ }^{\mathrm{TM}} 50 \mathrm{~W}-\mathrm{X} 8$ resin. This is because complexation at a binding site on the resin reduces the tendency of neighbouring sites to complex with another ion. This will generally weaken the binding ability of the metal of interest to the resin at higher ionic strengths. Additionally, it is evident that the weakening effect of ionic strength on the binding affinity decreased as the $\mathrm{pH}$ increased. This is most probably due to the counter-effect of $\mathrm{pH}$ on binding affinity to the resin, which generally increases the binding affinity as $\mathrm{pH}$ increases [62]. This is because higher $\mathrm{pH}$ increases dissociation of protons on the acidic functional groups of the complexant. This will strengthen the negative charge on the resin and will therefore increase the attraction of nickel ions to the resin and decrease the proton competition for 


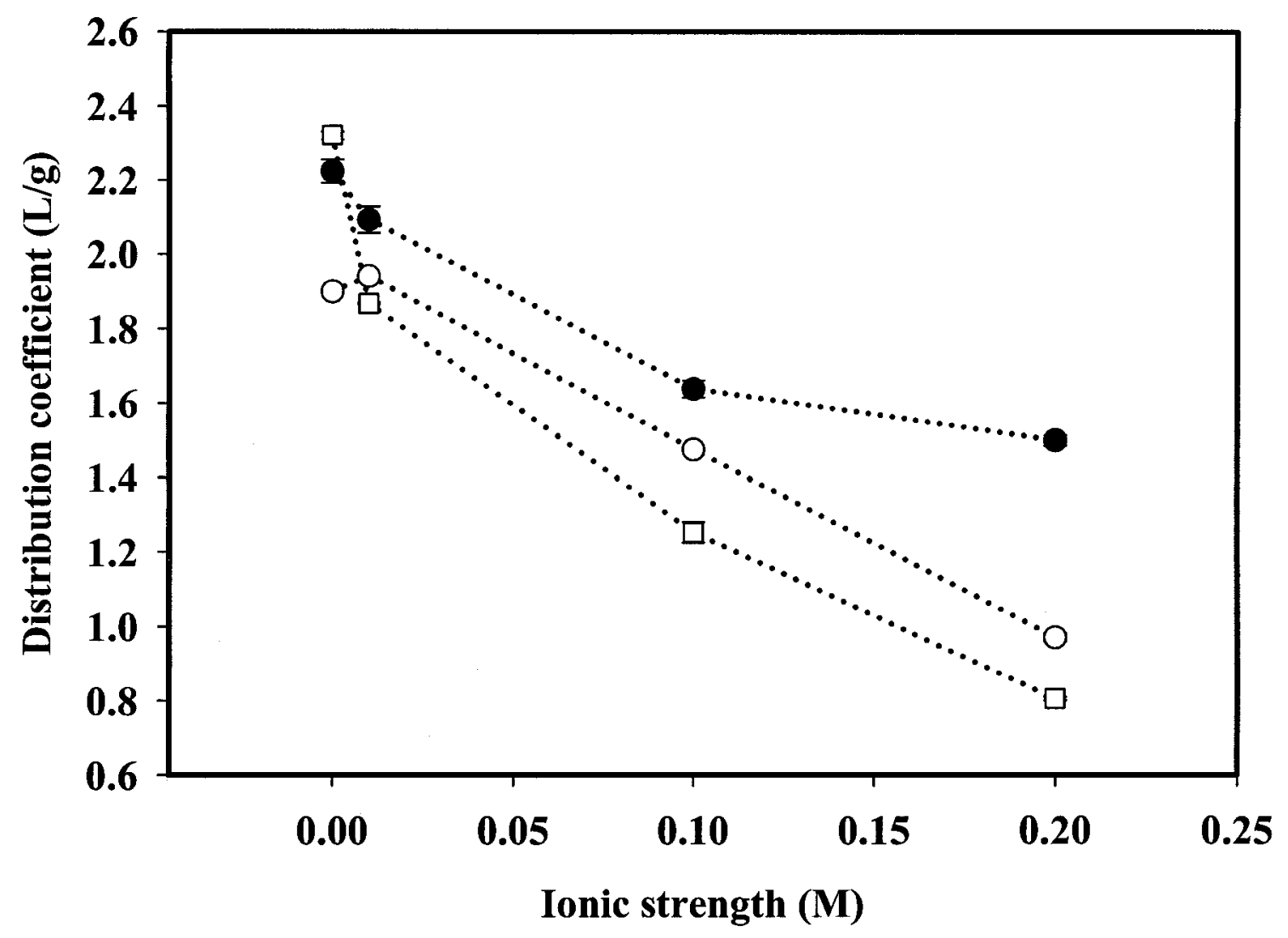

Figure 3.3 The effect of ionic strength on the distribution coefficient $\left(\lambda_{\mathrm{Ni}}\right)$ at various $\mathrm{pH}(\square, \mathrm{pH} 5.5 ; \circ, \mathrm{pH} 7.5 ; \bullet, \mathrm{pH} 8.5)$. The sample solutions contained 4.40 $\times 10^{-7} \mathrm{M}$ nickel and the $\mathrm{pH}$ buffer of $0.01 \mathrm{M}$ acetic acid - sodium acetate buffer (pH 5.5) or 0.01 M Tris (hydroxymethyl) aminomethane hydrochloride ( $\mathrm{pH} 7.5$ and 8.5). The vertical bars represent \pm 1 standard deviation of three replicate determinations (visible only when they are larger than the symbol). 
the binding sites. Based on these findings, it is advisable that all studies be calibrated by a solution at a $\mathrm{pH}$ very similar to the sample being tested. In addition, since the smallest $\mathrm{pH}$ effect was observed at an ionic strength of $0.01 \mathrm{M}$, this ionic strength appears to be the more suitable ionic strength for IET studies. Hence, real samples that are much lower in ionic strength may be adjusted to $0.01 \mathrm{M}$ without significantly affecting the results.

\subsubsection{Effect of $[\mathrm{Ni}(\mathrm{II})] /[\mathrm{LFA}]$ mole ratio on $\left[\mathrm{Ni}^{2+}\right]$}

The initial studies of Ni(II) by IET explores the effect of LFA complexation of $\mathrm{Ni}(\mathrm{II})$ on the free nickel ion concentration, $\left[\mathrm{Ni}^{2+}\right]$. LFA is a natural DOC which has been fully characterized for the concentration of carboxylate and phenolate binding sites [57], hence allowing for systematic testing for the effect of the DOC on $\left[\mathrm{Ni}^{2+}\right]$. Figure 3.4 illustrates the relationship between $[\mathrm{Ni}]_{\text {total }}$ and the IET-determined $\left[\mathrm{Ni}^{2+}\right]$ in the presence of varying [LFA]. Some parts of the curves are linear or nearly linear.

Figure 3.5a illustrates the effect of the [LFA] on the percentage of total $\mathrm{Ni}$ (II) found as free $\mathrm{Ni}^{2+}$ ion. It is evident that the $\% \mathrm{Ni}^{2+}$ decreases with increasing [LFA]. This is expected since humic substances contain binding sites that bind nickel metal, and hence, decrease the $\left[\mathrm{Ni}^{2+}\right]$ available in the solution. It is interesting to note, though, that the slopes are different for a $[\mathrm{Ni}(\mathrm{II})]_{\mathrm{total}}$ of $100 \mathrm{nM}$ compared to $200 \mathrm{nM}$, the latter is steeper. This is due to the difference in Ni(II)-to-[LFA] mole ratio (see Figure 3.5b). The Ni(II)to-[LFA] mole ratio usually determines the concentration of free $\mathrm{Ni}^{2+}$ ions. In Figure $3.5 \mathrm{~b}$, it is evident that as the Ni(II)-to-[LFA] mole ratio is increased, the percentage of $\mathrm{Ni}(\mathrm{II})$ found as free $\mathrm{Ni}^{2+}$ also increases. This is as expected, because a distinctive metal- 
complexing property of naturally occurring humic substances (HS), such as the LFA, which are heterogeneous complexants, is that their complexation with metal ions in natural waters is determined by their metal/binding site concentration ratio, usually known as metal ion loading, $(\Theta)$ [63-64]. HS are physically and chemically heterogeneous complexants and have $\leq 1$ to $10 \%$ strong binding sites and $\leq 99$ to $90 \%$ weak binding sites [65]. The strong binding sites form strong metal complexes which are non-labile, whereas the weak binding sites form weak metal complexes which are labile and they dissociate to yield free metal ions which are widely reported to be bioavailable and toxic to biota in natural waters. At very low nickel metal loading, i.e. [nickel]/[HS] ratio, typical of pristine natural waters, very strong metal complexes are formed which are non-labile and do not yield any free nickel ions. At higher metal loadings (i.e. higher $\Theta$ values) encountered in nickel metal mine and municipal run-offs in Sudbury area $(\mathrm{ON})$, more free nickel ions should be available. However, nickel-HS complexes are kinetically inert, compounding the problem of interpretation of the experimental observations, which should be based on self-consistent theoretical models of $\mathrm{Ni}$ (II)-HS interactions in aquatic systems. Structural changes (conformational) in fulvic acid following an increase in bound metal have been observed in light scattering measurements by Langford et al. [66]. Aggregation could also be induced by a combination of acidic and high ionic strength conditions [67].

Table 3.4 presents a comparison of solutions with different composition of dissolved nickel and LFA, but identical Ni(II)-to-LFA ratios. It is interesting to note that a large difference in $\% \mathrm{Ni}_{\text {free }}$ for the same $\mathrm{Ni}(\mathrm{II})$-to-LFA ratio $(0.0034)$ was observed. Had it 
been the case of a simple homogeneous ligand,(e.g. NTA), the same Ni(II)-to-ligand ratio would produce the same results. However, for the heterogeneous complexant, LFA, approximately $\sim 30 \%$ difference was observed for the $\mathrm{Ni}(\mathrm{II})$-to-[LFA] ratio of 0.0034 $(85.9 \pm 6.4$ for $1 \mathrm{mg} / \mathrm{L} \mathrm{LFA}, 58.1 \pm 5.7$ for $10 \mathrm{mg} / \mathrm{L} \mathrm{LFA})$. This was probably due to changes in the accessibility of some ligand sites on the LFA to metal ions because of conformational changes, degree of aggregation, and consequently the metal ion binding that comes into effect at high concentrations (e.g. with a 10 fold difference in the [LFA]). For a $\mathrm{Ni}$ (II)-to-LFA ratio of 0.0017 , not much difference in $\% \mathrm{Ni}_{\text {free }}$ was observed, probably as the result of an only 2 fold difference in $[\mathrm{Ni}(\mathrm{II})]_{\text {total }}$ and [LFA] compared to the 10 fold difference for the 0.0034 ratio. Also, the results at the ratio of 0.0017 are presumably because of reaching the geochemical limit [68], in which case the number of sites occupied on the LFA is so small that only the strongest binding sites contribute significantly to metal complexation.

\subsubsection{Sudbury mining and municipal aqueous effluents}

The concentrations of major cations, anions and trace metals other than Ni(II) in the aqueous effluent samples are presented in Table 3.5 . Table 3.6 presents the $\mathrm{pH}$, $[\mathrm{Ni}]_{\text {total }}$, $[\mathrm{DOC}],[\mathrm{Ni}]_{\text {total }} /[\mathrm{DOC}],\left[\mathrm{Ni}^{2+}\right]$ determined by IET, and $\left[\mathrm{Ni}^{2+}\right]$ predicted by WHAM VI, for the aqueous effluent samples. Dissolved nickel concentrations were higher in aqueous effluents in Garson Mine, Crean Hill, Nolin Creek WWTP, and Sudbury Waste Water Treatment Plant (WWTP), compared to Copper Cliff WWTP and Whistle Mine. However, the dissolved concentrations of nickel are not a reliable measure of the metal's toxicity. They do not represent the bioavailable nickel species which is determined by a 
variety of water chemistry factors. A critical factor with respect to mining aqueous effluents is the presence of DOC which can complex nickel species, thereby reducing the concentration of the nickel free metal ion [3]. Hence, this study examined nickel speciation in the aqueous effluent samples using the IET and the WHAM VI predictions, both of which provide $\left[\mathrm{Ni}^{2+}\right]$ (see Figure 7.5 in Appendix for a comparison). Previously, we studied the kinetic fractionation of nickel (i.e. labile nickel species) in water-diluted and undiluted samples of the Sudbury mine aqueous effluents [7] using Competing Ligand Exchange Method. This study found that dilution of the effluent samples with laboratory water increased the percentage of nickel released from $\mathrm{Ni}(\mathrm{II})-\mathrm{DOC}$ complexes. The importance of the free metal ion has been increasingly regarded as greater than that of the other labile metal species. In fact, the BLM approach is based on the concept that the free ion is the bioavailable species. In general, the binding capacity and affinity for metal binding is dependent on the number and type of ligands, on their position in the skeletal structure of the complexants, on the [Metal]/[HS] ratio, $\mathrm{pH}$, ionic strength and other factors [70].

Most of the aqueous effluent samples have DOC concentrations between $1.19-2.82$ mg/L, except Sudbury WWTP (8.79 mg/L) and Copper Cliff WWTP (6.55 mg/L). The nickel-DOC ratio usually determines the distribution of metal among the free and complexed forms. However, in mining and municipal aqueous effluent samples, this concept is much more complicated because of competition by other trace metals and major cations with nickel for the same binding sites on DOC, and the variability in metalbinding properties of DOC with the provenance of the DOC. 
The dissolved concentrations of nickel in Nolin Creek WWTP (pH 8.1) and in Sudbury WWTP (pH 7.4) are similar. The higher $\left[\mathrm{Ni}^{2+}\right]$ determined by IET in Nolin Creek is presumably because of its much higher nickel-DOC ratio (Table 3.6). Similarly, Copper Cliff aqueous effluent contained the lowest nickel-DOC ratio and resulted in the lowest $\left[\mathrm{Ni}^{2+}\right]$, determined by IET.

\subsubsection{Comparison of the IET results with WHAM VI predictions}

Free metal ion concentration can be predicted using a computational method based on discrete electrostatic binding called Windermere Humic Aqueous Model (WHAM) [911]. Assessment of the applicability of WHAM is important in view of it being the basis of BLM, which is being considered for inclusion in regulatory framework in North American and European nations. The U.S. Environmental Protection Agency has recently incorporated the BLM in determining Water Quality Criteria for Copper [34]. In order to validate the BLM for nickel speciation in natural waters, the reliability of BLM predictions must be assessed. Predictive models are useful for regulation of metal pollution because they avoid confounding factors such as sampling and storage loss and contamination, adsorption to container walls, disturbance of chemical equilibrium in the sample. These are involved in the sequential process of collection of field samples, bringing them to the laboratory for analysis, resulting in delay, decomposition and possible changes in metal speciation in the samples, especially water samples containing colloidal matters and dissolved and particulate metals. 
WHAM, developed by Tipping [10-11] to predict free metal concentration in complex aqueous solutions, is one of the most advanced speciation models available today. This equilibrium-based thermodynamic model (version VI) assumes discrete-site electrostatic binding and incorporates multiple binding sites of varying strength and binding site competition among various cations to predict metal speciation. WHAM VI's popularity is largely due to its comprehensive database of metal-DOC interactions, its agreement with experimental findings of various techniques [9,39] and simplicity for use. In addition, since WHAM VI is an equilibrium-based model and IET is an equilibrium-based technique, a comparison of the WHAM predictions with the IET determinations will be appropriate.

Figure 3.6 presents a comparison of the IET determined and the WHAM VI predicted free $\mathrm{Ni}(\mathrm{II})$ on a $\log$ scale, i.e., $\mathrm{pNi}_{\text {free }} \equiv-\log \left[\mathrm{Ni}^{2+}\right]$, for the model solutions. Generally, good correlation between the IET-determined $\mathrm{pNi}_{\text {free }}$ and the WHAM-predicted $\mathrm{pNi}_{\text {free }}$ was observed for all concentrations of the LFA. However, at higher nickel-to-fulvic acid ratios, WHAM VI slightly overestimated nickel free ion concentrations, which was similar to the findings of Doig and Liber (2007) [71]. These findings require more work for fine-tuning WHAM VI predictions for higher metal-to-DOC ratios in natural water conditions by improving the WHAM VI database for freshwater humic substances.

A major drawback in the WHAM modeling of real samples is that it requires an input datum for the concentration of "active" DOC (i.e. the concentration of DOC that behaves like isolated humic substances, and is actively involved in the binding of metals) [10]. 
This is an important parameter since it determines the number of binding sites available to the metals. Since the value of the "active" concentration of DOC, although critical, was not known, the aqueous effluent sample was modelled using three different "active" DOC concentrations: 40,65 and $100 \%$ of the DOC as "active" to determine the "active" DOC concentration that best fitted the measured free nickel ion concentrations. The WHAM VI model with $40 \%$ active DOC concentrations showed agreement with three of the experimental results of $\left[\mathrm{Ni}^{2+}\right]$ (Table 3.6); however, for Sudbury WWTP, the WHAM VI model with $40 \%$ "active" DOC concentration vastly underestimated the free nickel concentration compared with the measured values $\left(10^{5}\right.$ fold difference). Aside from the large deviation for Sudbury WWTP, Garson Mine and Copper Cliff WWTP showed 5fold and 17-fold differences, respectively. These deviations might be due to the presence of anthropogenic organic matter, which most likely had different characteristics from those of the humic substances used in the calibration of the WHAM. However, it is difficult to completely account for the differences between the WHAM VI predictions and the measured values of free nickel ion concentration because of the complexity of the samples. There are possible deficiencies in the wider applications of such a simple model as WHAM to independent data, and the artifacts associated with differences in analytical methods of experimental design confound the experimental results. Another source of error was the input data. For example, the data for phosphate level was very high for Sudbury WWTP and any error in that data could significantly affect the predictions. Three of the samples (Crean Hill, Whistle Mine and Nolin Creek WWTP) showed reasonable agreement with the predictions that ranged between 1.5 - and 2.6-fold differences of the IET measurements. 


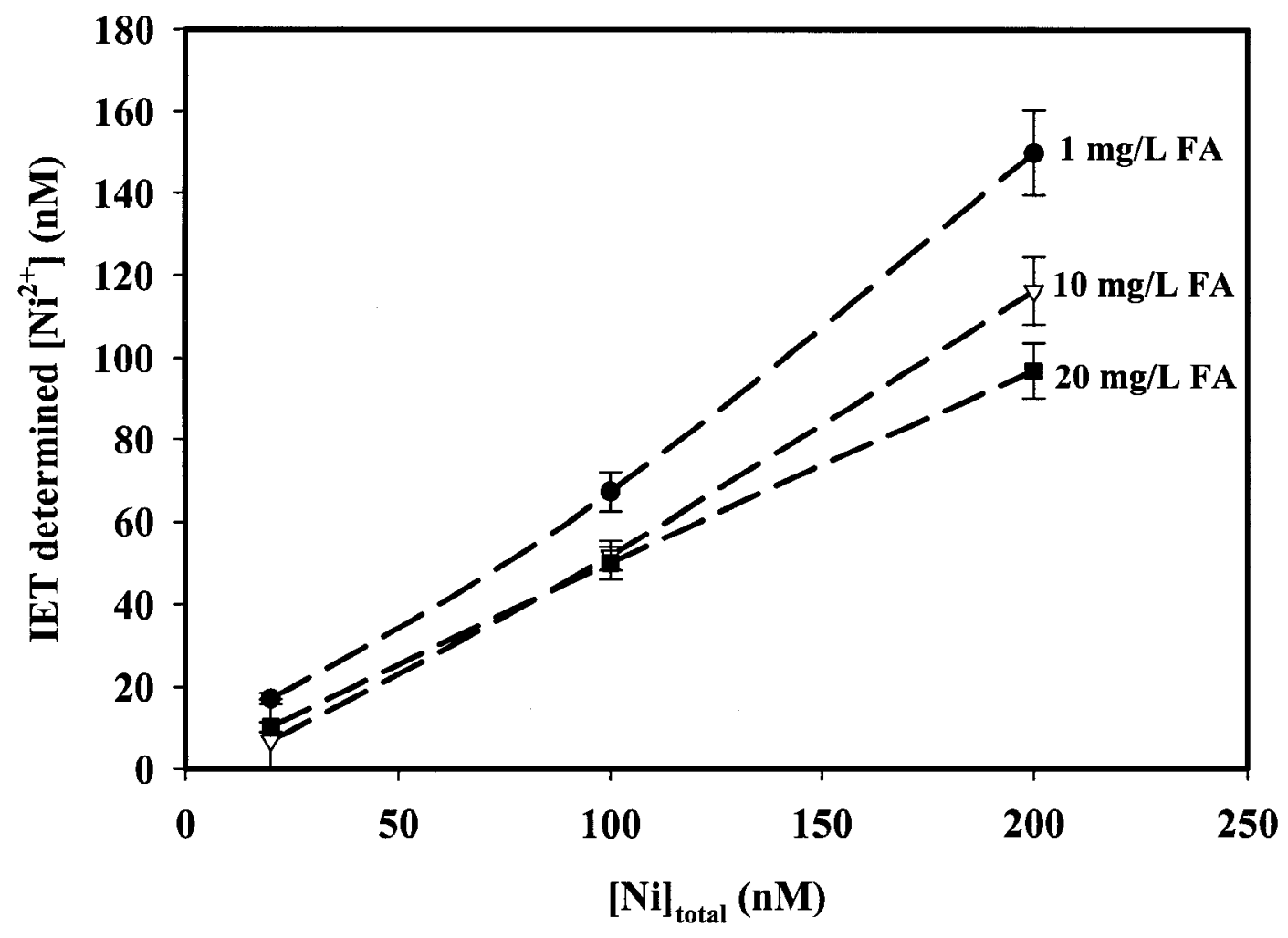

Figure 3.4 Relationship between total nickel and free nickel concentration determined by optimized IET in model solutions containing varying concentrations of Laurentian Fulvic Acid (•, $1 \mathrm{mg} / \mathrm{L} ; \nabla, 10 \mathrm{mg} / \mathrm{L} ; \mathbf{m}, 20 \mathrm{mg} / \mathrm{L})$. Samples had an ionic strength of $0.2 \mathrm{M}$ sodium nitrate at $\mathrm{pH} 5.5$ (buffered with 0.01 $\mathrm{M}$ acetic acid - sodium acetate buffer). Total nickel concentration in the samples varied between $2.00 \times 10^{-8}$ and $2.00 \times 10^{-7} \mathrm{M}$. The vertical error bars represent \pm 1 standard deviation, of three replicate determinations (visible only when they are larger than the symbols). The dashed lines were drawn to connect the experimental data points and do not represent linearity. 

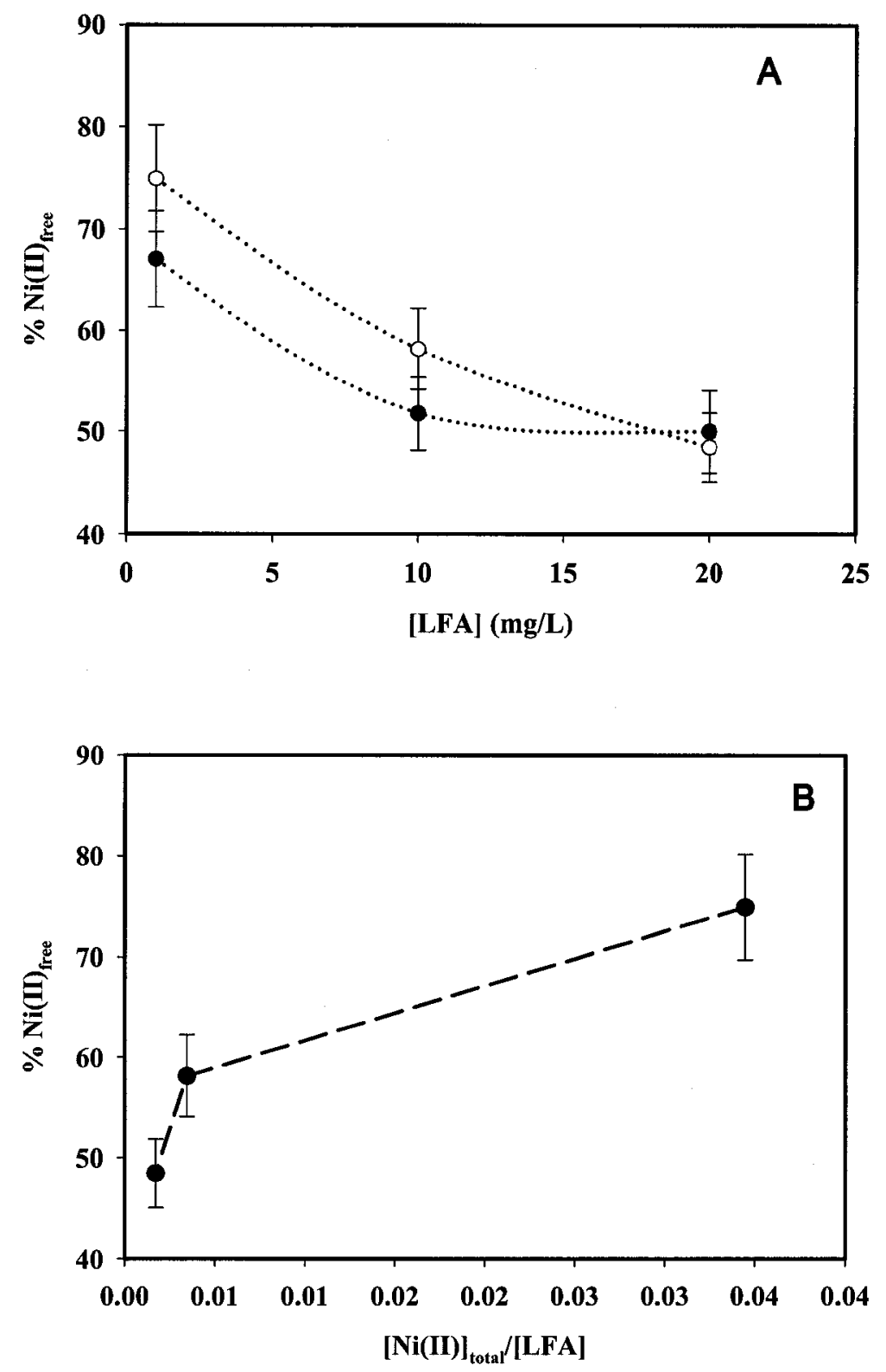

Figure 3.5 Using pre-equilibrated (72 hours) model solutions: (A) study of the effect of $[\mathrm{LFA}]$ on the nickel speciation, $100 \mathrm{nM} \mathrm{Ni}(\bullet), 200 \mathrm{nM}$ nickel (o); (B) study of the effect of $[\mathrm{Ni}(\mathrm{II})] /[\mathrm{LFA}]$ mole ratio on the $\% \mathrm{Ni}(\mathrm{II})$ found as free. Ionic strength was $0.2 \mathrm{M}$ (sodium nitrate) and $\mathrm{pH} 5.5$ (buffered with $0.01 \mathrm{M}$ acetic acid - sodium acetate buffer). The vertical error bars represent \pm 1 standard deviation, of three replicate determinations. 


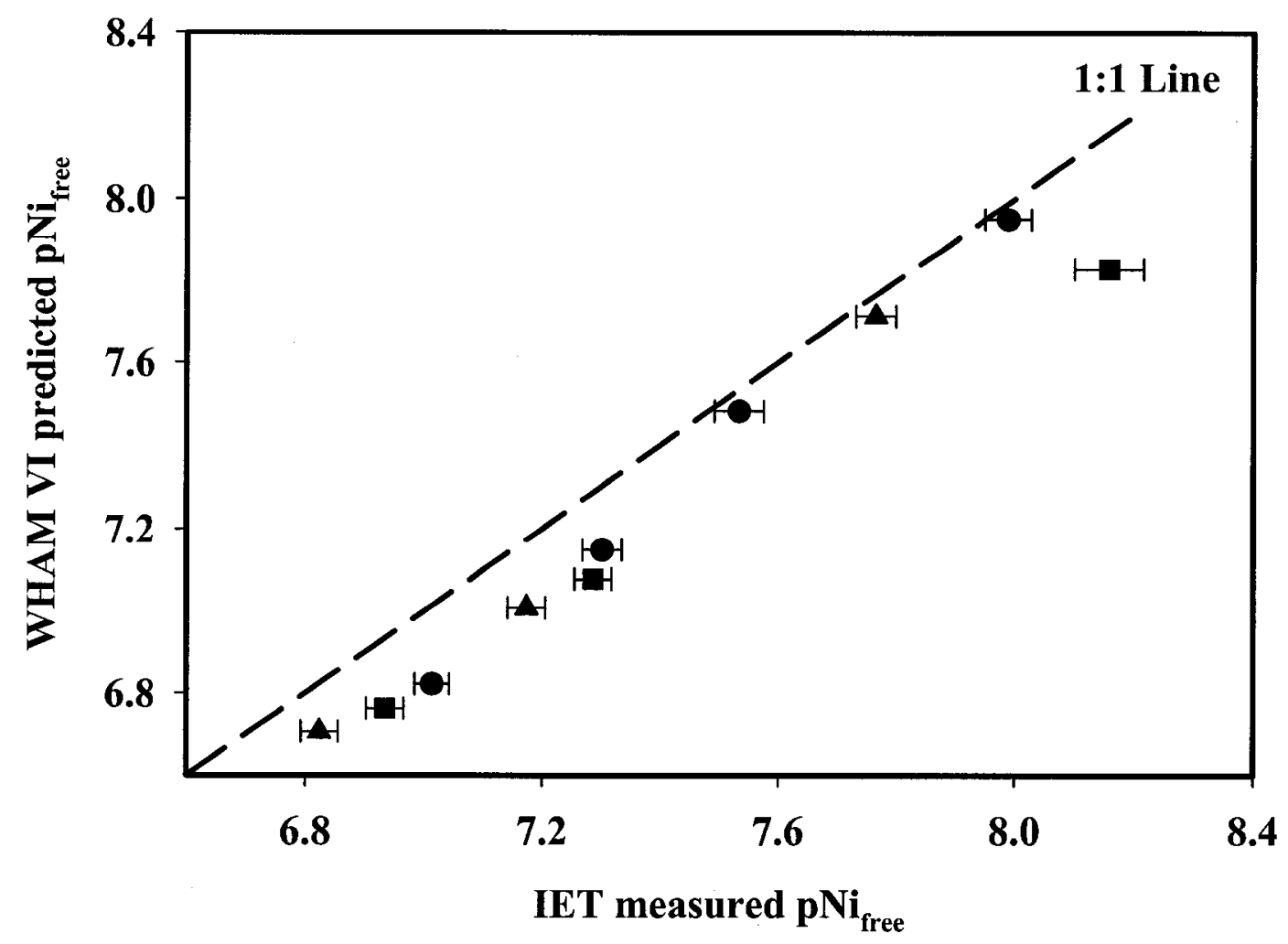

Figure 3.6 Comparison on a log scale of free nickel concentrations measured by optimized IET and that predicted by WHAM VI in model solutions containing the following concentrations of the Laurentian Fulvic Acid; 1 $\mathrm{mg} / \mathrm{L}(\mathbf{\Delta}), 10 \mathrm{mg} / \mathrm{L}(\boldsymbol{\bullet})$, or $20 \mathrm{mg} / \mathrm{L}(\bullet)$. The solutions had an ionic strength of $0.2 \mathrm{M}$ (sodium nitrate) and $\mathrm{pH} 5.5$ (buffered with $0.01 \mathrm{M}$ acetic acid - sodium acetate buffer). Total nickel concentration in the samples varied between $2.00 \times 10^{-8}-2.00 \times{ }^{10-7} \mathrm{M}$. The horizontal error bars represent \pm 1 standard deviation of three replicate determinations. 
Table 3.4 Effect of $[\mathrm{Ni}(\mathrm{II})] /[\mathrm{LFA}]$ mole ratio on the percentage of free $\mathrm{Ni}(\mathrm{II})$ (with respect to total nickel concentration) determined by column IET.

\begin{tabular}{cccc}
\hline $\begin{array}{c}{[\mathbf{N i}(\mathbf{I I})] /[\mathbf{L F A}]^{*}} \\
(\mathbf{M} / \mathbf{M})\end{array}$ & $\begin{array}{c}{[\mathbf{N i}]_{\text {total }}} \\
(\mathbf{n M})\end{array}$ & $\begin{array}{c}{[\mathbf{L F A}]} \\
(\mathbf{m g} / \mathbf{L})\end{array}$ & $\mathbf{\%}\left[\mathbf{N i}^{\mathbf{2 +}}\right]$ \\
\hline 0.0034 & 20 & 1 & $85.9 \pm 6.4$ \\
0.0034 & 200 & 10 & $58.1 \pm 5.7$ \\
0.0017 & 100 & 10 & $51.7 \pm 5.0$ \\
0.0017 & 200 & 20 & $48.4 \pm 3.4$ \\
\hline
\end{tabular}

* Based on the bi-dentate binding capacity of the Laurentian Fulvic Acid, $5.86 \times 10^{-3} \mathrm{M} / \mathrm{g}$ [69]. 
Table 3.5 Concentrations of major anions, major cations and other trace metals in the mine and municipal aqueous effluent water samples, collected from Sudbury, Ontario, in May 2006.

\begin{tabular}{|c|c|c|c|c|c|c|c|c|c|c|c|c|c|}
\hline \multirow{2}{*}{$\begin{array}{l}\text { Aqueous } \\
\text { Effluent } \\
\text { Sample }\end{array}$} & \multicolumn{4}{|c|}{ Major Cations } & \multicolumn{5}{|c|}{ Major Anions } & \multicolumn{4}{|c|}{ Trace Metals } \\
\hline & $\mathrm{Na}^{+}$ & $\begin{array}{r}\mathbf{K}^{+} \\
(\mathbf{m} \\
\end{array}$ & $\begin{array}{l}\mathrm{Mg}^{2+} \\
\mathrm{g}\end{array}$ & $\mathrm{Ca}^{2+}$ & $\mathbf{F}^{-}$ & $\mathrm{Cl}^{-}$ & $\begin{array}{c}\mathrm{NO}^{3-} \\
(\mathrm{mg} / \mathrm{L}) \\
\end{array}$ & $\mathrm{SO}_{4}{ }^{2-}$ & $\mathrm{PO}_{4}{ }^{3-}$ & $\mathrm{Cu}^{2+}$ & $\begin{array}{l}\mathrm{Zn}^{2+} \\
(\mu \mathrm{g} / \mathrm{I} \\
\end{array}$ & $\mathrm{Cd}^{2+}$ & $\mathbf{P b}^{2+}$ \\
\hline $\begin{array}{l}\text { Crean Hill } \\
\text { Mine }\end{array}$ & 2.05 & 0.97 & 2.36 & 34.63 & 0.12 & 4.49 & 0.32 & 67.64 & 0.03 & 10.37 & 15.37 & ND & 0.45 \\
\hline Garson Mine & 69.31 & 12.50 & 14.42 & 244.66 & 1.14 & 151.65 & 31.02 & 736.99 & 0.03 & 6.29 & 68.79 & ND & 0.30 \\
\hline Whistle Mine & 2.05 & 5.28 & 7.07 & 46.73 & 0.08 & 10.03 & 5.77 & 136.09 & 0.09 & 4.10 & 17.14 & ND & 1.98 \\
\hline $\begin{array}{l}\text { Copper Cliff } \\
\text { WWTP }\end{array}$ & 138.24 & 38.06 & 15.78 & 461.71 & 2.63 & 97.10 & 5.21 & 1528.03 & 0.04 & 173.36 & 178.76 & 0.35 & 3.49 \\
\hline $\begin{array}{c}\text { Nolin Creek } \\
\text { WWTP }\end{array}$ & 33.59 & 2.60 & 1.63 & 75.12 & 0.08 & 89.87 & - & 217.48 & 0.04 & 5.27 & 12.75 & ND & 0.35 \\
\hline $\begin{array}{l}\text { Sudbury } \\
\text { WWTP }\end{array}$ & 93.35 & 5.88 & 7.16 & 29.33 & 0.43 & 158.03 & 1.42 & 49.80 & 0.32 & 9.57 & 42.12 & ND & 0.30 \\
\hline
\end{tabular}


Table 3.6 The IET determined free nickel ion concentration compared with the predictions of WHAM VI (assuming $40 \%$ of Dissolved Organic Carbon as "active") and the nickel-to-DOC mole ratio as a parameter.

\begin{tabular}{|c|c|c|c|c|c|c|c|}
\hline $\begin{array}{l}\text { Aqueous Effluent } \\
\text { Sample }\end{array}$ & pH & $\begin{array}{c}{[\mathbf{N i}]_{\text {total }}} \\
(\mathbf{M})\end{array}$ & $\begin{array}{c}\mathrm{DOC} \\
(\mathrm{mg} / \mathrm{L})\end{array}$ & $\begin{array}{c}{[\mathrm{Ni}]_{\text {total }} /[\mathrm{DOC}]} \\
(\mathbf{M} / \mathbf{m g} / \mathbf{L})\end{array}$ & $\begin{array}{c}\text { IET } \\
\text { measured } \\
{\left[\mathbf{N i}^{2+}\right]} \\
(\mathbf{M}) \\
\end{array}$ & $\begin{array}{c}\text { WHAM VI } \\
\text { predicted }\left[\mathrm{Ni}^{2+}\right] \\
(\mathrm{M})\end{array}$ & $\begin{array}{c}\text { Difference between } \\
\text { IET \& WHAM } \\
\text { results }\end{array}$ \\
\hline Crean Hill Mine & 7.7 & $1.76 \times 10^{-06}$ & 2.23 & $7.91 \times 10^{-07}$ & $6.19 \times 10^{-07}$ & $4.01 \times 10^{-07}$ & $1.5 \mathrm{X}$ \\
\hline Garson Mine & 7.8 & $2.33 \times 10^{-06}$ & 2.82 & $8.27 \times 10^{-07}$ & $2.42 \times 10^{-07}$ & $1.27 \times 10^{-06}$ & $5.2 \mathrm{X}$ \\
\hline Whistle Mine & 8.0 & $4.91 \times 10^{-07}$ & 2.14 & $2.29 \times 10^{-07}$ & $7.53 \times 10^{-08}$ & $2.84 \times 10^{-08}$ & $2.6 \mathrm{X}$ \\
\hline $\begin{array}{l}\text { Copper Cliff } \\
\text { WWTP }\end{array}$ & 7.1 & $6.97 \times 10^{-07}$ & 6.55 & $1.06 \times 10^{-07}$ & $2.89 \times 10^{-08}$ & $4.97 \times 10^{-07}$ & $17 X$ \\
\hline $\begin{array}{c}\text { Nolin Creek } \\
\text { WWTP }\end{array}$ & 8.1 & $1.28 \times 10^{-06}$ & 1.19 & $1.07 \times 10^{-06}$ & $2.89 \times 10^{-07}$ & $4.64 \times 10^{-07}$ & $1.6 \mathrm{X}$ \\
\hline Sudbury WWTP & 7.4 & $1.32 \times 10^{-06}$ & 8.79 & $1.50 \times 10^{-07}$ & $2.41 \times 10^{-07}$ & $2.44 \times 10^{-12}$ & $10^{5} \mathrm{X}$ \\
\hline
\end{tabular}




\section{Relationships between equilibrium- and kinetics- based estimates of nickel speciation to algal toxicity in aqueous mining and municipal effluents}




\section{Relationships between equilibrium- and kinetics-based estimates of nickel speciation to algal toxicity in aqueous mining and municipal effluents}

\subsection{Introduction}

Trace metals are of concern because they are essential micronutrients at low levels but are toxic at higher concentrations. Hence, regular monitoring of freshwater supply and setting of adequate water quality criteria are becoming more and more critical in protecting and safeguarding human and environmental health. Surface waters (freshwaters, estuarine and seawaters) are representative media of the chemical complexities that can exist in the environment which make the task of monitoring difficult for environmental chemists. To name just a few, complexities include: wide range of metal concentrations, dissolved organic matter of mainly unknown structure, inorganic and organic colloidal material, and the presence of microorganisms which consume and excrete dissolved chemicals.

Since the natural environment is being extensively exposed to trace metals, the past two decades have promoted a large surge in metal speciation research. However, in spite of significant progress, speciation of trace metals, their transport and their related toxicological effects, continue to be an important field of research. More must be done quickly to stop and reverse the current trend of environmental degradation brought about by anthropogenic invasion of the natural habitat of freshwater biota - natural waters.

Labile metal species are widely reported to be indicators of metal bioavailability [8]; however, today, the majorities agree that the free metal ion concentration is a better 
predictor of bioavailability [28]. The Free Ion Activity Model (FIAM) is based on thermodynamic control of metal bioavailability. This chemical equilibrium basis assumes that the rate of metal uptake across a cell surface is slow compared to the rate of diffusion to the cell surface, and surface-bound metal rapidly comes into pseudo-equilibrium with the metal in the bulk solution [44]. Exceptions to this assumption were not many. In fact, 52 out of 59 cases conformed to the assumption according to a review by Campbell (1995) [3]; this validated the applicability of FIAM. Recently, the Gill Surface Interaction Model (GSIM) [29] has been combined with FIAM concepts to form the Biotic Ligand Model (BLM) [23]. The BLM holds that toxicity is due to accumulation of metal at physiologically active sites such as the gill in fish. The BLM approach has already received wide acceptance and has been incorporated in the regulatory framework for copper by the U.S. EPA [34]. The European Union is following suit.

A key knowledge gap is the inability to effectively identify the causes of toxicity in aquatic biota. Field studies have several disadvantages including exposure to confounding factors and inherent variability, high cost, and results that are not always comprehensible. Hence, it would be beneficial and cost effective to create mechanistic geochemical and toxicological models that could provide reliable predictions on not just acute toxicity alone, but also the chronic impacts of mining aqueous effluents based on laboratory-based determination of metal speciation and water chemistry factors. Further research in this field is necessary to reduce uncertainties associated with measuring longterm impacts of mining aqueous effluents. One of the vital steps to the above approach is the exploration of the link between geochemical speciation of metals in mining aqueous 
effluents and their bioavailability and toxicity. Since bioassay toxicity testing requires rigorous quality control, and is expensive and time consuming, predictive computer speciation and toxicological models will provide an attractive alternative.

Hence, the objective of this work was to any study linkages between the observed toxicity to freshwater green alga and the free metal and labile metal ion concentrations determined experimentally. This was attempted by a combination of speciation analysis (equilibrium- and kinetics-based) and bioassay toxicity studies. This study will also test the hypothesis that BLM (based on Windermere Humic Aqueous Model, WHAM VI) is a satisfactory model to predict toxicity to freshwater biota in metal-contaminated natural waters. Thus, field validation of the WHAM VI was undertaken by comparing the measured speciation and the toxicity results in the laboratory.

\subsection{The Kinetic Model}

\subsubsection{Competing Ligand Exchange Method (CLEM)}

The modified version [72-73] of the kinetic model originally proposed by Olson and Shuman [74] was utilized to investigate the kinetic speciation of nickel and copper in mining and municipal aqueous effluents. Consider an aqueous sample of $n$ components, in which each component, $M L$, exists in equilibrium with its dissociation products: $M$ (the free metal ion) and L (the ligand which is a naturally occurring heterogeneous complexant such as humic acid). Charges are omitted for simplicity. Assuming the following rates of reaction:

$$
\mathrm{ML} \underset{\mathrm{k}_{\mathrm{f}}}{\stackrel{\mathrm{k}_{d}}{\rightleftarrows}} \mathrm{M}+\mathrm{L} \quad \text { (slow) }
$$


$\mathrm{M}+$ Chelex $\longrightarrow \mathrm{M}$ - Chelex

where the formation and dissociation rate constants $\left(\mathrm{k}_{\mathrm{f}}\right.$ and $\mathrm{k}_{\mathrm{d}}$, respectively) are coupled by the stability constant, $K=\mathrm{k}_{\mathrm{f}} / \mathrm{k}_{\mathrm{d}}$, through the principle of microscopic reversibility.

If each complex, $\mathrm{ML}_{\mathrm{x}}$, dissociates simultaneously and independently (at a rate that depends on the nature of the functional group, its position on the macromolecule, and the residual charge), the concentration of the free metal ion, $\mathrm{cM}$, and the total concentration of all complexes, cML, at any time, $t$, are given by a summation of exponentials as shown in equations 3 and 4 , respectively.

$$
\begin{aligned}
& \operatorname{cM}(t)=\sum_{x=1}^{n} c^{\circ} \mathrm{ML}_{x} \cdot\left[1-\exp \left(-\mathrm{k}_{d, x} \cdot t\right)\right] \\
& \operatorname{cML}(\mathrm{t})=\sum_{x=1}^{\mathrm{n}} \mathrm{c}^{\circ} \mathrm{ML}_{\mathrm{x}} \cdot \exp \left(-\mathrm{k}_{\mathrm{d}, \mathrm{x}} \cdot \mathrm{t}\right)
\end{aligned}
$$

where $\operatorname{cM}(t)$ is the concentration of metal $M$ at any time $t, c^{\circ} \mathrm{ML}_{\mathrm{x}}$ is the initial concentration of $\mathrm{ML}_{\mathrm{x}}$ and $\mathrm{cML}_{\mathrm{x}}(\mathrm{t})$ is the concentration of $\mathrm{ML}_{\mathrm{x}}$ at any time, $\mathrm{t}$.

When a competing ligand, such as Chelex-100 chelating resin, is added to the sample solution containing a metal M, M-Chelex is formed. Provided that the dissociation of the complex ML is slow and the complex formation by Chelex (M-Chelex) is fast and the MChelex is thermodynamically much stronger than ML, then with a large excess of Chelex-100, reaction 1 is driven to the right. 
Assumptions in the model include; 1) reactions are first-order, or pseudo-first-order; 2) reaction 2 is much faster than reaction 1, making reaction 1 the rate-determining step, and the measured kinetics then represent the kinetics of the dissociation of ML; 3) ML does not bind with the Chelex resin; 4) M-Chelex complex is thermodynamically much stronger than ML complex; 5) Concentration of Chelex is much larger than $\mathrm{cM}$.

\subsubsection{Algal bioassays}

The green alga, Pseudokirchneriella subcapitata (formerly known as Selenastrum capricornutum), was used as the test species in this study to determine the toxicity of mining and municipal aqueous effluents. Algal bioassays are well-known tools for assessing metal toxicity at the phytoplankton level, given that appropriate measures are taken to achieve reliable results. For this reason, the Environment Canada [75] protocol was utilized.

Pseudokirchneriella subcapitata is a unicellular, non-flagellated, crescent-shaped, freshwater green alga (Chlorophyceae), and can be found throughout North America. According to the Environment Canada report [75-76]. P. subcapitata is moderately sensitive to toxic substances. In addition, algae are known to be highly sensitive to metals and cationic surfactants [77]. P. subcapitata divides rapidly and is easy to culture in the laboratory. It is also relatively easy to enumerate because it rarely clumps [75]. Most importantly, algae were not found to have any significant influence on metal speciation, such as by excretion of chelating exudates or other chemicals [78]. 


\subsection{Experimental section}

\subsubsection{Containers for water samples}

All sample containers were made of Teflon and were pre-cleaned by soaking in $10 \%$ $\mathrm{HNO}_{3}$ (AR grade) for 1 week at room temperature, followed by a 5 time rinse with ultrapure water. The containers were kept filled with ultrapure water until used [58].

\subsubsection{Materials and reagents}

All solutions were prepared with ultrapure water (resistivity $18.2 \mathrm{M} \Omega-\mathrm{cm}$ ) which was obtained direct from a Nanopure Diamond purification system (Barnstead, USA), fitted with a purifying column to remove organic matter. Standard solutions of $\mathrm{Ni}$ (II) and $\mathrm{Cu}(\mathrm{II})$ were prepared individually by dilution of $1000 \mathrm{mg} / \mathrm{L}$ high-purity nickel and copper aqueous standards (ICP grade, SCP Science, Montreal, Quebec). These standard solutions were used to prepare working standards for GFAAS by serial dilution and acidification of the diluted standards to contain $1 \%(\mathrm{v} / \mathrm{v})$ ultrapure nitric acid (Baseline, Seastar Chemicals) in order to prevent metal loss by adsorption on the container walls. A stock solution of $2 \mathrm{M}$ sodium acetate solution was prepared by dissolving sodium acetate trihydrate (ANALAR, EMD) in ultrapure water. A $0.1 \mathrm{M}$ sodium hydroxide solution was prepared by dissolving sodium hydroxide pellets (puriss. p.a. Reag. ACS, Riedel-de Haën) in ultrapure water. The $\mathrm{pH}$ of samples was measured using an Accumet 20 $\mathrm{pH} /$ conductivity meter (Fisher).

\subsubsection{Mining and municipal aqueous effluent samples}

See Section 3.4.3 for details of the effluent samples. 


\subsubsection{Algal bioassay}

Algal bioassays were used to examine toxicity of metal species in the Sudbury mine and municipal aqueous effluents. The bioassays were performed in accordance with the Environment Canada [75] protocol for algal bioassays using green alga Pseudokirchneriella subcapitata (commonly known as Selenastrum capricornutum). An axenic culture was obtained from the University of Toronto Culture Collection and cultured in $250-\mathrm{mL}$ Erlenmeyer flasks at $24^{\circ} \mathrm{C} \pm 2^{\circ} \mathrm{C}$ using AAP medium [75]. The cultures were renewed weekly under sterile conditions. Because of the purpose of the tests, modifications to the above-cited protocol included a four-fold increase in phosphate levels in the growth and test mediums, and additionally, EDTA was omitted from the test medium. Table 4.1 presents the modified composition of the growth and test media. Further modification to the protocol included an alternative to using 96-well, flatbottomed polystyrene microplates for tests. Preliminary tests showed algal growth inhibition in the control microplates (see Figures 7.7 to 7.9 in Appendix for various growth curves). The reasons for the inhibition are unknown. Tests were conducted in triplicate in 50-mL Erlenmeyer flasks covered with aerated tin foil and incubated for $72 \mathrm{~h}$ at $24^{\circ} \mathrm{C}$ under cool white fluorescent lights. At the end of the test, the samples were completely suspended and transferred to microplates, and algal growth was measured by fluorescence using a microplate fluorometer (calibration curve, Figure 7.10 in Appendix).

A series of 8 dilutions were prepared for each sample (e.g. $100 \%, 80 \%, 60 \%, 40 \%, 20 \%$, $10 \%, 5 \%, 0 \%$ of effluent water). $\mathrm{IC}_{25}$ (defined as the concentration or amount of a test 
sample which causes $25 \%$ inhibition in growth of test organism) values were calculated using the software ICPIN, or manually.

\subsubsection{Competing Ligand Exchange Method (CLEM)}

Competing Ligand Exchange Method/Graphite Furnace Atomic Absorption Spectrometry (CLEM/GFAAS) was used as follows: $3 \mathrm{~g}(1 \% \mathrm{w} / \mathrm{v})$ of Chelex-100 was added to $300 \mathrm{~mL}$ of sample in a cylindrical Teflon Reactor. The sample solution was filtered with an online $0.45-\mu \mathrm{m}$ polycarbonate membrane filter to separate the Chelex resin. Aliquots of the filtrate were collected and the $\mathrm{Ni}$ and $\mathrm{Cu}$ concentrations were measured using GFAAS.

\subsubsection{Ion Exchange Technique (IET)}

A column ion exchange technique was used to determine the $\left[\mathrm{Ni}^{2+}\right]$. The micro-column consisted of Teflon tubing ( $3 \mathrm{~mm}$ internal diameter, $3 \mathrm{~cm}$ long), in which 7.8-8.0 $\mathrm{mg}$ (dry weight) of resin (Dowex ${ }^{\mathrm{TM}} 50 \mathrm{~W}-\mathrm{X} 8$ ) was trapped by two pieces of porous polyethylene discs that were fitted into polypropylene Luer tips (both supplied by Kimble Kontes). Refer to Section 3.4.4 for a detailed description of the IET procedure.

\subsection{7 $Q A / Q C$}

To achieve quality control, the analysis schedule included a blank for every fifth sample, and a Certified Reference Standard (NIST 1640) was run at midway and near the end of the run. If a difference of $>10 \%$ from certified value was observed, the selected set of samples were re-analyzed. All samples were analyzed in quadruplicate and the mean was 
used in the data analysis. The relative standard deviation among replicate determinations was typically $\leq 5 \%$.

\subsubsection{WHAM VI predictions}

See Section 3.4.7 for details.

\subsection{Results and discussion}

\subsubsection{Nickel speciation.}

Major cation and anion concentrations and trace metal concentrations in the effluent samples are presented in Table 3.5. Copper Cliff Waste Water Treatment Plant aqueous effluent had high copper and zinc concentrations of 173 and $178 \mu \mathrm{g} / \mathrm{L}$, respectively. Crean Hill Mine and Garson Mine aqueous effluents had high total nickel concentrations of 103 and $136 \mu \mathrm{g} / \mathrm{L}$, respectively. A high concentration of sulfate $(1528 \mathrm{mg} / \mathrm{L})$ was found in Copper Cliff WWTP and an elevated concentration of phosphate $(0.32 \mathrm{mg} / \mathrm{L})$ in Sudbury WWTP. In addition, calcium concentrations were high in Copper Cliff WWTP $(471 \mathrm{mg} / \mathrm{L})$ and in Garson Mine effluent $(245 \mathrm{mg} / \mathrm{L})$. Such concentrations of major cations $\left(\mathrm{Ca}^{2+}\right)$, because of their effects on both the electrostatic and the covalent binding of $\mathrm{Ni}^{2+}$ ions by humate polyanions, result in release of nickel from the $\mathrm{Ni}(\mathrm{II})-\mathrm{DOC}$ complexes [79]. High concentrations of $\mathrm{Ca}^{2+}$ increase the screening of electrostatic attractions (non-specific binding) between the positively charged $\mathrm{Ni}^{2+}$ ions and the negatively charged humate polyanions, thereby decreasing the electrostatic attractions between the opposite charges. The $\mathrm{Ca}^{2+}$ ions may also compete with the $\mathrm{Ni}^{2+}$ for specific binding (covalent binding) if both of them bind to the same anionic binding sites on the 
humate polyanions. This will also result in decrease in the site-specific bonding, i.e. covalent bonding of $\mathrm{Ni}(\mathrm{II})$ with humic substances. In summary, the effect is a decrease in both the electrostatic bonding and the covalent bonding between $\mathrm{Ni}$ (II) and humic substances, resulting in release of nickel from the $\mathrm{Ni}(\mathrm{II})$-DOC complexes in natural waters. High cation and anion concentrations in aqueous effluent samples are usually a result of treatment activities.

Percentage of the Ni-DOC complexes remaining undissociated in the solution was plotted as a function of time for the water samples collected in May 2006 (Figure 4.1). Labile nickel and copper (Figure 7.6 in Appendix) concentrations were determined in the same samples by Competing Ligand Exchange Method using Graphite Furnace Atomic Absorption Spectrometry (CLEM/GFAAS). Labile copper was also measured since it has a significant presence in the aqueous effluent samples. The results were used to aid in the interpretation of the toxicity results discussed later. Kinetically distinguishable components of the nickel and copper complexes are presented in Table 4.2. The fastest kinetically distinguishable component $\left(\mathrm{C}_{1}\right)$ of different aqueous effluent samples from various sources represent approximately $37-96 \%$ of the total $\mathrm{Ni}$ (II)-DOC complexes and $19-88 \%$ of the total $\mathrm{Cu}(\mathrm{II})$-DOC complexes, depending on the sources of the aqueous effluent samples.

Free nickel ion concentrations determined by the Ion Exchange Technique (IET) and also that predicted by WHAM VI are reported in Section 3. In Table 4.3, a comparison of the IET-determined and the WHAM VI-predicted free nickel concentrations and the 
CLEM/GFAAS-determined free plus labile nickel concentrations along with the Ni-toDOC ratios are presented (see Figures 7.11 and 7.12 in Appendix for WHAM VI predictions versus CLEM measurements and CLEM versus IET measurements, respectively). The $\mathrm{pH}$ of the samples ranged from 7.1 to 8.1 . Table 4.3 shows that the mining aqueous samples had a Ni-to-DOC ratio (mol/g) ranging from $1.06 \times 10^{-04}$ to 1.07 $\mathrm{x} 10^{-03}$, a free nickel concentration ranging from $2.89 \times 10^{-08} \mathrm{M}$ to $6.19 \times 10^{-07} \mathrm{M}$, and a labile nickel concentration ranging from $4.20 \times 10^{-07} \mathrm{M}$ to $1.85 \times 10^{-06} \mathrm{M}$. The WHAM VI predictions of free nickel ion concentration ranged from $2.44 \times 10^{-12}$ to $1.27 \times 10^{-06} \mathrm{M}$. Crean Hill Mine effluent had a Ni-to-DOC ratio of $7.91 \times 10^{-04} \mathrm{~mol} / \mathrm{g}$ and Nolin Creek WWTP aqueous effluent had a ratio of $1.07 \times 10^{-03} \mathrm{~mol} / \mathrm{g}$, which was only a 1.3 fold difference. The measured free nickel concentration was 2.1 fold lower for Nolin Creek; however, the predicted free nickel and the measured labile nickel were similar for both samples. For the WHAM VI predictions, $45 \%$ of the DOC was assumed to be "active" based on the best fit and the estimates by Morel and Hering (1993) [47], who suggested that approximately $50 \%$ of DOC is found as humic substances. According to the WHAM VI predictions, Garson Mine aqueous effluent had the highest free nickel ion concentration $\left(1.27 \times 10^{-06} \mathrm{M}\right)$; however, the measured free nickel ion concentration was much lower $\left(2.42 \times 10^{-07} \mathrm{M}\right)$ and second to that of the Crean Hill Mine effluent $(6.19 \mathrm{x}$ $\left.10^{-07} \mathrm{M}\right)$. As expected, the CLEM-measured concentrations of labile plus free nickel species were higher than the measured and the predicted free nickel concentrations for all samples. Interestingly, for Sudbury WWTP, the WHAM VI predictions reported a very much lower free nickel concentration than the measured concentration (approx. $10^{5}$ fold) (see Section 3.5.6 for a detailed discussion). 
Figure 4.2 shows the effect of $\mathrm{Ni} / \mathrm{DOC}$ ratio on the free nickel ion concentration (measured by IET) and the labile nickel species (measured by CLEM-GFAAS) in the mining and municipal effluent water samples collected from the Sudbury area (Ontario, Canada) in May 2006. Error bars in all figures represent $95.5 \%$ confidence levels (i.e. \pm $2 \mathrm{x}$ Relative Standard Deviation). Figure 4.2 shows that, in general, the concentration of free plus labile nickel species increases with increasing Ni/DOC ratio. Similarly, concentration of free nickel ion determined by IET also increases with increasing $\mathrm{Ni} / \mathrm{DOC}$ ratio, although to a smaller degree. As the Ni/DOC ratio increases, the strong binding sites are fully occupied (1-10\% of the total binding sites of the DOC), leaving the remaining nickel to bind to weak sites (99-90\% of the total binding sites of the DOC) [65]. These weak nickel complexes are labile and release free $\mathrm{Ni}^{2+}$ ions.

\subsubsection{Algal bioassay}

Algal (P. subcapitata) yield in the control flasks with standard media in Milli Q laboratory water was from 300000 to 500000 cells $/ \mathrm{mL}$ after a 72 -h growth period under continuous light (see Figure 7.11 in Appendix for growth curve for stock culture). However, in the Reference River (regarded as receiving water i.e. Vermillion River, Sudbury, Ontario), the algal yield was between 1800000 and 3500000 cells/mL. The range in control biomass can be a result of variations in lag phase (up to several hours) and inoculation at different times of the exponential growth phase. The test samples were spiked with growth media to avoid nutrient limitation on algal growth. Nevertheless, algal growth was stimulated by exposure to Reference River water. This may be because 
of higher dissolved organic carbon levels in the Reference River water $(9.90 \mathrm{mg} / \mathrm{L})$ which improves algal growth by reducing availability of toxic metals. Also, the additional available nutrients may have had an effect.

An initial algal stimulation was observed in most of the effluent samples (Figures 4.3 and 4.4; Figures 7.13 to 7.15 in Appendix), followed by inhibition with greater amounts of the test sample. Similar observations were reported by Mandal et al. (2002) [2]. The stimulation in algal growth was unexpected since the growth media was believed to contain the necessary amount of nutrients. Figure 4.3 illustrates algal bioassays for the mining aqueous effluent samples: Garson Mine aqueous effluent (Figure 4.3a) and Copper Cliff WWTP (Figure 4.3b), diluted with the Reference River water (Vermillion River) and with laboratory water. It shows that algal growth is increased when Reference River water is used. However, an overall toxic effect of the aqueous effluent sample is still observed. For Garson Mine aqueous effluent, the observed toxicity in the Reference River water was greater $\left(\mathrm{IC}_{25} 12.0 \%\right)$ than that in the laboratory water $\left(\mathrm{IC}_{25} 25.6 \%\right)$ (Table 4.4). For Copper Cliff WWTP, the opposite effect was observed: in the Reference River water, the observed toxicity was lower $\left(\mathrm{IC}_{25} 55.6 \%\right)$ than that in laboratory water $\left(\mathrm{IC}_{25} 28.9 \%\right)$. Similarly, toxicity was reduced in the Reference River water for standard copper and nickel tests (see Figures 7.16 to 7.19 in Appendix for growth curves). In addition, the stimulation effect, as seen in the laboratory water, was observed to a lesser extent when performed in the Reference River water. This suggests that the use of receiving waters (such as Vermillion River, Sudbury, Ontario) instead of laboratory water for studying toxicity of aqueous effluents may be a better approach, since the stimulation 
effect will be masked by the receiving water and a more comprehensible toxicity effect can be observed.

With respect to speciation, a previous study from our laboratory observed that dilution of the mining aqueous effluents with the Reference River water affected nickel speciation. Dilution of the effluent samples with the receiving water increased the percentage of nickel released from Ni(II)-DOC complexes as measured by both CLEM using Adsorptive Cathodic Stripping Voltammetry and CLEM/GFAAS [7]. An increase in nickel release means more nickel is bioavailable and can cause toxicity. This agrees with the observations for Garson Mine aqueous effluent where a greater toxicity was observed in the Reference River water. However, this observation may be the result of differences in the actual toxicity testing rather than the chemical speciation. In fact, the other toxicity tests in the Reference River water (CCWWTP, standard copper and nickel) all contradict the above conclusion. For those samples, the use of receiving water for dilution decreased the overall algal toxicity $\left(\mathrm{IC}_{25}\right)$ (Table 4.4$)$. For example, the $\mathrm{IC}_{25}$ for standard nickel increased from $0.427 \mu \mathrm{M}$ to $0.920 \mu \mathrm{M}$ (2 fold) and for copper it increased from 0.064 $\mu \mathrm{M}$ to $0.202 \mu \mathrm{M}$ (3 fold) for laboratory water versus Reference River water, respectively. Nonetheless, numerous confounding factors in effluent waters make it difficult to make definite conclusions.

Figure 4.4 shows the algal bioassay curve for Sudbury Waste Water Treatment Plant effluent sample. For up to $60 \%$ of the test sample composition, algal growth was greatly stimulated. As mentioned earlier, this sample was high in DOC (up to 7.4 fold higher 
than the other effluent samples) and in phosphate concentrations (up to 10.7 fold higher than the other effluent samples). The high DOC levels present greater complexation of trace metals, which reduces toxicity. However, the abundance in phosphate $(0.32 \mathrm{mg} / \mathrm{L})$, a well known algal nutrient, may have had the most significant effect on the stimulation. This observation was unexpected since the algal growth medium was already adjusted to contain 4 times more phosphate (Table 4.1) than that in the original Environment Canada protocol [75] in order to reduce the effect of high phosphate levels in the effluent waters.

To investigate the effect of added nutrients further, a study was conducted with added zinc, phosphate and nitrate levels over a time period of 72 hours. The results were plotted as a percentage of growth in the control water in Figure 4.5. Figure 4.5a shows the effect of addition of 10,100 and $200 \mu \mathrm{g} / \mathrm{L}$ of zinc to the growth media. A stimulation effect was evident for a low concentration $(10 \mu \mathrm{g} / \mathrm{L})$ of zinc and by the third day this effect was diminished. At the higher concentrations (100 and $200 \mu \mathrm{g} / \mathrm{L})$ of zinc, the growth of algae was inhibited. This shows that the effluents samples with excess zinc concentrations probably caused only toxicity rather than stimulation. Figure $4.5 \mathrm{~b}$ shows that the added low phosphate concentration $(0.05 \mathrm{mg} \mathrm{P} / \mathrm{L})$ had a significant stimulation effect by the third day. The higher concentration $(0.3 \mathrm{mg} \mathrm{P} / \mathrm{L})$ also stimulated algal growth, but at a greatly lower degree. The low concentration of added nitrate $(1.5 \mathrm{mg} \mathrm{N} / \mathrm{L})$ had a large stimulation effect by the third day but was again lower for the higher, $30 \mathrm{mg} \mathrm{N} / \mathrm{L}$ nitrate addition. Hence, both phosphate and nitrate levels tended to stimulate algal growth even though the growth media presumably contained sufficient nutrients. However, the higher levels of phosphate and nitrate, which relate to the highest phosphate and nitrate 
concentrations measured in the effluent waters in this study, were probably stimulating at a lower degree because of the added effect of toxicity at such high levels. It is also important to note that the stimulation tests were performed in laboratory water. The complexation effects would have been lower in laboratory water than in effluent or Receiving River waters, and as a result, the effect in effluent waters may be quite different for the same concentrations.

Table 4.4 presents the calculated $\mathrm{IC}_{25}$ levels for the effluent waters. Both Crean Hill and Sudbury WWTP had an $\mathrm{IC}_{25}$ of more than $100 \%$ effluent, indicating the absence of significant toxicity. As discussed above, the toxic effects of these samples may have been masked by the observed stimulation, especially in Sudbury WWTP. Garson and Copper Cliff samples showed the highest toxicity with an $\mathrm{IC}_{25}$ of $25.6 \%$ and $28.9 \%$, respectively. These toxicity data correlate well with labile $\mathrm{Ni}$ and $\mathrm{Cu}$ concentrations determined by CLEM/GFAAS and the free Ni ion concentrations predicted by WHAM VI. Garson effluent was found to have the highest $\left[\mathrm{Ni}_{\text {labile }}\right](1.85 \mu \mathrm{M})$ and Copper Cliff had the highest $\left[\mathrm{Cu}_{\text {labile }}\right](2.40 \mu \mathrm{M})($ Table 4.2$)$. WHAM VI also predicted highest $\left[\mathrm{Ni}^{2+}\right](1.27$ $\mu \mathrm{M}$ ) for Garson (Table 4.3). Nolin Creek and Sudbury WWTP had very similar $\left[\mathrm{Ni}_{\text {total }}\right]$ (1.28 $\mu \mathrm{M}$ and $1.32 \mu \mathrm{M}$, respectively). However, the difference in lability $(96.5 \%$ and $37.3 \%$, respectively) and the immense stimulation effect in Sudbury WWTP most likely caused the difference in toxicity observed for the two samples. Correlation between the IET measured $\left[\mathrm{Ni}^{2+}\right]$ and the observed toxicity was less. According to the IET measurements, Crean Hill had the highest $\left[\mathrm{Ni}^{2+}\right]$ of $6.19 \times 10^{-07} \mathrm{M}$, followed by similar concentrations for Nolin Creek Mine, Garson Mine and Sudbury WWTP effluents (2.41 x 
$\left.10^{-07}-2.89 \times 10^{-07} \mathrm{M}\right)$. However, the measured $\left[\mathrm{Ni}^{2+}\right]$ correlated better with the Ni-toDOC ratio $\left(r^{2}=0.911\right)$ than the measured labile nickel $\left(r^{2}=0.784\right)$. Ni-to-DOC ratio was previously shown to indicate both the release of free $\mathrm{Ni}^{2+}$ and the resulting toxicity of nickel-polluted effluent waters [72]. In addition, some of the samples contained high zinc levels (up to $180 \mu \mathrm{g} / \mathrm{L}$ ) and this might also have affected the toxicity results. Further research on the application of IET for determination of $\left[\mathrm{Ni}^{2+}\right]$ in freshwater systems, especially mining effluents, is necessary to determine the strengths and weaknesses of IET. However, regardless of the confounding factors, the results seem to indicate that for effluent waters, measurement of labile metal concentrations may give satisfactory indications of bioavailability and toxicity. This is reasonable since effluent waters are more likely systems that are dynamic rather than at chemical equilibrium.

A controversy still exists on whether the free metal ion concentration or the labile metal concentration is a better indicator of bioavailability. The chemical equilibrium-control model (such as FIAM), under which only the free metal ion is bioavailable, assumes that the rate of metal uptake into the aquatic organisms is relatively slow compared to the rate of diffusion in the bulk solution to the cell surface. Hence, the surface-bound metal rapidly comes into pseudo-equilibrium with the metal in the bulk solution [8]. This means that the metal bioavailability is under thermodynamic control. The kinetic-control model assumes that the above may be incorrect and that the rate of metal uptake by the organism is faster than the rate of diffusion of the metal species to the cell surface (i.e. the biotic ligand). Since this will create a concentration gradient surrounding the cell surface, the labile metal complexes will dissociate to offset the disturbance in the chemical 
equilibrium near the cell surface. Examples of samples under kinetic control have been illustrated previously [80], particularly at low free metal ion concentrations for organisms with high membrane permeability and thus high metal uptake rates. However, a majority of the cases has conformed to the FIAM [3]. Also, the Biotic Ligand Model (BLM), which is based on FIAM, has gained increasing acceptance in the chemical equilibriumbased toxicity predictions and has already been incorporated into the U.S. E.P.A's Ambient Water Quality Criteria for copper [34]. The capabilities of geochemical speciation and toxicity prediction models have greatly improved in the past decade, especially in incorporating the effect of dissolved organic matter. However, more field validations are still required. In addition, extension of the BLM to chronic toxicity effects is still a challenge. 


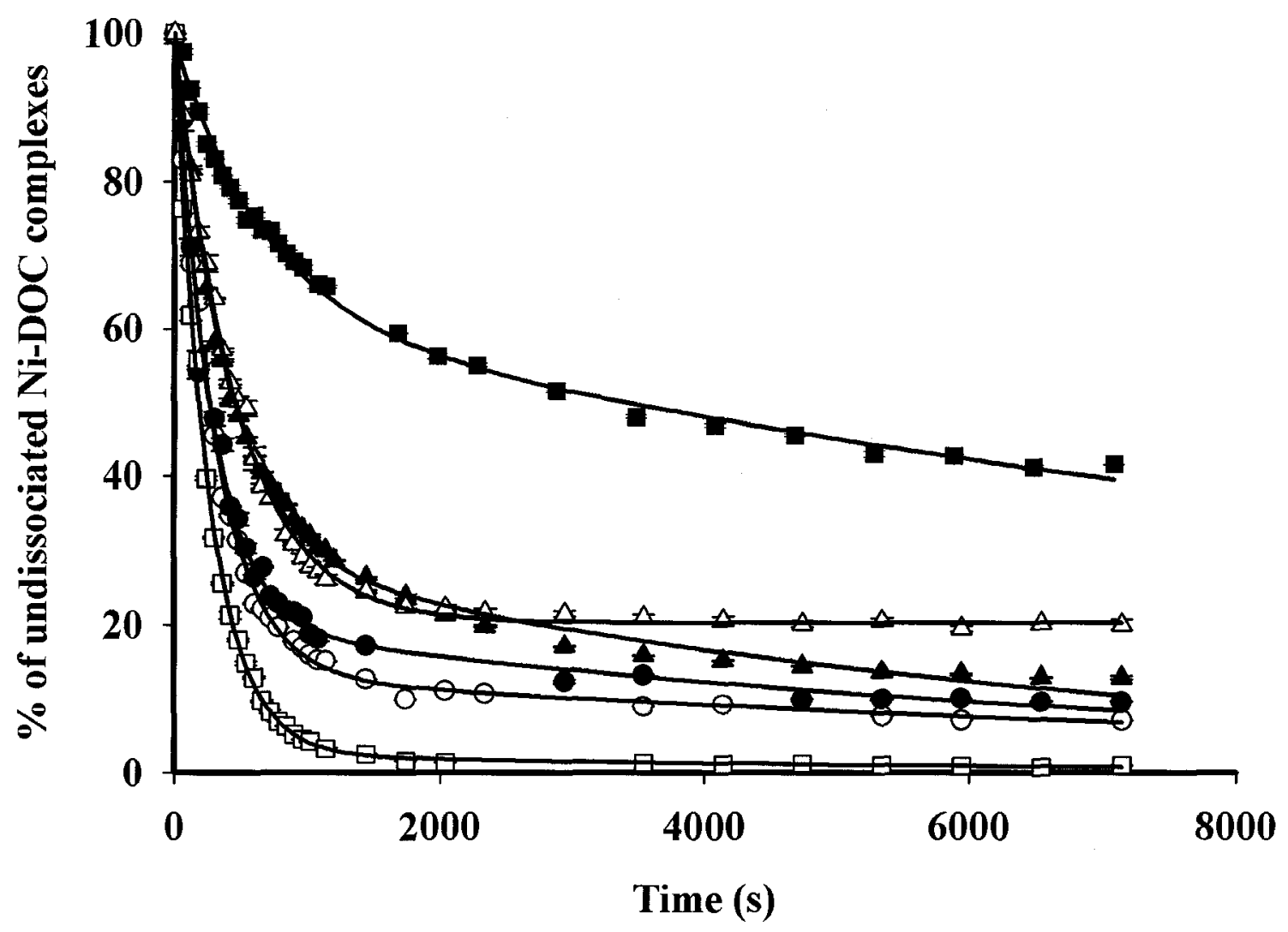

Figure 4.1 Percentage of Ni(II) released from Ni(II)-DOC complexes in mining and municipal effluent water samples, determined by CLEM/GFAAS. Chelex 100 was the competing ligand. ( $)$ Sudbury WWTP; $(\triangle)$ Garson Mine;

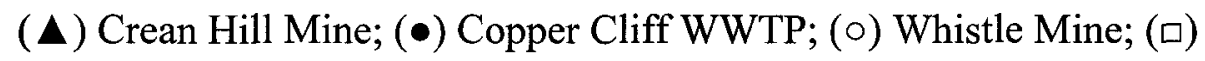
Nolin Creek WWTP. Solid lines represent non-linear curve fitting. The vertical error bars represent \pm 1 standard deviation, of three replicate determinations (visible only when larger than the symbols). 


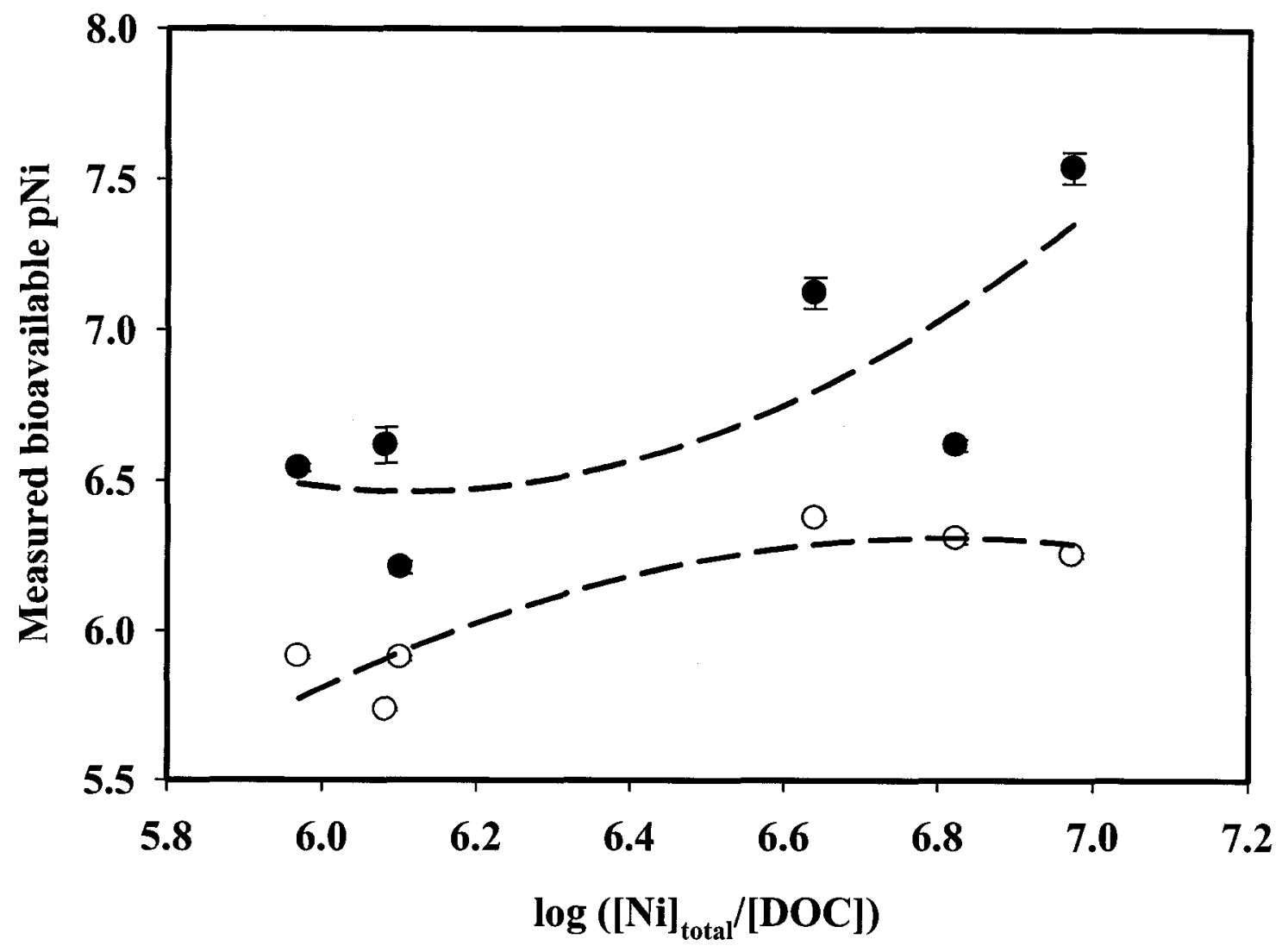

Figure 4.2 Effect of Ni/DOC ratio on the free (filled symbols) and labile (unfilled symbols) nickel species in mining and municipal effluent water samples collected from the Sudbury area, Ontario, Canada. Solid lines represent non-linear curve fitting. The vertical error bars represent \pm 1 standard deviation of three replicate determinations (visible only when larger than the symbols). 

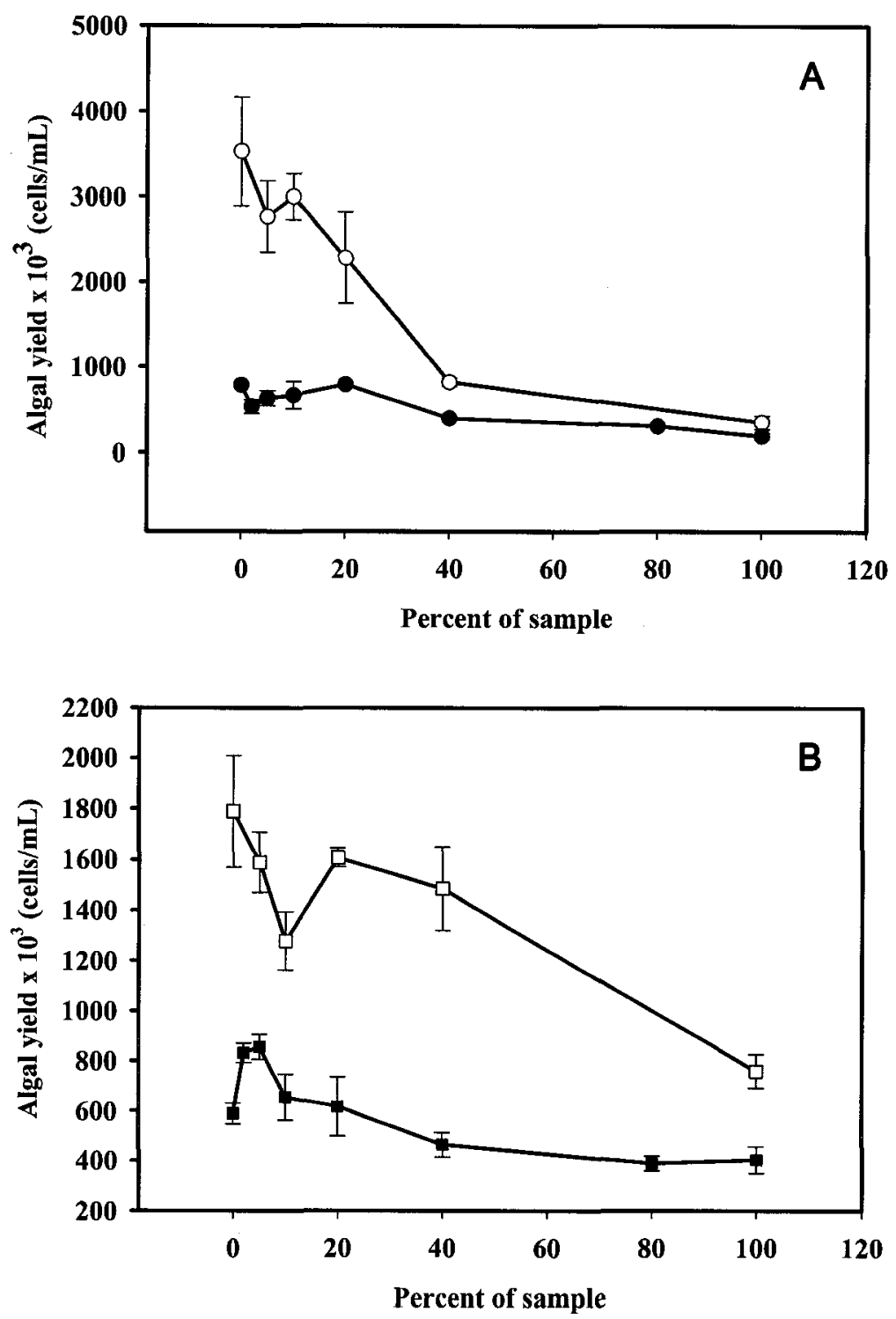

Figure 4.3 Algal bioassays (P. subcapitata) as function of percent water sample for the mining effluent samples diluted with Reference River water (unfilled symbols) and laboratory water (filled symbols). a) Garson Mine effluent b) Copper Cliff WWTP. The vertical error bars represent \pm 1 standard deviation of three replicate determinations (visible only when larger than the symbols). 


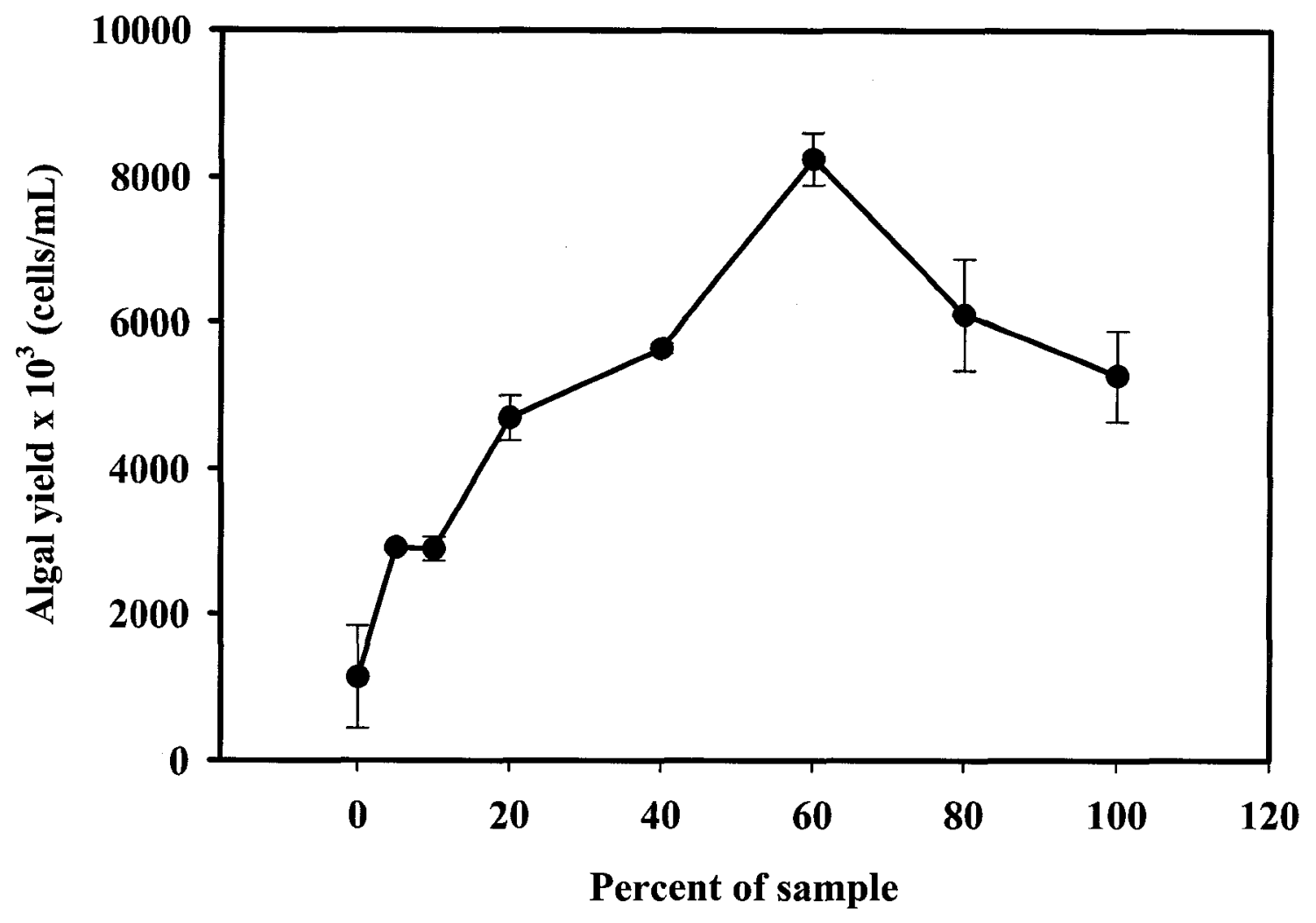

Figure 4.4 Algal (P. subcapitata) bioassay curve for Sudbury Waste Water Treatment Plant effluent sample as a function of percent sample. The vertical error bars represent \pm 1 standard deviation of three replicate determinations (visible only when larger than the symbols). 

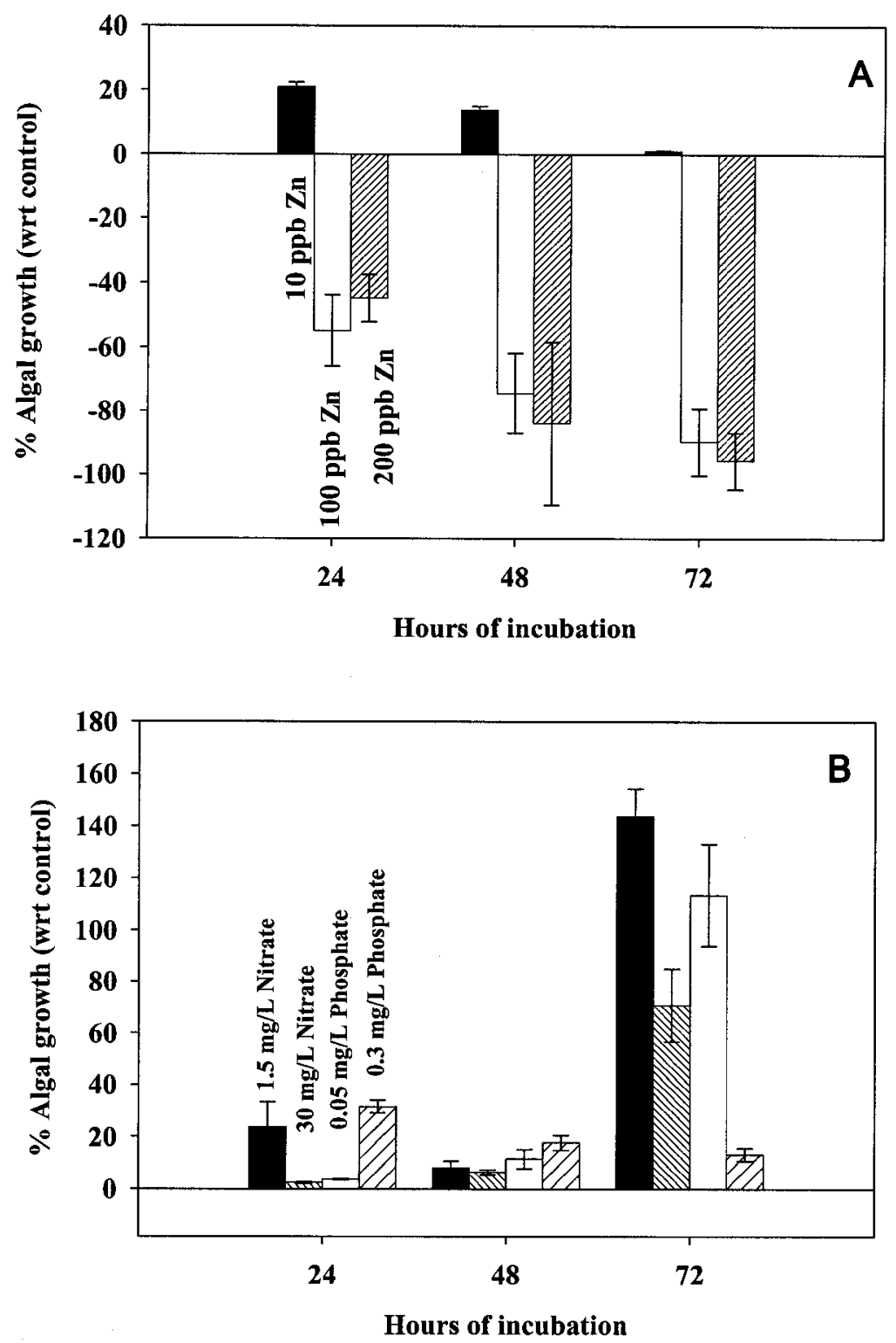

Figure 4.5 Effect of additional nutrients on algal ( $P$. subcapitata) growth with respect to the control. a) Effect of an additional 10, 100 and $200 \mathrm{ug} / \mathrm{L}$ of $\mathrm{Zn}$ in the algal growth media b) Effect of an additional $1.5 \mathrm{mg} / \mathrm{L}$ nitrate, $30 \mathrm{mg} / \mathrm{L}$ nitrate, $0.05 \mathrm{mg} / \mathrm{L}$ phosphate, or $0.3 \mathrm{mg} / \mathrm{L}$ phosphate in the algal growth media. The vertical error bars represent \pm 1 standard deviation of three replicate determinations (visible only when larger than the symbols). 
Table 4.1 Composition of the modified algal growth medium used for the algal culture and the exposure medium used for the test experiments (AAP medium; modified from Environment Canada (1992) [75].

\begin{tabular}{ccc}
\hline & Growth Medium & Test Medium \\
\hline Macronutrients & Concentration (mg/L) & Concentration $(\mathbf{m g} / \mathbf{L})$ \\
\hline $\mathrm{NaNO}_{3}$ & 25.5 & 15.94 \\
$\mathrm{MgCl}_{2}-6 \mathrm{H}_{2} \mathrm{O}$ & 10.0 & 6.25 \\
$\mathrm{CaCl}_{2}$ & 4.42 & 2.76 \\
$\mathrm{MgSO}_{4}-7 \mathrm{H}_{2} \mathrm{O}$ & 14.7 & 9.19 \\
$\mathrm{~K}_{2} \mathrm{HPO}_{4}$ & 4.16 & 2.6 \\
$\mathrm{NaHCO}_{3}$ & 15.0 & 9.38 \\
\hline $\mathrm{Micronutrients}$ & Concentration $(\boldsymbol{\mu g} / \mathbf{L})$ & Concentration $(\boldsymbol{\mu g} / \mathrm{L})$ \\
\hline $\mathrm{H}_{3} \mathrm{BO}_{3}$ & 185.52 & 115.95 \\
$\mathrm{MnCl}_{2}-4 \mathrm{H}_{2} \mathrm{O}$ & 415.62 & 259.76 \\
$\mathrm{ZnCl}_{2}$ & 3.28 & 2.05 \\
$\mathrm{CoCl}_{2}-6 \mathrm{H}_{2} \mathrm{O}$ & 1.43 & 0.89 \\
$\mathrm{CuCl}_{2}-2 \mathrm{H}_{2} \mathrm{O}$ & 0.012 & 0.008 \\
$\mathrm{Na}_{2} \mathrm{MoO}_{4}-2 \mathrm{H}_{2} \mathrm{O}$ & 7.26 & 4.54 \\
$\mathrm{FeCl}_{3}-6 \mathrm{H}_{2} \mathrm{O}$ & 160 & 100 \\
$\mathrm{Na}_{2} \mathrm{EDTA}_{-}-\mathrm{H}_{2} \mathrm{O}$ & 300 & - \\
\hline & & \\
\hline
\end{tabular}


Table 4.2 Ligand exchange kinetics of $\mathrm{Ni}(\mathrm{II})$-DOC and $\mathrm{Cu}(\mathrm{II})$-DOC complexes in mining and municipal effluent water samples collected from Sudbury, Ontario (May 2006), determined by Competing Ligand Exchange Method/Graphite Furnace Atomic Absorption Spectrometry (CLEM/GFAAS), using Chelex 100 as the competing ligand. Temperature $23 \pm 2^{\circ} \mathrm{C}$.

\begin{tabular}{|c|c|c|c|c|c|c|c|c|}
\hline \multirow{2}{*}{$\begin{array}{l}\text { Aqueous effluent } \\
\text { samples }\end{array}$} & \multirow{2}{*}{$\begin{array}{c}{[\mathbf{N i}]_{\text {total }}} \\
(\mu \mathrm{M})\end{array}$} & \multicolumn{2}{|c|}{$\begin{array}{l}\text { Kinetically distinguishable } \\
\text { components }\end{array}$} & \multirow{2}{*}{$\begin{array}{l}{[\mathrm{Ni}]_{\text {labile }}} \\
(\mu \mathrm{M})\end{array}$} & \multirow{2}{*}{$\begin{array}{l}{[\mathrm{Cu}]_{\text {total }}} \\
(\mu \mathrm{M})\end{array}$} & \multicolumn{2}{|c|}{$\begin{array}{l}\text { Kinetically distinguishable } \\
\text { components }\end{array}$} & \multirow{2}{*}{$\begin{array}{l}{[\mathbf{C u}]_{\text {labile }}} \\
\quad(\boldsymbol{\mu M})\end{array}$} \\
\hline & & $\mathrm{C}_{1}(\%)$ & $\mathrm{C}_{2}(\%)$ & & & $\mathrm{C}_{1}(\%)$ & $\mathrm{C}_{2}(\%)$ & \\
\hline Crean Hill Mine & 1.76 & $70.1 \pm 1.3$ & $30.1 \pm 1.3$ & 1.24 & 0.162 & $19.1 \pm 2.1$ & $80.8 \pm 0.7$ & 0.030 \\
\hline Garson Mine & 2.33 & $79.4 \pm 1.0$ & $20.3 \pm 0.9$ & 1.85 & 0.099 & $19.7 \pm 1.2$ & $81.2 \pm 1.0$ & 0.020 \\
\hline Whistle Mine & 0.49 & $85.9 \pm 1.3$ & $13.5 \pm 1.0$ & 0.42 & 0.064 & $56.2 \pm 8.3$ & $43.5 \pm 8.7$ & 0.040 \\
\hline Copper Cliff WWTP & 0.70 & $80.3 \pm 2.0$ & $20.1 \pm 1.6$ & 0.56 & 2.699 & $88.0 \pm 1.4$ & $11.3 \pm 1.5$ & 2.400 \\
\hline Nolin Creek WWTP & 1.28 & $96.1 \pm 1.2$ & $2.6 \pm 0.9$ & 1.23 & 0.083 & $76.4 \pm 1.8$ & $23.6 \pm 0.7$ & 0.060 \\
\hline Sudbury WWTP & 1.32 & $37.3 \pm 1.6$ & $61.5 \pm 1.7$ & 0.49 & 0.162 & $29.7 \pm 1.3$ & $70.3 \pm 0.4$ & 0.040 \\
\hline
\end{tabular}


Table 4.3 IET measured free nickel ion concentrations and predictions of WHAM VI (assuming $40 \%$ of dissolved organic carbon as "active"), and labile nickel concentrations measured by CLEM/GFAAS, and the effect of nickel/DOC ratios.

\begin{tabular}{|c|c|c|c|c|c|c|c|}
\hline $\begin{array}{l}\text { Effluent } \\
\text { Sample }\end{array}$ & pH & $\begin{array}{l}{[\mathbf{N i}]_{\text {total }}} \\
(\mathbf{M})\end{array}$ & $\begin{array}{c}\text { DOC } \\
(\mathrm{mg} / \mathrm{L})\end{array}$ & $\begin{array}{c}{[\mathrm{Ni}]_{\text {total }} /[\mathrm{DOC}]} \\
(\mathrm{mol} / \mathrm{g})\end{array}$ & $\begin{array}{c}\text { IET measured } \\
{\left[\mathrm{Ni}^{2+}\right]} \\
(\mathrm{M}) \\
\end{array}$ & $\begin{array}{c}\text { WHAM VI } \\
\text { predicted }\left[\mathrm{Ni}^{2+}\right] \\
(\mathrm{M})\end{array}$ & $\begin{array}{l}\text { CLEM/GFAAS } \\
\text { measured }[\mathrm{Ni}]_{\text {labile }} \\
(\mathrm{M})\end{array}$ \\
\hline $\begin{array}{l}\text { Crean Hill } \\
\text { Mine }\end{array}$ & 7.7 & $1.76 \times 10^{-06}$ & 2.23 & $7.91 \times 10^{-04}$ & $6.19 \times 10^{-07}$ & $4.01 \times 10^{-07}$ & $1.24 \times 10^{-06}$ \\
\hline Garson Mine & 7.8 & $2.33 \times 10^{-06}$ & 2.82 & $8.27 \times 10^{-04}$ & $2.42 \times 10^{-07}$ & $1.27 \times 10^{-06}$ & $1.85 \times 10^{-06}$ \\
\hline Whistle Mine & 8.0 & $4.91 \times 10^{-07}$ & 2.14 & $2.29 \times 10^{-04}$ & $7.53 \times 10^{-08}$ & $2.84 \times 10^{-08}$ & $4.20 \times 10^{-07}$ \\
\hline $\begin{array}{c}\text { Copper Cliff } \\
\text { WWTP }\end{array}$ & 7.1 & $6.97 \times 10^{-07}$ & 6.55 & $1.06 \times 10^{-04}$ & $2.89 \times 10^{-08}$ & $4.97 \times 10^{-07}$ & $5.60 \times 10^{-07}$ \\
\hline $\begin{array}{c}\text { Nolin Creek } \\
\text { WWTP }\end{array}$ & 8.1 & $1.28 \times 10^{-06}$ & 1.19 & $1.07 \times 10^{-03}$ & $2.89 \times 10^{-07}$ & $4.64 \times 10^{-07}$ & $1.23 \times 10^{-06}$ \\
\hline $\begin{array}{l}\text { Sudbury } \\
\text { WWTP }\end{array}$ & 7.4 & $1.32 \times 10^{-06}$ & 8.79 & $1.50 \times 10^{-04}$ & $2.41 \times 10^{-07}$ & $2.44 \times 10^{-12}$ & $4.93 \times 10^{-07}$ \\
\hline
\end{tabular}


Table 4.4 Growth inhibition at the $25 \%$ level $\left(\mathrm{IC}_{25}\right)$ for $\mathrm{P}$. subcapitata in mining and municipal effluent water samples collected from Sudbury, Ontario, in May 2006 and in reference toxicity tests using nickel and copper standards.

\begin{tabular}{lcc}
\hline \multirow{2}{*}{ Samples } & \multicolumn{3}{c}{$\begin{array}{c}\text { IC } 25 \\
\text { (\% effluent })\end{array}$} \\
\cline { 2 - 3 } & Diluted in Reference River water & Diluted in laboratory water \\
\hline Crean Hill & -- & $>100$ \\
Garson & 12.0 & 25.6 \\
Whistle & -- & 72.9 \\
Copper Cliff & 55.6 & 28.9 \\
Nolin Creek & -- & 63.4 \\
Sudbury & -- & $>100$ \\
Copper standard & $0.202 \mu \mathrm{M}$ & $0.064 \mu \mathrm{M}$ \\
Nickel standard & $0.920 \mu \mathrm{M}$ & $0.427 \mu \mathrm{M}$ \\
\hline
\end{tabular}




\section{Conclusions}




\section{Conclusions}

The free metal ion is generally considered to be the most reactive and bioavailable metal form to aquatic biota in natural waters. This necessitates a reliable determination of free metal ion concentrations. In this study, a column IET was tested to measure $\left[\mathrm{Ni}^{2+}\right]$ in model solutions and field-collected water samples from around the mining areas. The reliability of the IET method was satisfactory in model solutions as the results were comparable to the WHAM VI predictions. However, for the mining aqueous effluents, large deviations were observed in some samples. In addition, the measured labile nickel concentrations correlated better with the observed algal toxicity than the IET measured free nickel ion concentrations. Therefore, under more dynamic conditions, such as for effluent waters, the labile metal concentration is likely a more precautionary indicator of metal bioavailability.

In this study it was shown that the toxicity in mining aqueous effluents measured by algal bioassay can be confounded by factors such as the diluent water used in the bioassay and the nutrients present in the test sample. The presence of additional nitrate and phosphate in the effluent waters tend to stimulate algal growth. Performing the bioassay tests with a Reference River water as the diluent has proven to be a better approach. Overall, the best approach for a comprehensive analysis of the environmental impact of a sample is the concurrent use of speciation methods and toxicity testing with a predictive model such as the WHAM and the BLM. Further validation of the IET and of such predictive models as the WHAM is crucial for incorporating them into regulatory systems. 


\section{References}




\section{References}

1. Stumm W, Morgan JJ (1996) Aquatic chemistry, chemical equilibria and rates in natural waters, third edition. John Wiley \& Sons, New York, pp 161, 588.

2. Mandal R, Hassan NM, Murimboh J, Chakrabarti CL, Back MH, Rahayu U, Lean DRS (2002) Chemical speciation and toxicity of nickel species in natural waters from the Sudbury area (Canada). Environ Sci Technol 36:1477-1484.

3. Campbell PGC (1995) Interactions between trace metals and aquatic organisms: a critique of the free-ion activity model. In: Tessier A, Turner DR (eds) Metal speciation and bioavailability in aquatic systems. Wiley, Chichester UK, pp 45102.

4. Department of Fisheries and Oceans Canada. Metal Mining Effluent Regulations (2002) Canada Gazette, Part II:1411-1462.

5. Cantwell FC, Nielson JS, Hrudey SE (1982) Free nickel ion concentration in sewage by an ion exchange column-equilibration method. Anal Chem 54:14981503.

6. Fortin C, Campbell PGC (1998) An ion-exchange technique for free-metal ion measurements $\left(\mathrm{Cd}^{2+}, \mathrm{Zn}^{2+}\right)$ : Application to complex aqueous media. Int $\mathrm{J}$ Environ Anal Chem 72:173-194.

7. Chakraborty P, Gopalapillai Y, Murimboh J, Fasfous II, Chakrabarti CL (2006) Kinetic speciation of nickel in mining and municipal effluents. Anal Bioanal Chem 386:1803-1813.

8. Apte SC, Batley GE, Bowles KC, Brown PL, Creighton N, Hales LT, Hyne RV, Julli M, Markich SJ, Pablo F, Rogers NJ, Stauber JL, Wilde K (2005) A 
comparison of copper speciation measurements with the toxic response of three sensitive freshwater organisms. Environ Chem 2:320-330.

9. Guthrie JW, Hassan NM, Salam MSA, Fasfous II, Murimboh CA, Murimboh J, Chakrabarti CL, Gregoire DC (2005) Complexation of Ni, Cu, Zn, and Cd by DOC in some metal-impacted freshwater lakes: a comparison of approaches using electrochemical determination of free-metal-ion and labile complexes and a computer speciation model, WHAM V and VI. Anal Chim Acta 528:205-218.

10. Tipping E (1998) Humic ion-binding model VI: an improved description of the interactions of protons and metal ions with humic substances. Aquat Geochem $4: 3-48$.

11. Tipping E (2002) Cation binding by humic substances. Cambridge University Press, Cambridge, UK.

12. Sturgeon RE (1997) Graphite furnace atomic absorption spectrometry and environmental challenges at the ultratrace level--a review. Spectrochimica Acta Part B 52:1451-1457.

13. Templeton D, Ariese F, Cornelis R, Danielson LG, Muntau H, Van Leeuwen H, Lobinski R (2000) Guidelines for terms related to chemical speciation and fractionation of elements: Definitions, structural aspects and methodological approaches (IUPAC Recommendations 2000). Pure Appl Chem, 72: 1453-1471.

14. Turner DR (1995) Problems in Trace Metal Speciation Modeling. In: Tessier, A. and Turner DR (Eds.) Metal Speciation and Bioavailability in Aquatic Systems. John Wiley \& Sons, NY, USA. 
15. Schaumloffel D (2005) Speciation of Nickel. In: Cornelis R, Caruso J, Crews H, Heumann KG (eds.) Handbook of Elemental Speciation II: Species in the Environment, Food, Medicine \& Occupational Health. John Wiley and Sons, Chichester, West Sussex, UK.

16. Muyssen BTA, Brix KV, DeForest DK, Janssen CR (2004) Nickel essentiality and homeostasis in aquatic organisms. Environ Rev 12:113-131.

17. Paquin PR, Santore RC, Wu KB, Kavvadas CD, DiToro DM (2000) The Biotic Ligand Model: a model of the acute toxicity of metals to aquatic life. Environ Sci Pol 3:S175-S182.

18. Pickering, WF (2002) General Strategies for speciation. In: A.M. Ure and C.M. Davidson. (eds.) Chemical Speciation in the Environment, Second Edition. Blackwell Science Ltd, Oxford, UK.

19. Tessier A, Buffle J, and Campbell PGC (1994) Uptake of Trace Metals by Aquatic Organisms. In: Buffle J and De Vitre RR (eds.) Chemical and Biological Regulation of Aquatic Systems. CRC Press, Inc., Boca Raton, USA.

20. Allen HE (2002) The Biotic Ligand Model Addresses Effects of Water Chemistry on Metal Toxicity. International Council on Mining and Metals, London, United Kingdom.

21. Di Toro DM, Allen HE, Bergman HL, Meyer JS, and Santore RC (Eds.) (2000) The Biotic Ligand Model, A Computational Approach for Assessing The Ecological Effects of Copper and Other Metals in Aquatic Systems. International Copper Association, Ltd., NY, USA. 
22. Schulten HR, Schnitzer M (1993) The state of the art structural concept for humic substances. Naturwissenschaften 80:29-30.

23. Paquin PR, Gorsuch JW, Apte S, Batley GE, Bowles KC, Campbell PGC, Delos CG, Di Toro DM, Dwyer RL, Galvez F, Gensemer RW, Goss GG, Hogstrand C, Janssen CR, McGeer JC, Naddy RB, Playle RC, Santore RC, Schneider U, Stubblefield WA, Wood CM, Wu KB (2002) The biotic ligand model: A historical overview. Comp Biochem Phys - C 133(1-2):3-35.

24. Sunda WG, Lewis JAM (1978) Effect of complexation by natural organic ligands on the toxicity of copper to a unicellular alga, Monochrysis lutheri. Limnol Oceanogr 23:870-876.

25. Zitko V (1976) Structure-activity relations and the toxicity of trace elements to aquatic biota. Proceedings of Toxicity to Biota of Metal Forms in Natural Water, International Joint Commission, pp. 9-32.

26. Zitko V, Carson WV, Carson WG (1973) Prediction of incipient lethal levels ofcopper to juvenile Atlantic salmon in the presence of humic acid by cupric electrode. Bull Environ Contam Toxicol 10:265-271.

27. Pagenkopf GK, Russo RC, Thurston RV (1974) Effect of complexation on toxicity of copper to fishes. J Fish Res Board Can 31:462-465.

28. Morel FMM (1983) Principles of Aquatic Chemistry. Wiley-Interscience, New York.

29. Pagenkopf GK (1983) Gill surface interaction model for trace metal toxicity to fish: role of complexation, $\mathrm{pH}$, and water hardness. Environ Sci Technol 17:342347. 
30. Playle RC, Gensemer RW, Dixon DG (1992) Copper accumulation on gills of fathead minnows: influence of water hardness, complexation and $\mathrm{pH}$ on the gill microenvironment. Environ Toxicol Chem 11:381-391.

31. Playle RC, Dixon DG, Burnison K (1993) Copper and cadmium binding to fish gills: modification by dissolved organic carbon and synthetic ligands. Can J Fish Aquat Sci 50:2667-2677.

32. Playle RC, Dixon DG, Burnison K (1993) Copper and cadmium binding to fish gills: estimates of metal-gill stability constants and modeling of metal accumulation. Can J Fish Aquat Sci 50:2678-2687.

33. Di Toro DM, Allen HE, Bergman HL, Meyer JS, Paquin PR, Santore RC (2001) A biotic ligand model of the acute toxicity of metals I. Technical basis. Environ Toxicol Chem 20:2383-2396.

34. US Environmental Protection Agency (2007) Aquatic Life Ambient Freshwater Quality Criteria, Copper, 2007 Revision. US EPA Office of Water, Washington, DC.

35. Canadian Council of Ministers of the Environment (1999) Canadian Environmental Quality Guidelines. Winnipeg, MB, Canada: CCME.

36. Niyogi S, Wood CM (2004) Biotic ligand model, a flexible tool for developing site-specific water quality guidelines for metals. Environ Sci Technol 38(23):6177-6192.

37. de Bolster MWG (1997) Glossary of terms used in bioinorganic chemistry (IUPAC recommendations 1997). Pure Appl Chem 69:1251-1303. 
38. Zhang H, Davison W (2000) Direct in situ measurements of labile inorganic and organically bound metal species in synthetic solutions and natural waters using diffusive gradients in thin films. Anal Chem 72:4447-4457.

39. Unsworth ER, Warnken KW, Zhang H, Davison W, Black F, Buffle J, Cao J, Cleven R, Galceran J, Gunkel P, Kalis E, Kistler D, van Leeuwen HP, Martin M, Noël S Nur Y, Odzak N, Puy J, Riemsdijk WV, Sigg L, Temminghoff E, TercierWaeber M-L, Toepperwien S, Town RM, Weng L, Xue H (2006) Model predictions of metal speciation in freshwaters compared to measurements by in situ techniques. Environ Sci Technol 40:1942-1949.

40. Unsworth ER, Zhang H, Davison W (2005) Use of diffusive gradients in thin films to measure cadmium speciation in solutions with synthetic and natural ligands: comparison with model predictions. Environ Sci Technol 39:624-630.

41. Sigg L, Black F, Buffle J, Cao J, Cleven R, Davison W, Galceran J, Gunkel P, Kalis E, Kistler D, Martin M, Noël S, Nur Y, Odzak N, Puy J, Riemsdijk WV, Temminghoff E, Tercier-Waeber M-L, Toepperwien S, Town RM, Unsworth ER, Warnken KW, Weng L, Xue H, Zhang H (2006) Comparison of analytical techniques for dynamic trace metal speciation in natural freshwaters. Environ Sci Technol 40:1934-1941.

42. Fasfous II, Yapici T, Murimboh J, Hassan NM, Chakrabarti CL, Back MH, Lean DRS, Grégoire DC (2004) Kinetics of trace metal competitionin the freshwater environment: Some fundamental characteristics. Environ Sci Technol 38:49794986. 
43. Temminghoff EJ M, Plette ACC, Van Eck R, Riemsdijk WH (2000)

Determination of the chemical speciation of trace metals in aqueous systems by the Wageningen Donnan Membrane Technique. Anal Chim Acta 417:149-157.

44. Batley GE, Apte SC, Stauber JL (2004) Speciation and bioavailability of trace metals in water: Progress since 1982. Australian Journal of Chemistry 57(10):903-919.

45. MacRae RK, Smith DE, Swoboda-Colberg N, Meyer JS, Bergman HL (1999) Copper binding affinity of rainbow trout (Oncorhynchus mykiss) and brook trout (Salvelinus fontinalis) gills. Environ Toxicol Chem 18:1180-1189.

46. Meyer JS, Santore RC, Bobbitt JP, Debrey LD, Boese CJ, Paquin PR, Allen HE, Bergman HL, DiToro DM (1999) Binding of nickel and copper to fish gills predicts toxicity when water hardness varies, but free-ion activity does not. Environ Sci Technol 33:913-916.

47. Morel FMM, Hering JG (1993) Principles of Aquatic Chemistry. Wiley, New York, pp 360, 380-388.

48. Sutton R, Sposito G (2005) Molecular structure in soil humic substances: The new view. Environ Sci Technol 39:9009-9015.

49. Fortin C, Caron F (2000) Complexing capacity of low-level radioactive waste leachates for ${ }^{60} \mathrm{Co}$ and ${ }^{109} \mathrm{Cd}$ using an ion-exchange technique. Anal Chim Acta $410(1-2): 107-117$.

50. Ge Y, Sauve S, Hendershot WH (2005) Equilibrium Speciation of Cadmium, Copper, and Lead in Soil Solutions. Commun Soil Sci Plant Anal 36:1537-1556. 
51. Vigneault B, Campbell PGC (2005) Uptake of cadmium by freshwater green algae: effects of $\mathrm{pH}$ and aquatic humic substances. J. Phycol 41:55-61.

52. Worms IAM, Parthasarathy N, Wilkinson KJ (2007) Ni uptake by a green alga. 1 . Validation of equilibrium models for complexation effects. Environ Sci Technol 41:4258-4263.

53. Apte SC, Batley GE (1995) Trace Metal Speciation of Labile Chemical Species in Natural Waters and Sediments: Non-Electrochemical Approaches. In: Tessier A, Turner DR (eds) Metal speciation and bioavailability in aquatic systems. Wiley, Chichester UK.

54. Sweileh JA, Lucyk D, Kratochvil B, Cantwell FF (1987) Specificity of the ion exchange/atomic absorption method for free copper(II) species determination in natural waters. Anal Chem 59:586-592.

55. Sigma-Aldrich Corporation. DOWEX ${ }^{\mathrm{TM}}$ Ion Exchange Resins: Using Ion Exchange Resin Selectivity Coefficients [Online]. Available: http://www.dow.com/PublishedLiterature/dh 061c/09002f138061c12c.pdf?filepat $\underline{\mathrm{h}=\text { liquidseps/pdfs/noreg/177-01755.pdf\&fromPage=GetDoc. }}$ Cited 16 July 2007.

56. Ren H, Kratochvil B (1995) Determination of free calcium and magnesium concentrations in urine samples by an ion exchange-inductively couple plasma atomic emission spectroscopy method. Int J Environ Anal Chem 60:303-312.

57. Tramonti V (1988) M.Sc. Thesis, Concordia University, Montreal, Canada.

58. Chakrabarti CL, Lu Y, Cheng J, Grégoire DC, Back MH, Schroeder WH (1993) Studies on metal speciation in the natural environment. Anal Chim Acta 267: 4754. 
59. National Institute of Standards and Technology (2004) (NIST Standard Reference Database 46) Critical Stability Constants of Metal complexes Database, Version 8.0; Department of Commerce: Gaithersburg, Maryland.

60. Schlemmer G, Radziuk B (1999) Analytical graphite furnace atomic absorption spectrometry: a laboratory guide. Birkhauser, Basel, Switzerland.

61. Xue HB, Jansen S, Prasch A, Sigg L (2001) Nickel speciation and complexation kinetics in freshwater by ligand exchange and DPSCV. Environ Sci Technol $35: 539-546$.

62. Cao J, Xue H, Sigg L (2006) Effects of $\mathrm{pH}$ and Ca competition on complexation of cadmium by fulvic acids and by natural organic ligands from a river and a lake. Aquat Geochem 12:375-387.

63. Filella M, Buffle J and Van Leeuwen HP (1990) Effect of physico-chemical heterogeneity of natural complexants: Part I. Voltammetry of labile metal-fulvic complexes. Anal Chim Acta 232(1):209-223.

64. Buffle J (1988) Complexation reactions in aquatic systems, an analytical approach. Ellis Horwood, Chichester, UK.

65. Buffle J, Altmann RS, Filella M, Tessier A (1990) Complexation by natural heterogeneous compounds: site occupation distribution functions, a normalized description of metal complexation. Geochim Cosmochim Acta 54:1535-1553.

66. Langford CH, Gamble DS, Underdown AW, Lee S (1983) Aquatic and terrestrial humic materials. Ann Arbor Science, pp 222-224. 
67. Underdown AW, Langford CH, and Gamble DS (1985) Light scattering studies of the relationship between cation binding and aggregation of a fulvic acid. Environ Sci Technol 19:132-136.

68. Langford CH, Cook RL (1995) Kinetics versus equilibrium studies for the speciation of metal complexes with ligands from soil and water. Analyst 120:591596.

69. Wang ZD (1989) Ph.D. Thesis, Concordia University, Montreal, Canada.

70. Guthrie JW, Mandal R, Salam MSA, Hassan NM, Murimboh J, Chakrabarti CL, Back MH and Grégoire DC (2003) Kinetic studies of nickel speciation in model solutions of a well-characterized humic acid using the competing ligand exchange method. Anal Chim Acta 480(1):157-169.

71. Doig LE, Liber K (2007) Nickel speciation in the presence of different sources and fractions of dissolved organic matter. Ecotox Environ Safe 66(2):169-177.

72. Mandal R, Salam MSA, Murimboh J, Hassan NM, Chakrabarti CL, Back MH, Gregoire DC, Scrhoeder WH (1999) Effect of the competition of copper and cobalt on the lability of Ni(II)-organic ligand complexes, Part II: in freshwaters (Rideau River surface waters). Anal Chim Acta 395:323-334.

73. Lu Y, Chakrabarti CL, Back MH, Gregoire DC, Schroeder WH (1994) Kinetic studies of aluminum and zinc speciation in river water and snow. Anal Chim Acta 293:95-108.

74. Olson DL, Shuman MS (1985) Copper dissociation from estuarine humic materials. Geochim Cosmochim Acta 49:1371-1375. 
75. Environment Canada (1992) Biological test method: growth inhibition test using the freshwater alga Selenastrum capricornutum. Ottawa: Environment Canada. Environment Canada Environmental Protection Series. Report EPS 1/RM/25.

76. Radix P, Leonard M, Papantoniou C, Roman G, Saouter E, Gallotti-Schmitt S, Thiebaud H, Vasseur P (2000) Ecotoxicology and Environmental Safety, 47:186194.

77. Lewis MA (1995) Algae and vascular plant tests. In: Rand, GM (ed.) Fundamentals of Aquatic Toxicology: Effects, Environmental Fact, and Risk Assessment, Second Edition. Taylor \& Francis, London.

78. Guy RD, Kean AR (1980) Algae as a chemical speciation monitor - I: a comparison of algal growth and computer calculated speciation. Water Research 14:891-899.

79. Mandal R, Salam MSA, Murimboh J, Hassan NM, Chakrabarti CL, Back MH, Gregoire DC (2000) Competition of $\mathrm{Ca}$ (II) and $\mathrm{Mg}$ (II) with $\mathrm{Ni(II)}$ for binding by a well-characterized fulvic acid in model solutions. Environ Sci Technol 34: 2201-2208.

80. Campbell PGC, Errécalde O, Fortin C, Hiriart VP and Vigneault B (2002) Metal bioavailability to phytoplankton - applicability of the Biotic Ligand Model. Comp Biochem Physiol C 133(1-2): 189-206. 


\section{Appendix}




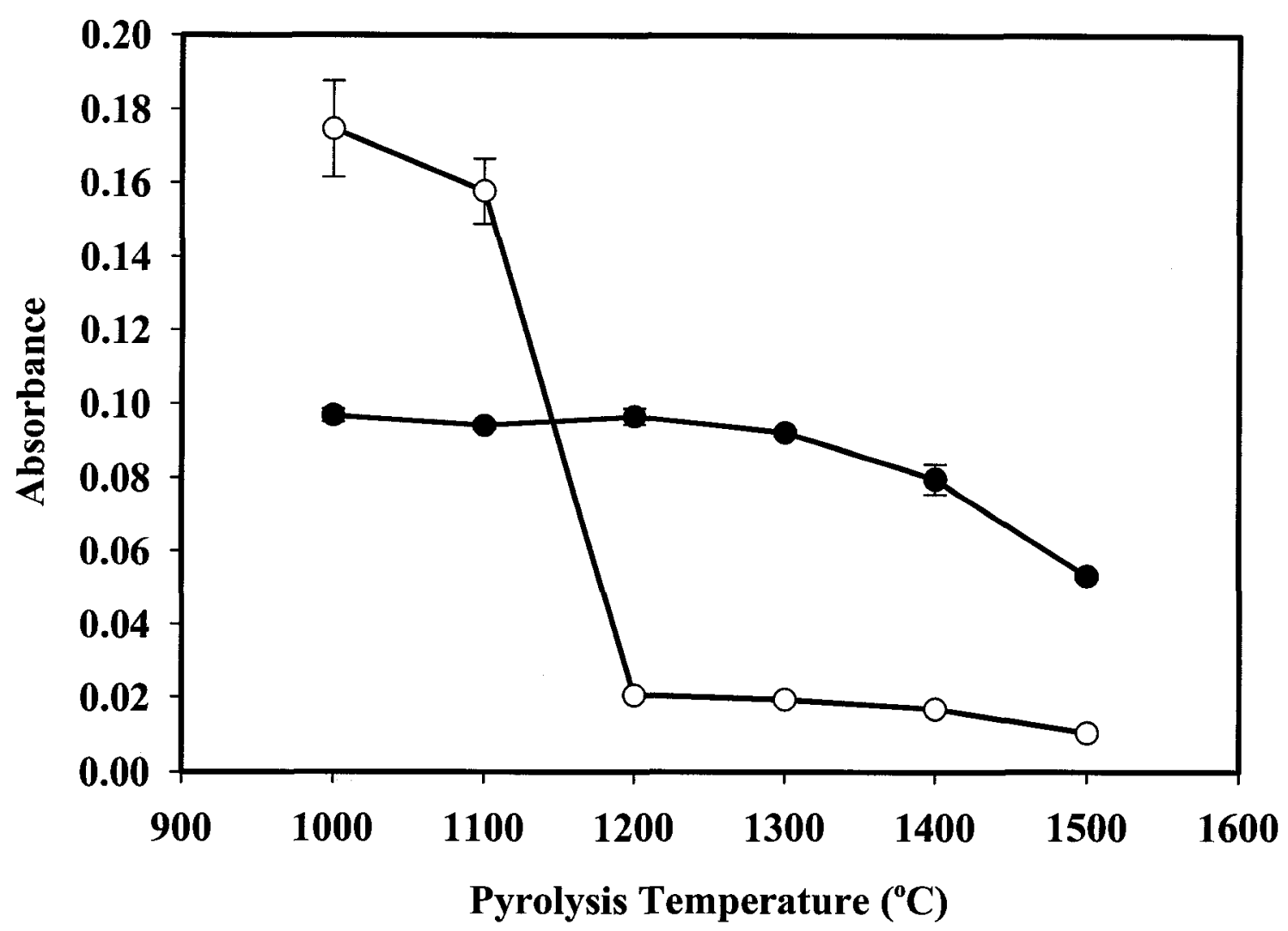

Figure 7.1 Optimization of pyrolysis temperature for determination of $[\mathrm{Ni}(\mathrm{II})]_{\text {total }}$ in samples of high ionic strength and low $\mathrm{pH}$ by GFAAS. The sample solution contained $4.40 \times 10^{-7} \mathrm{M} \mathrm{Ni}(\mathrm{II})$ and $0.2 \mathrm{M} \mathrm{NaNO}_{3}$ at $\mathrm{pH} 5.5(0.01$ $\mathrm{M} \mathrm{C}_{2} \mathrm{H}_{3} \mathrm{O}_{2} \mathrm{Na} \mathrm{pH}$ buffer). The atomization temperature was kept at $2250^{\circ} \mathrm{C}$. (•, Ni absorbance;, background absorbance; vertical error bars represent \pm 1 standard deviation of three replicate determinations, visible when they are larger than the symbol) 


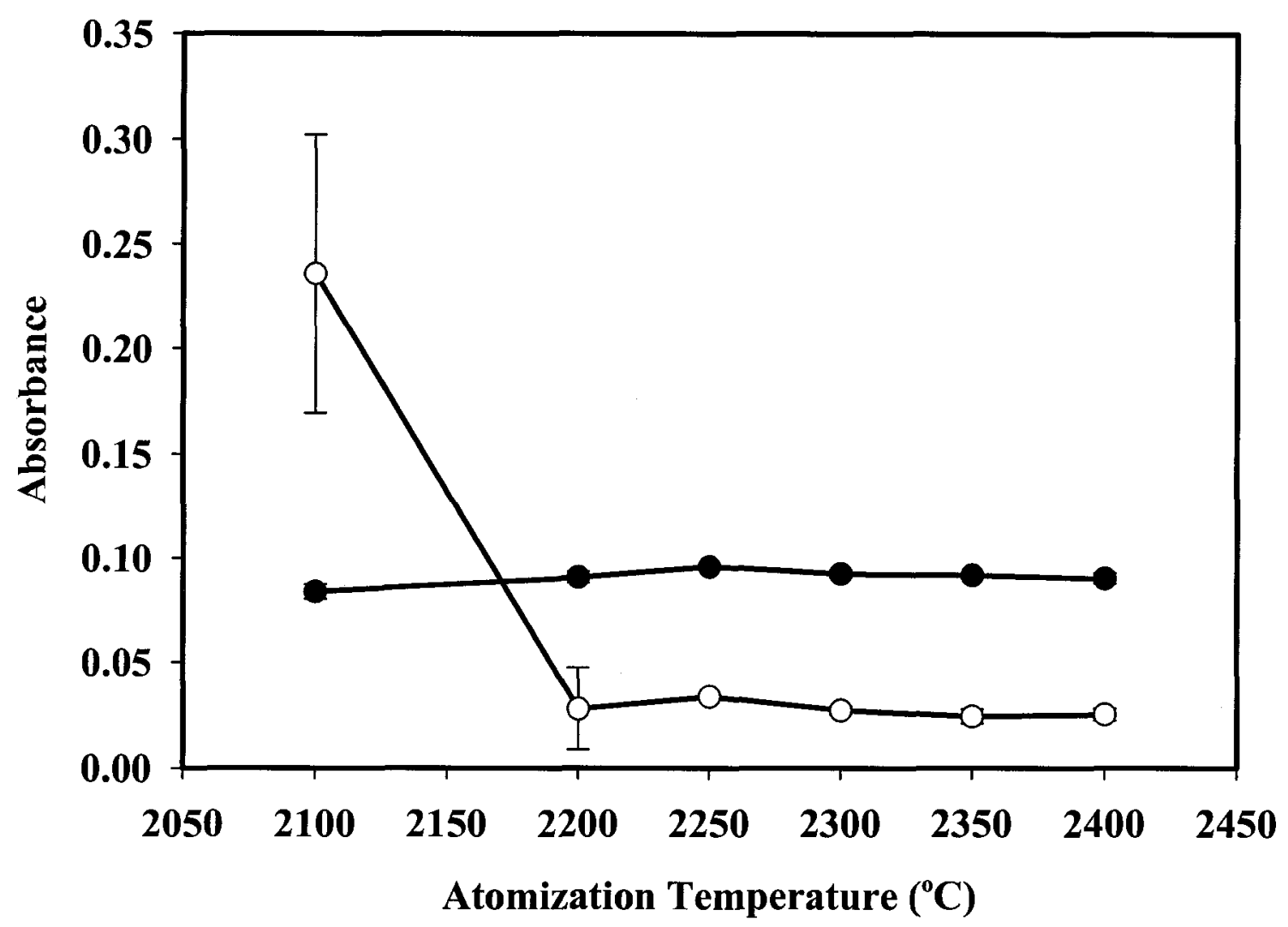

Figure 7.2 Optimization of atomization temperature for determination of $[\mathrm{Ni}(\mathrm{II})]_{\text {total }}$ in samples of high ionic strength and low $\mathrm{pH}$ for GFAAS. The sample solution contained $4.40 \times 10^{-7} \mathrm{M} \mathrm{Ni}(\mathrm{II})$ and $0.2 \mathrm{M} \mathrm{NaNO}_{3}$ at $\mathrm{pH} 5.5(0.01$ $\mathrm{M} \mathrm{C}_{2} \mathrm{H}_{3} \mathrm{O}_{2} \mathrm{Na} \mathrm{pH}$ buffer). The pyrolysis temperature was kept at $1200^{\circ} \mathrm{C}$. $(\bullet, \mathrm{Ni}$ absorbance; $\circ$, background absorbance; vertical error bars represent \pm 1 standard deviation of three replicate determinations, visible only when they are larger than they symbols). 


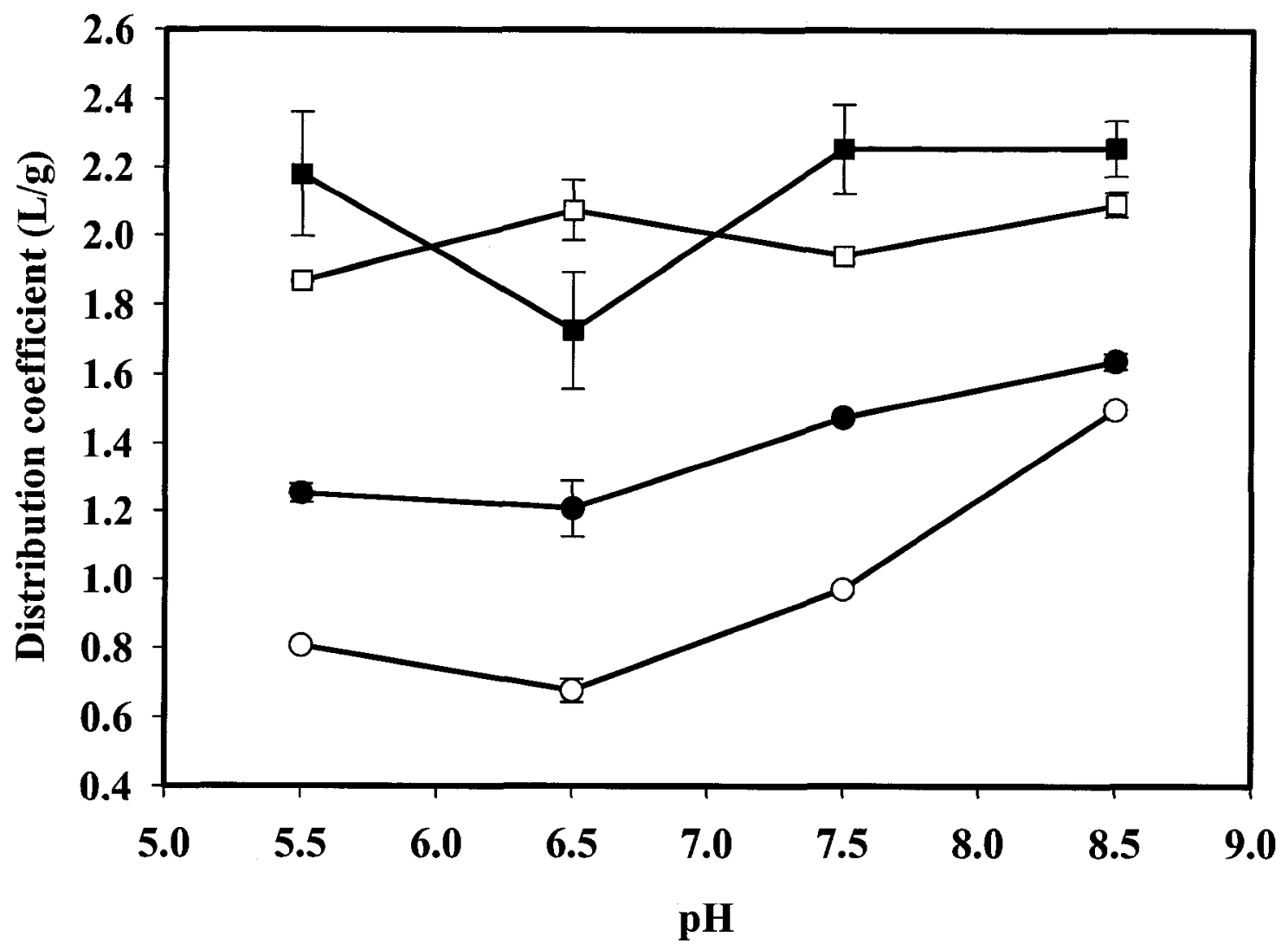

Figure 7.3 The effect of $\mathrm{pH}$ on the $\lambda_{\mathrm{Ni}}$ at various ionic strength $(\mathbf{m}, 0.001 \mathrm{M} ; \square, 0.01$ $\mathrm{M} ; \bullet, 0.1 \mathrm{M} ; \circ, 0.2 \mathrm{M}$ ) using the same $\mathrm{pH}$ buffer. The sample solutions contained $4.40 \times 10^{-7} \mathrm{M} \mathrm{Ni}(\mathrm{II})$ and a $\mathrm{pH}$ buffer $0.01 \mathrm{M}$ tris- $\mathrm{HCl}$. The vertical error bars represent \pm 1 standard deviation of three replicate determinations (visible only when they are larger than the symbols). 

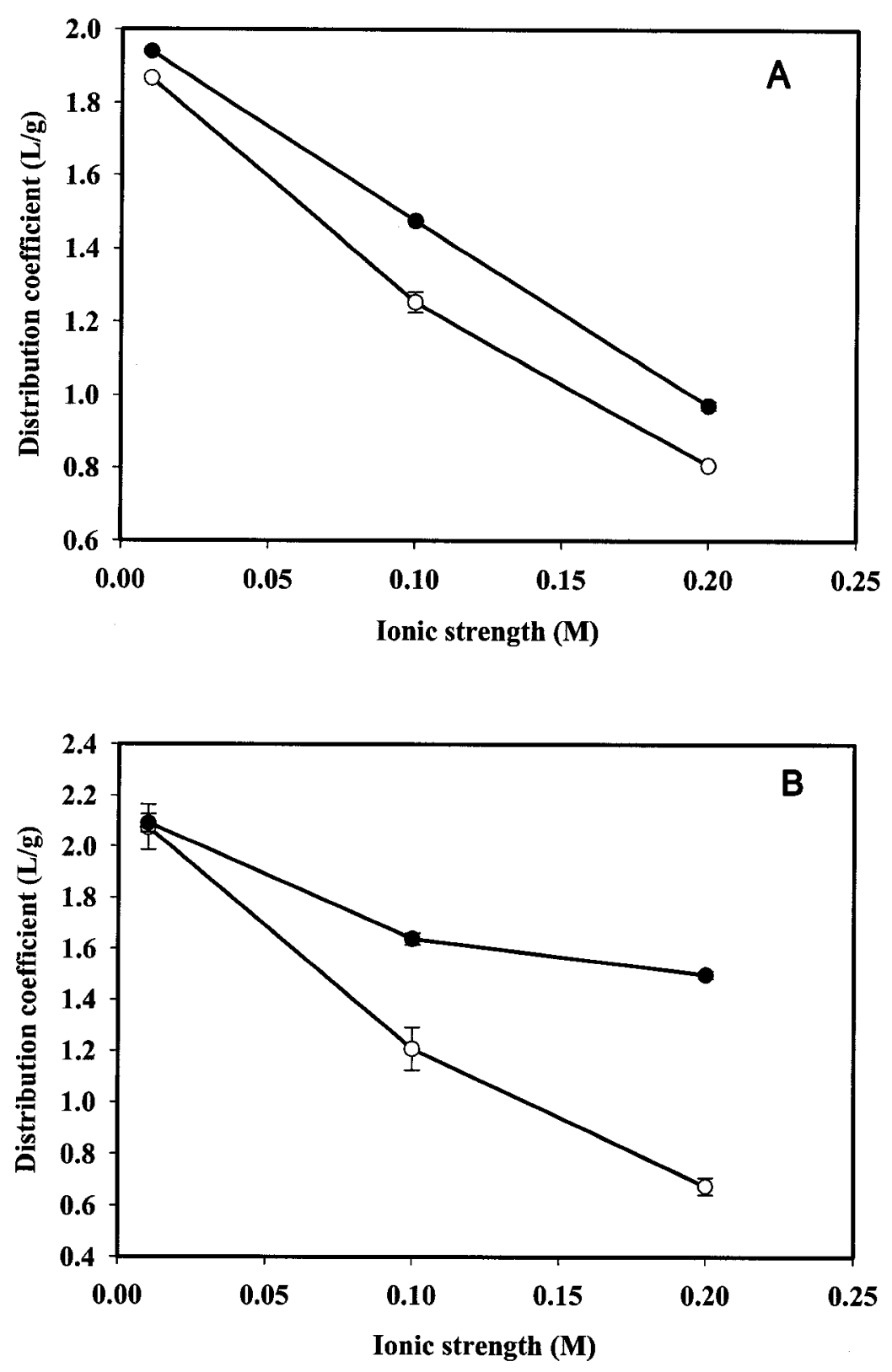

Figure 7.4 The effect of $\mathrm{pH}$ buffer on $\lambda_{\mathrm{Ni}}$ as a function of ionic strength $(\bullet, 0.01 \mathrm{M}$ $\mathrm{C}_{2} \mathrm{H}_{3} \mathrm{O}_{2} \mathrm{Na} ; \circ, 0.01 \mathrm{M}$ tris- $\left.\mathrm{HCl}\right)$. The sample solutions contained $4.40 \times 10^{-}$ ${ }^{7} \mathrm{M} \mathrm{Ni}(\mathrm{II})$ at a pH of 5.5 (a) and at a $\mathrm{pH}$ of 6.5 (b). The vertical error bars represent \pm 1 standard deviation of three replicate determinations (visible only when they are larger than the symbols). 


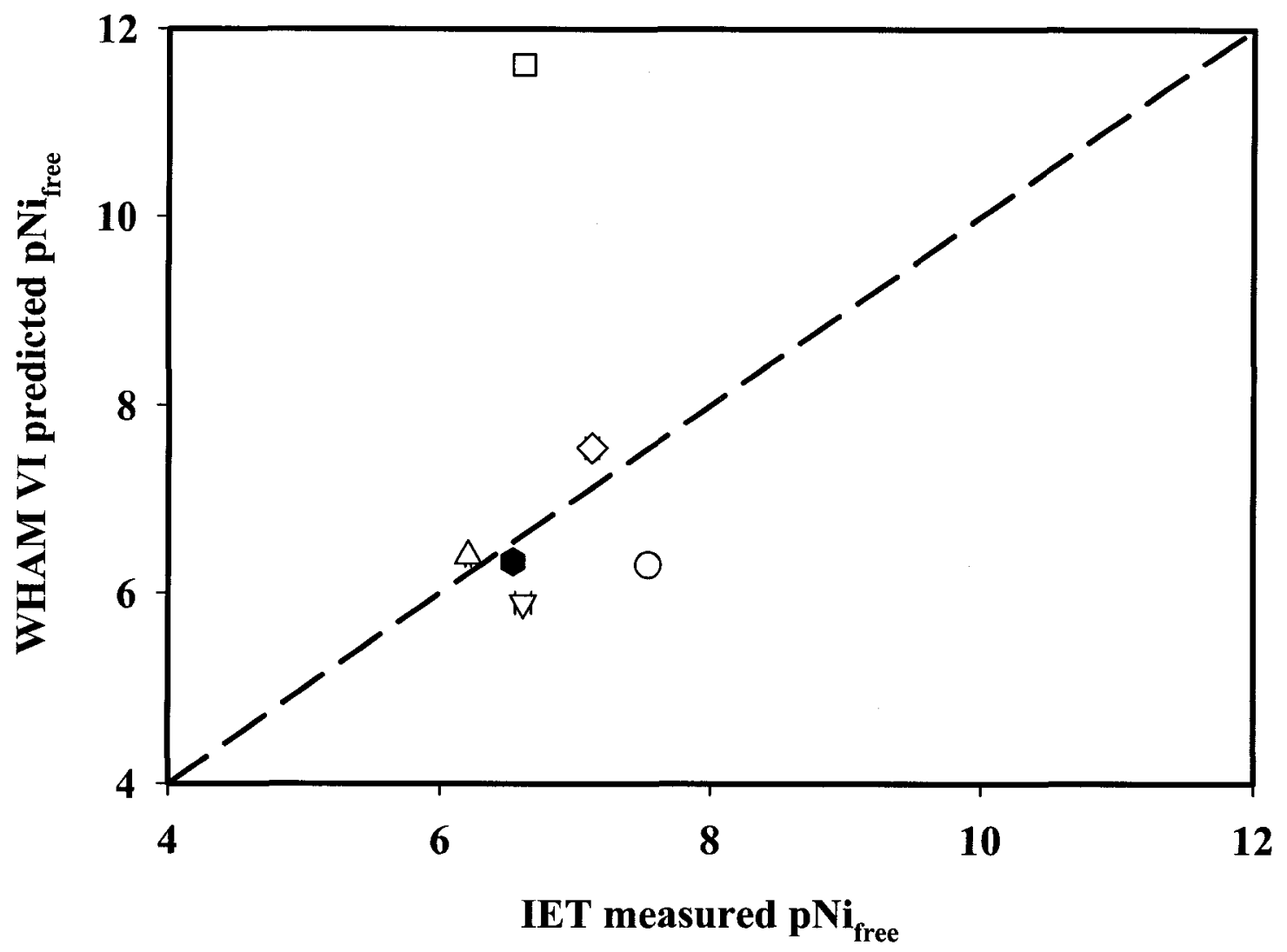

Figure 7.5 Comparison on a log scale of $[\mathrm{Ni}(\mathrm{II})]_{\text {free }}$ measured by optimized IET and that predicted by WHAM VI in mining and municipal effluent water samples collected from the Sudbury area, Ontario, Canada; ( $\square$ ) Sudbury WWTP; $(\nabla)$ Garson Mine; $(\triangle)$ Crean Hill Mine; ( $)$ Copper Cliff WWTP; $(\diamond)$ Whistle Mine; $(\bullet)$ Nolin Creek WWTP. The solutions were adjusted to an ionic strength of $0.01 \mathrm{M}$ using $\mathrm{NaNO}_{3}$. The horizontal error bars represent \pm 1 standard deviation of three replicate determinations. 


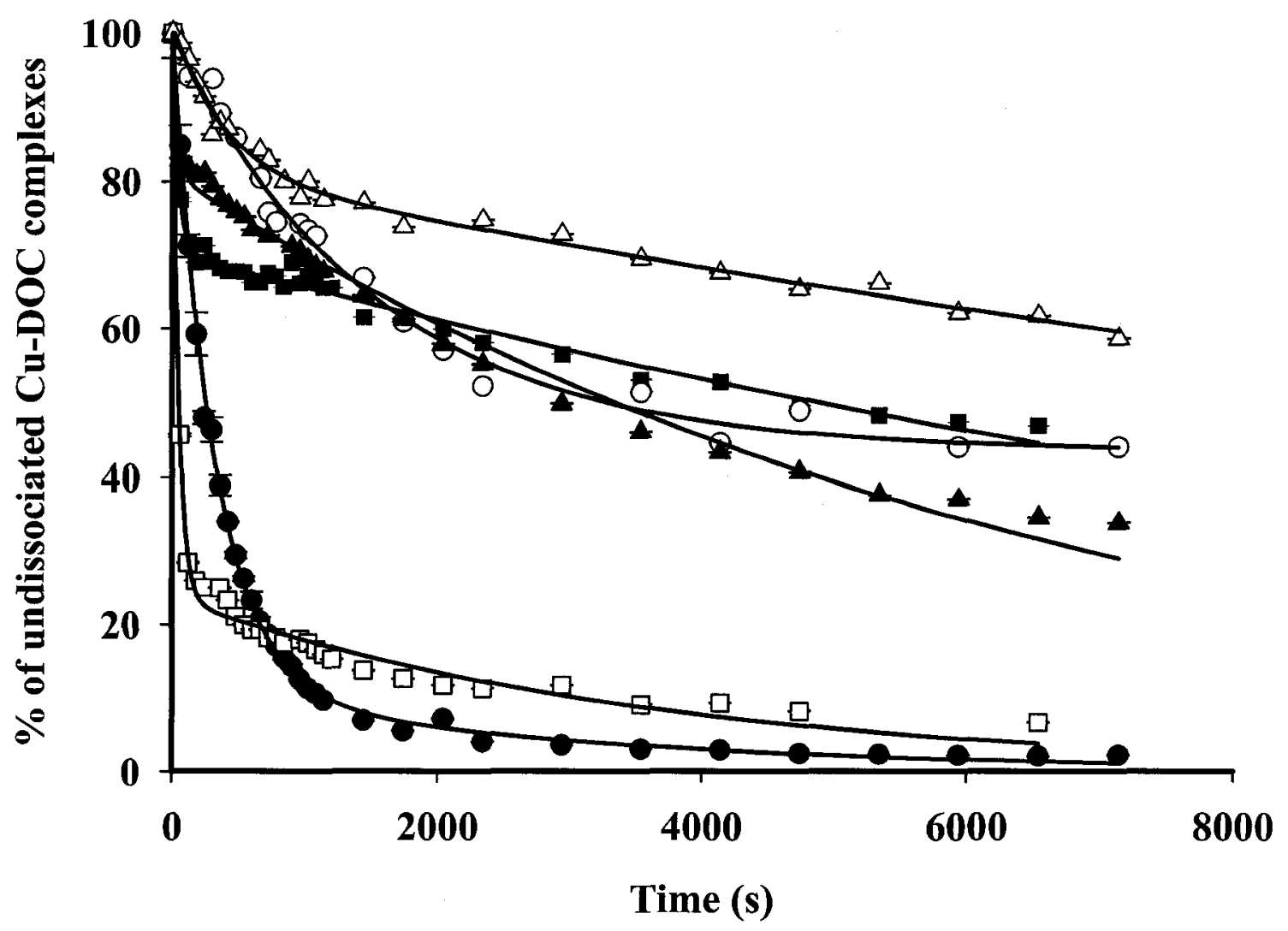

Figure 7.6 Percentage of $\mathrm{Cu}(\mathrm{II})$ released from $\mathrm{Cu}$ (II)-DOC complexes in mining and municipal effluent water samples as function of time, determined by CLEM/GFAAS. Chelex 100 was the competing ligand. (a) Sudbury WWTP; $(\triangle)$ Garson Mine; $(\boldsymbol{\Delta})$ Crean Hill Mine; $(\bullet)$ Copper Cliff WWTP; (०) Whistle Mine; (口) Nolin Creek WWTP. Solid lines represent non-linear curve fitting. The vertical error bars represent \pm 1 standard deviation of three replicate determinations (visible only when they are larger than the symbols). 


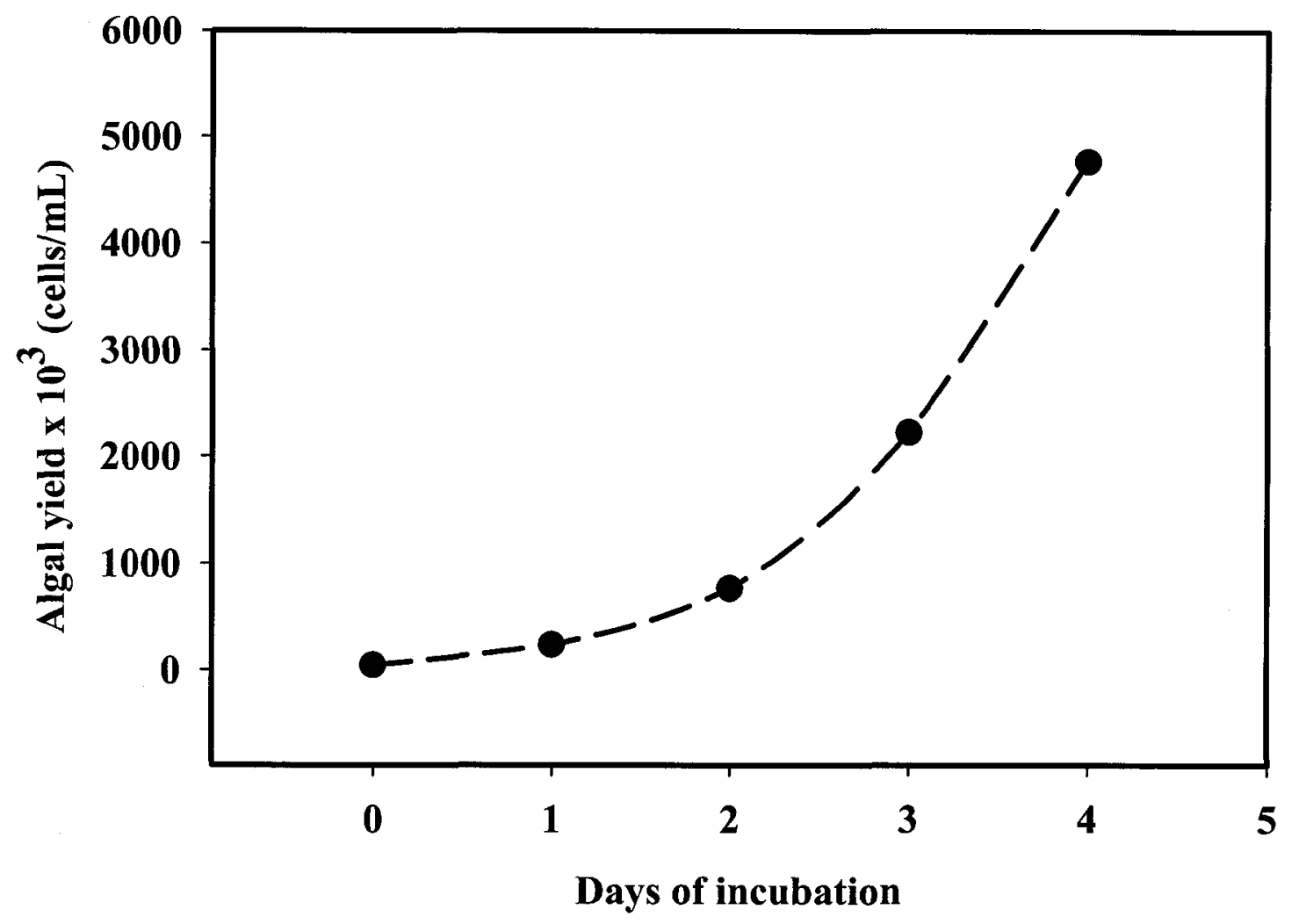

Figure 7.7 Growth curve for the algal stock culture. 


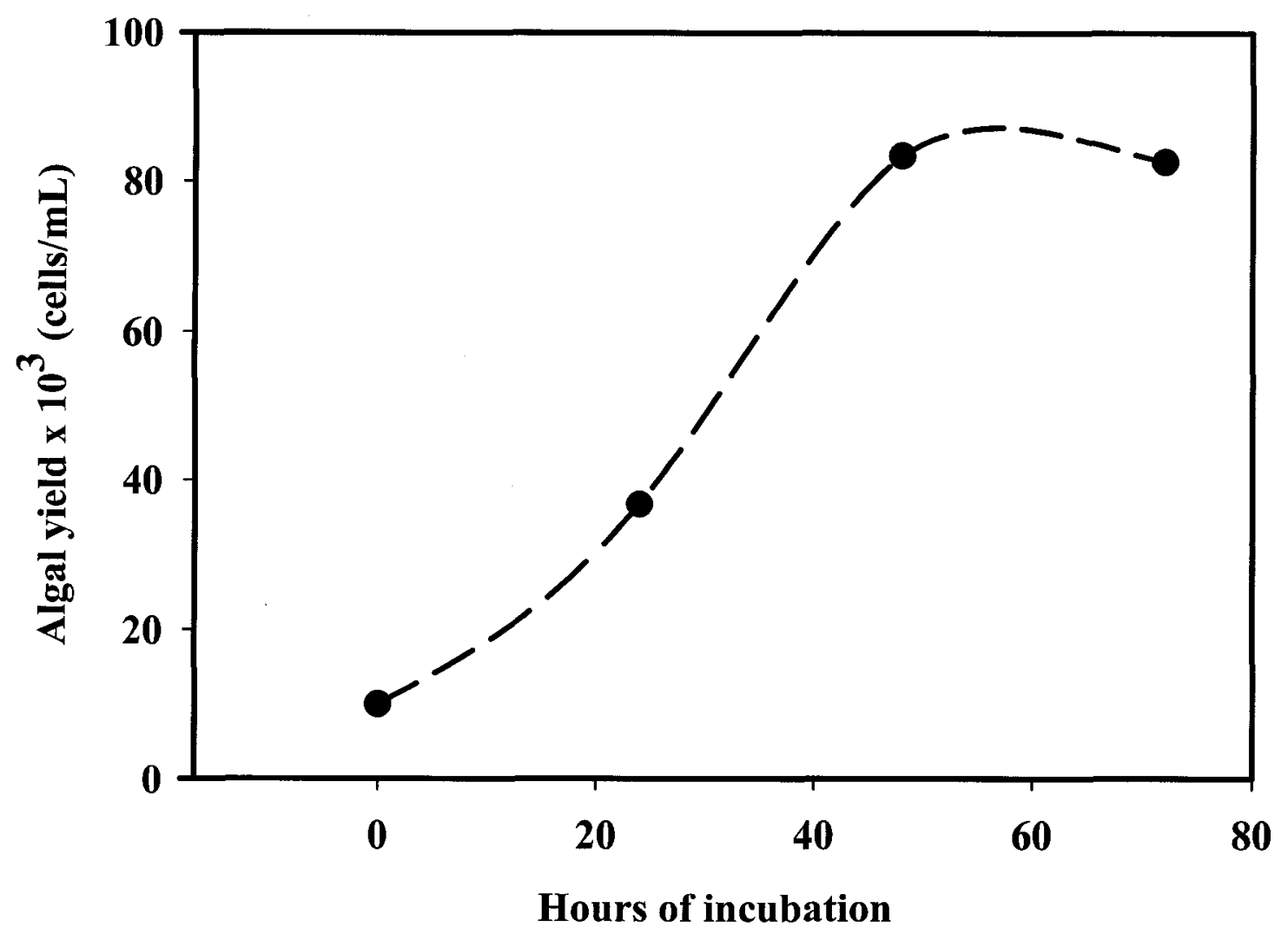

Figure 7.8 Growth curve (72-hour) for algae in the control microplate. 


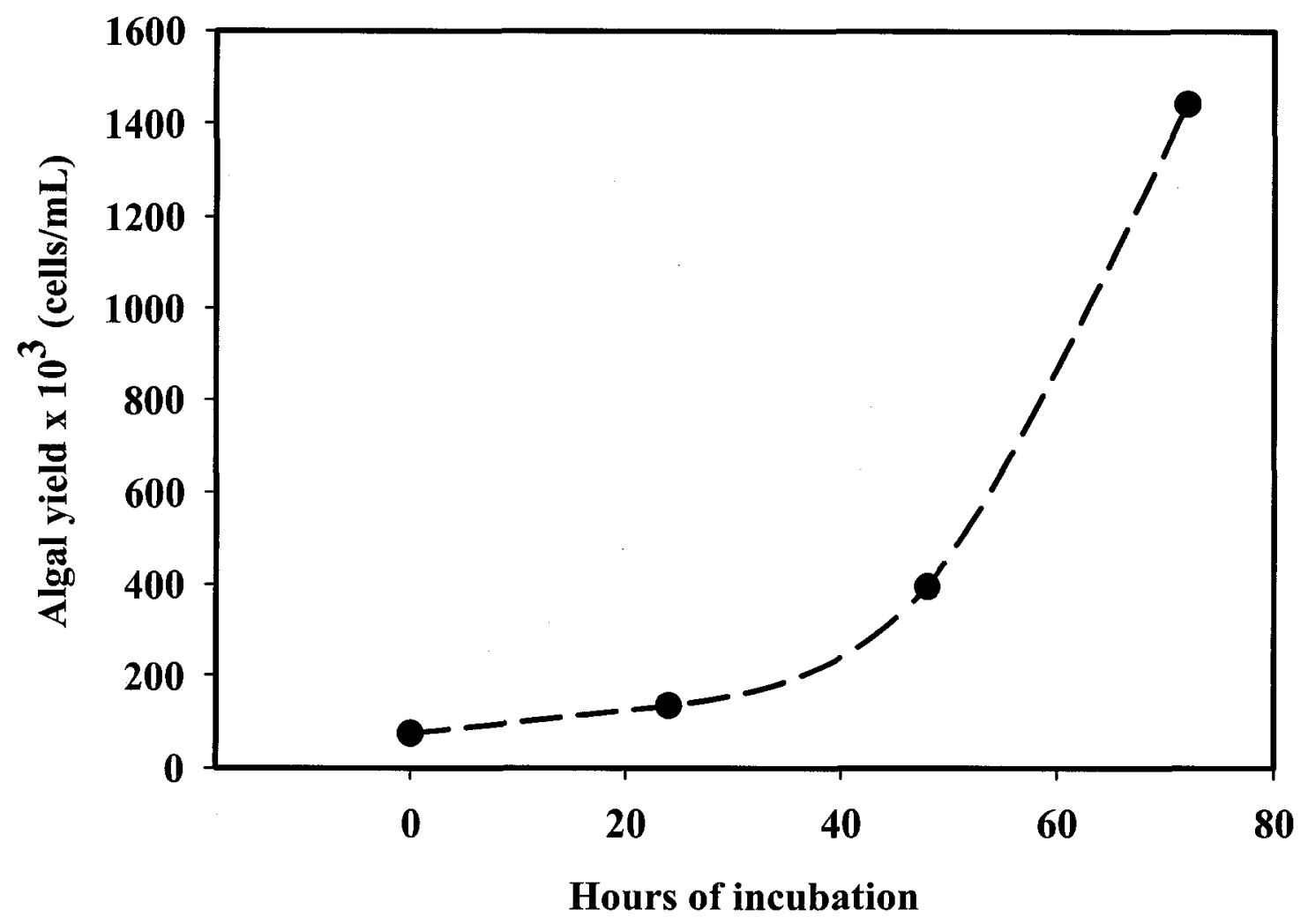

Figure 7.9 Growth curve (72-hour) for algae in the control $50 \mathrm{~mL}$ Erlenmeyer test flasks. 


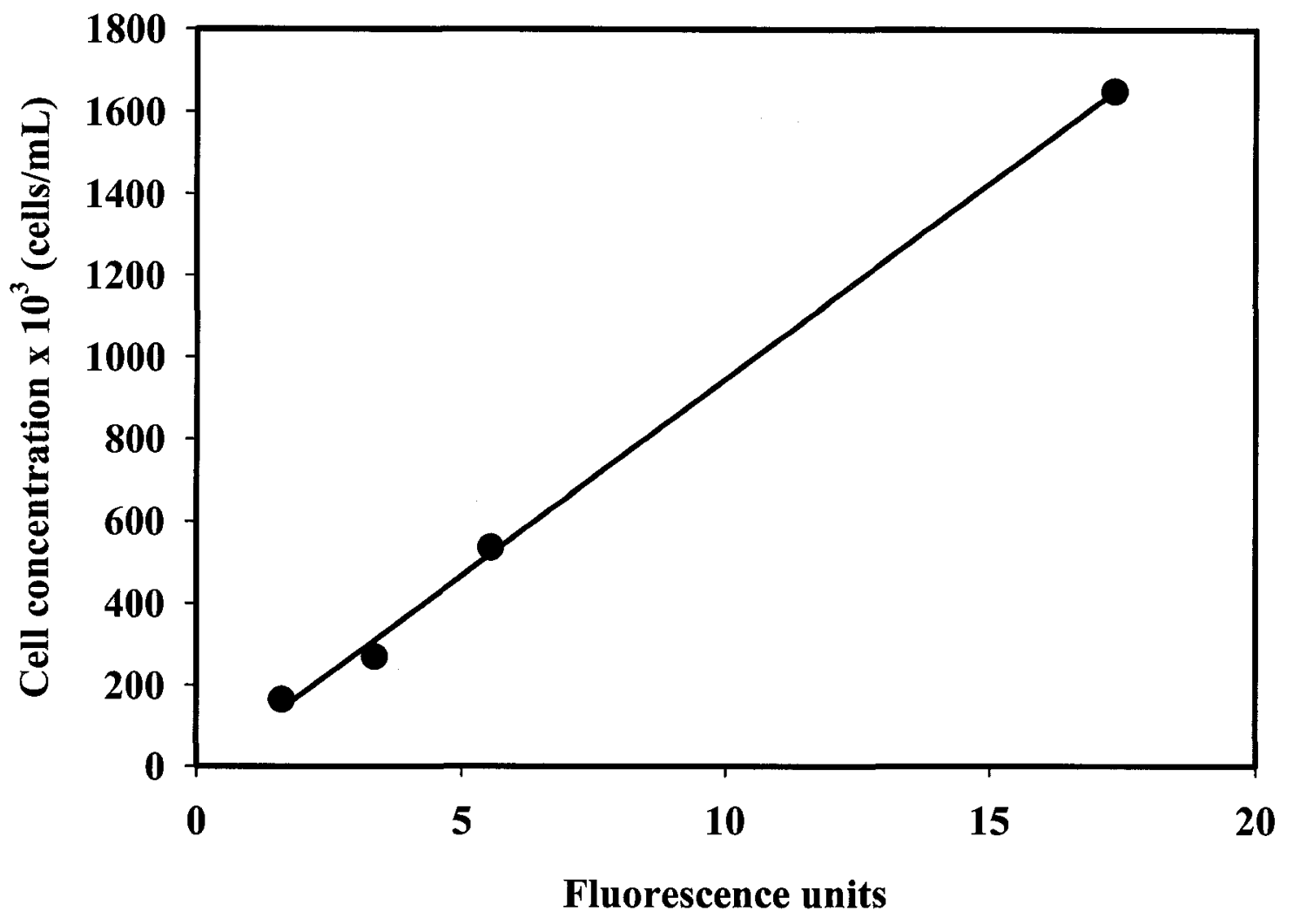

Figure 7.10 Standard calibration curve for algal concentration measured by fluorescence using a microplate spectrofluorometer. 


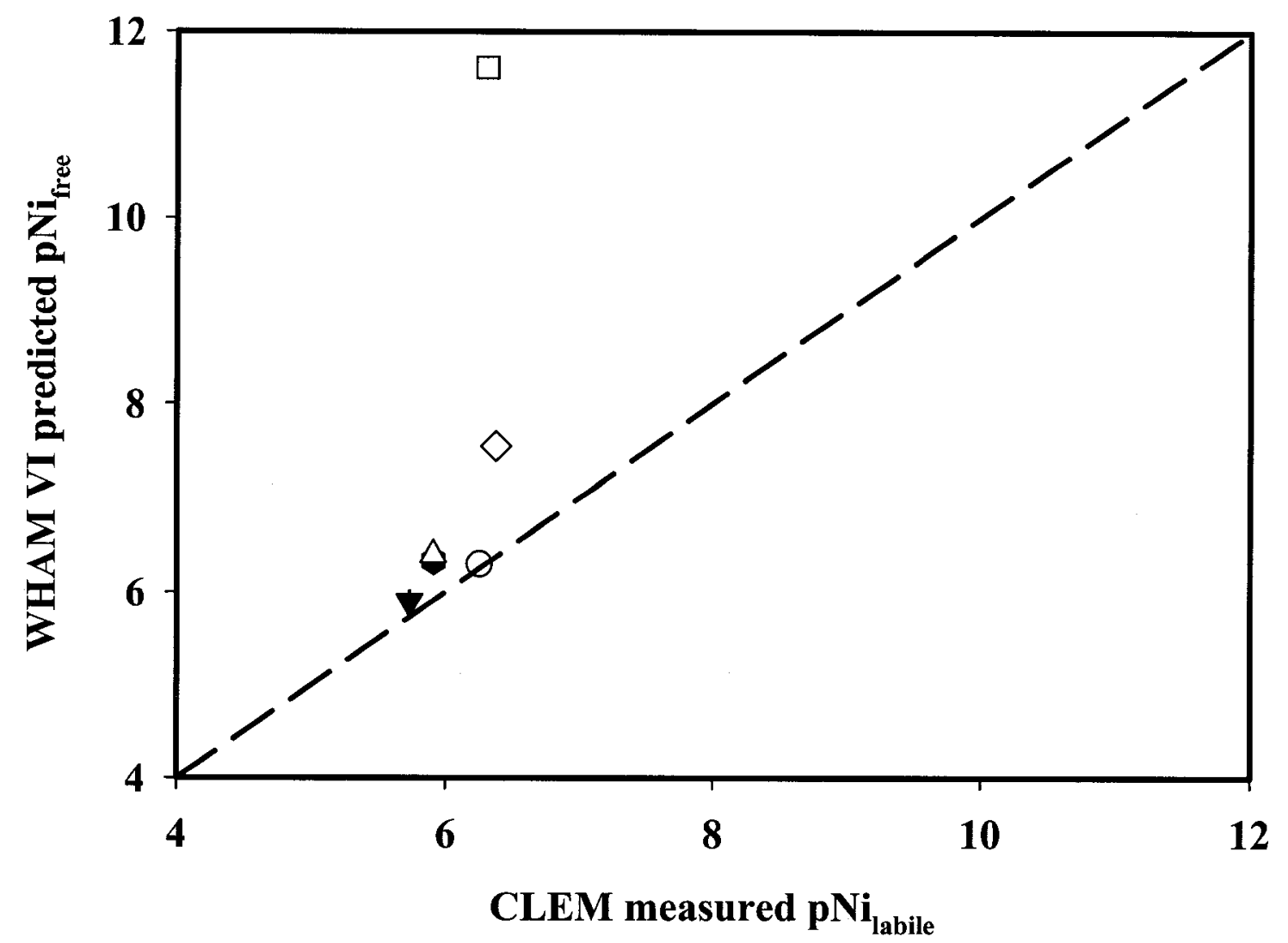

Figure 7.11 Comparison on a $\log$ scale of $[\mathrm{Ni}]_{\mathrm{labile}}$ measured by CLEM and that predicted by WHAM VI in mining and municipal effluent water samples collected from the Sudbury area, Ontario, Canada; () Sudbury WWTP; $(\nabla)$ Garson Mine; $(\triangle)$ Crean Hill Mine; ( $)$ Copper Cliff WWTP; $(\diamond)$ Whistle Mine; ( ) Nolin Creek WWTP. The horizontal error bars represent \pm 1 standard deviation of three replicate determinations. 


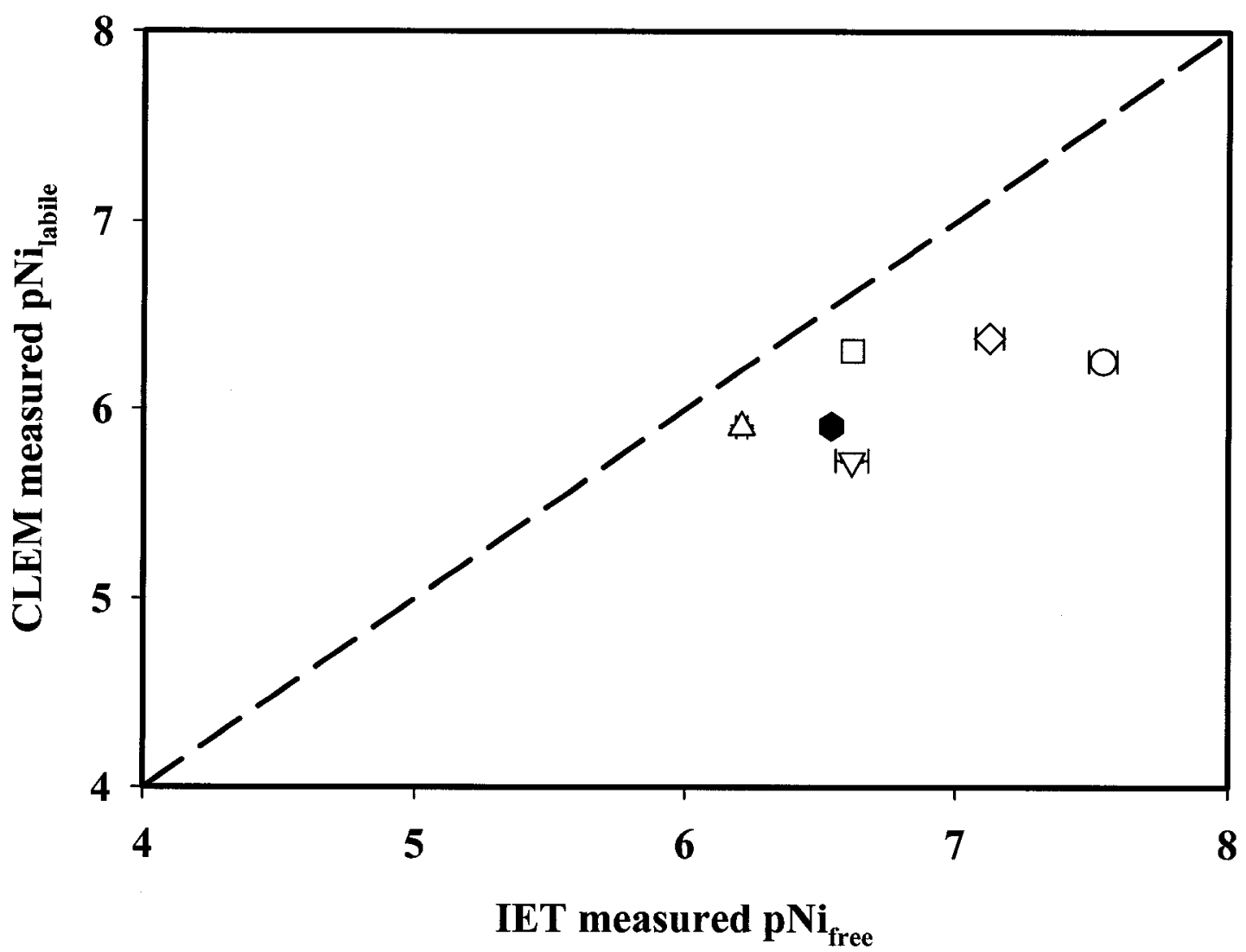

Figure 7.12 Comparison on a $\log$ scale of $[\mathrm{Ni}]_{\text {labile }}$ measured by CLEM and the $[\mathrm{Ni}(\mathrm{II})]_{\text {free }}$ measured by optimized IET in mining and municipal effluent water samples collected from the Sudbury area, Ontario, Canada; ( $\square$ ) Sudbury WWTP; $(\nabla)$ Garson Mine; $(\triangle)$ Crean Hill Mine; $(\circ)$ Copper Cliff WWTP; $(\diamond)$ Whistle Mine; $(\bullet)$ Nolin Creek WWTP. For IET, the solutions were adjusted to an ionic strength of $0.01 \mathrm{M}$ using $\mathrm{NaNO}_{3}$. The horizontal bars represent \pm 1 standard deviation of three replicate determinations. 


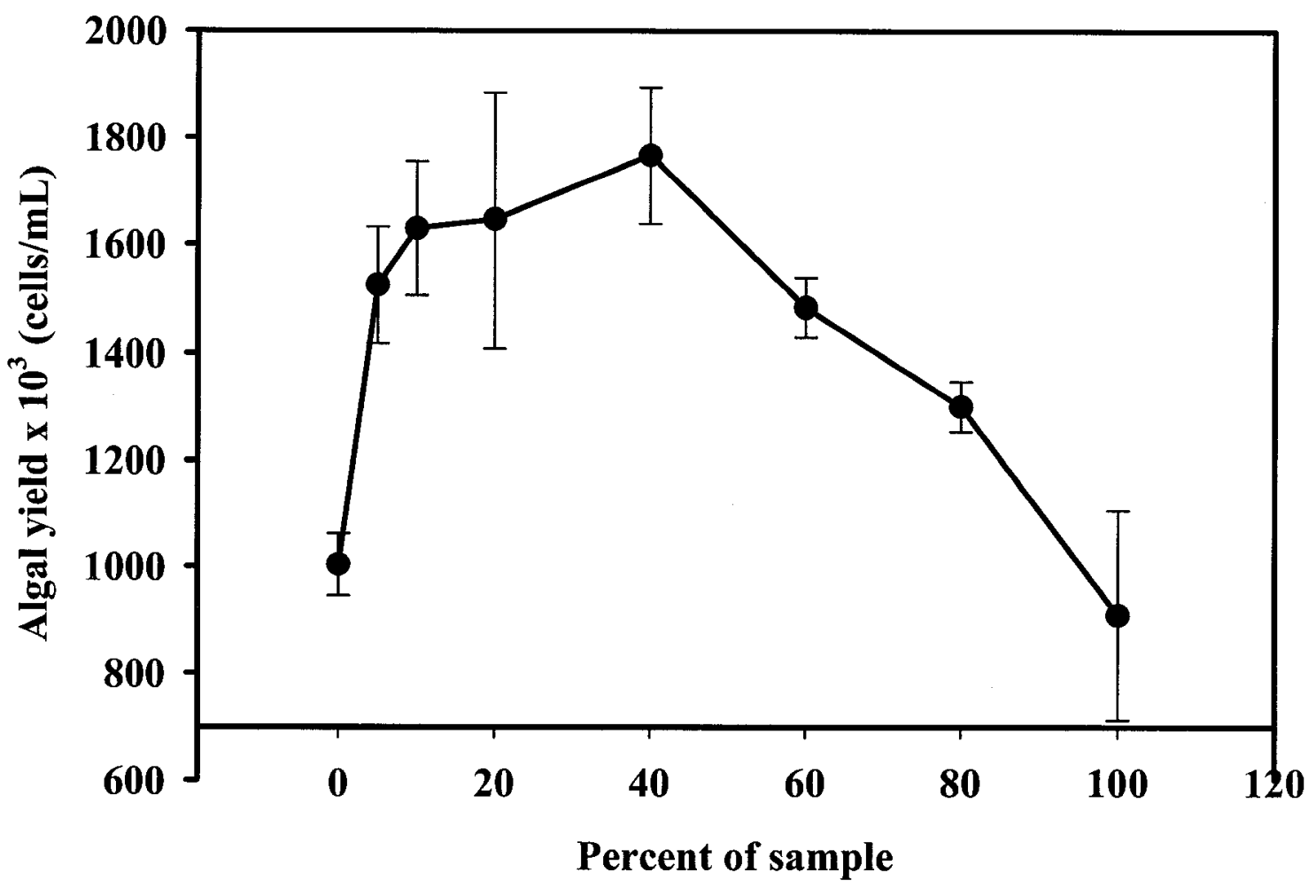

Figure 7.13 Algal bioassay as a function of percent water sample for Crean Hill Mine effluent collected in May 2006. The error bars represent $95.5 \%$ confidence intervals. 


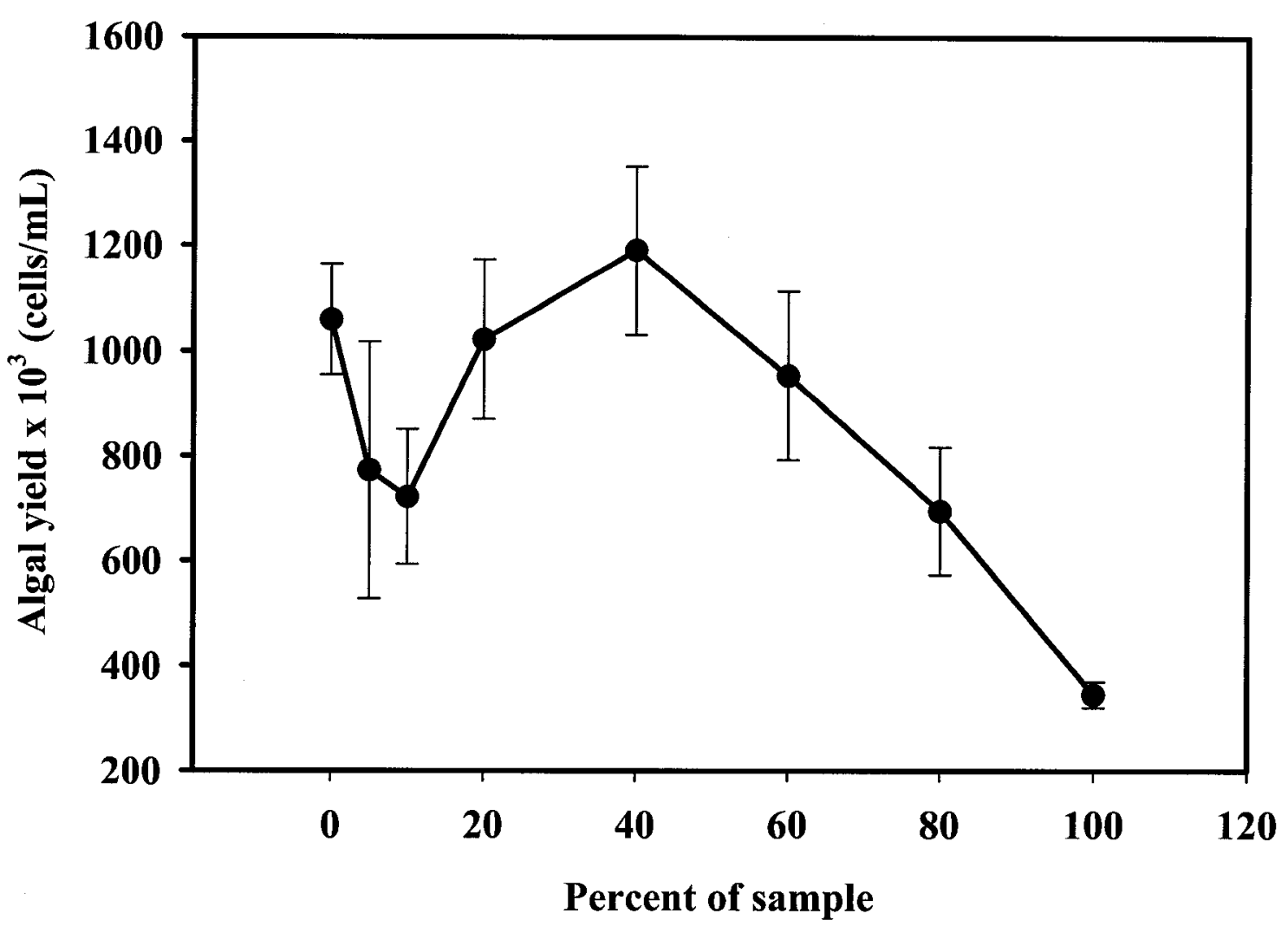

Figure 7.14 Algal bioassay as a function of percent water sample for Nolin Creek Waste Water Treatment Plant effluent collected in May 2006. The error bars represent $95.5 \%$ confidence intervals. 


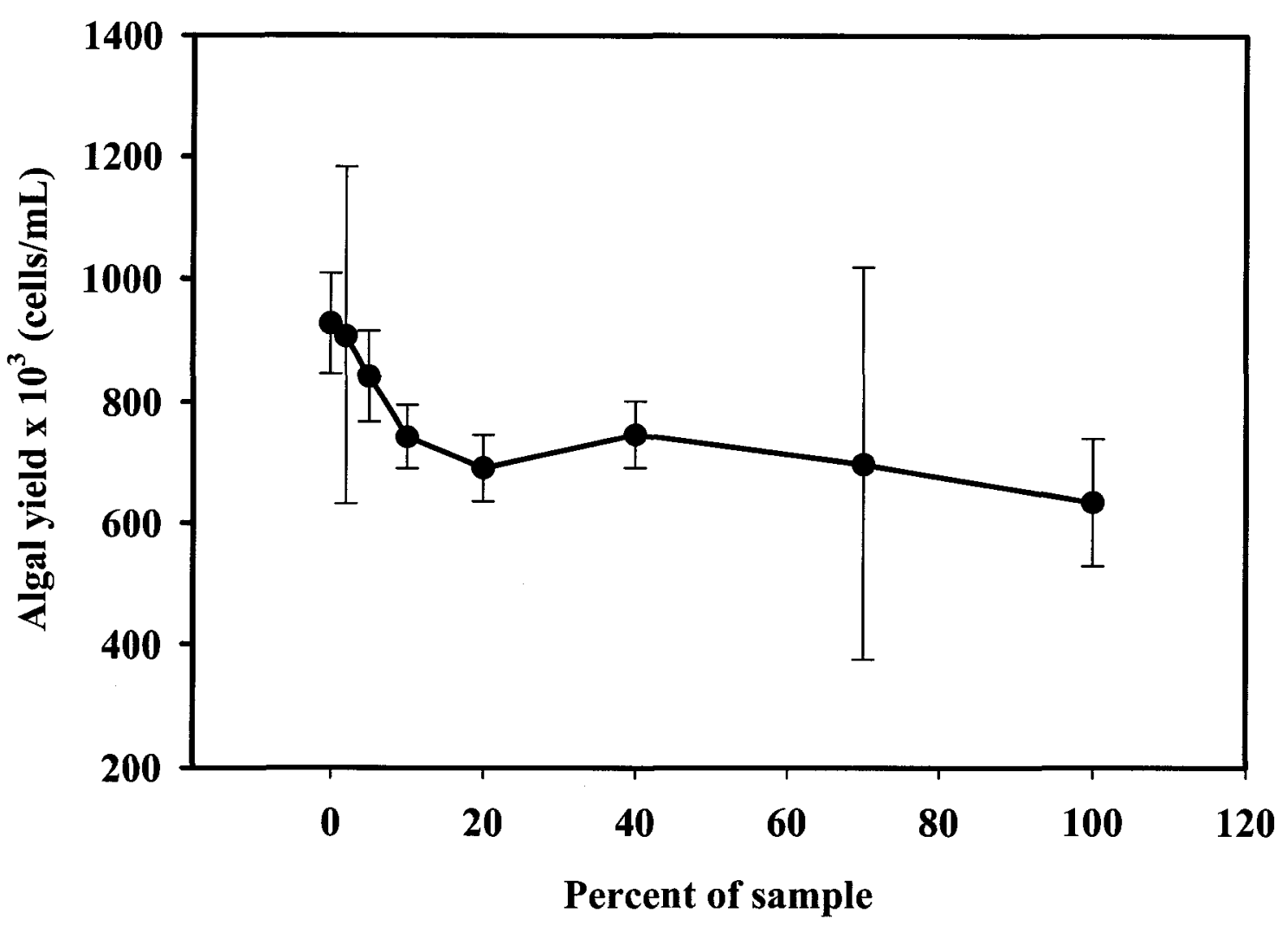

Figure 7.15 Algal bioassay as a function of percent water sample for Whistle Mine effluent collected in May 2006. The error bars represent $95.5 \%$ confidence intervals. 


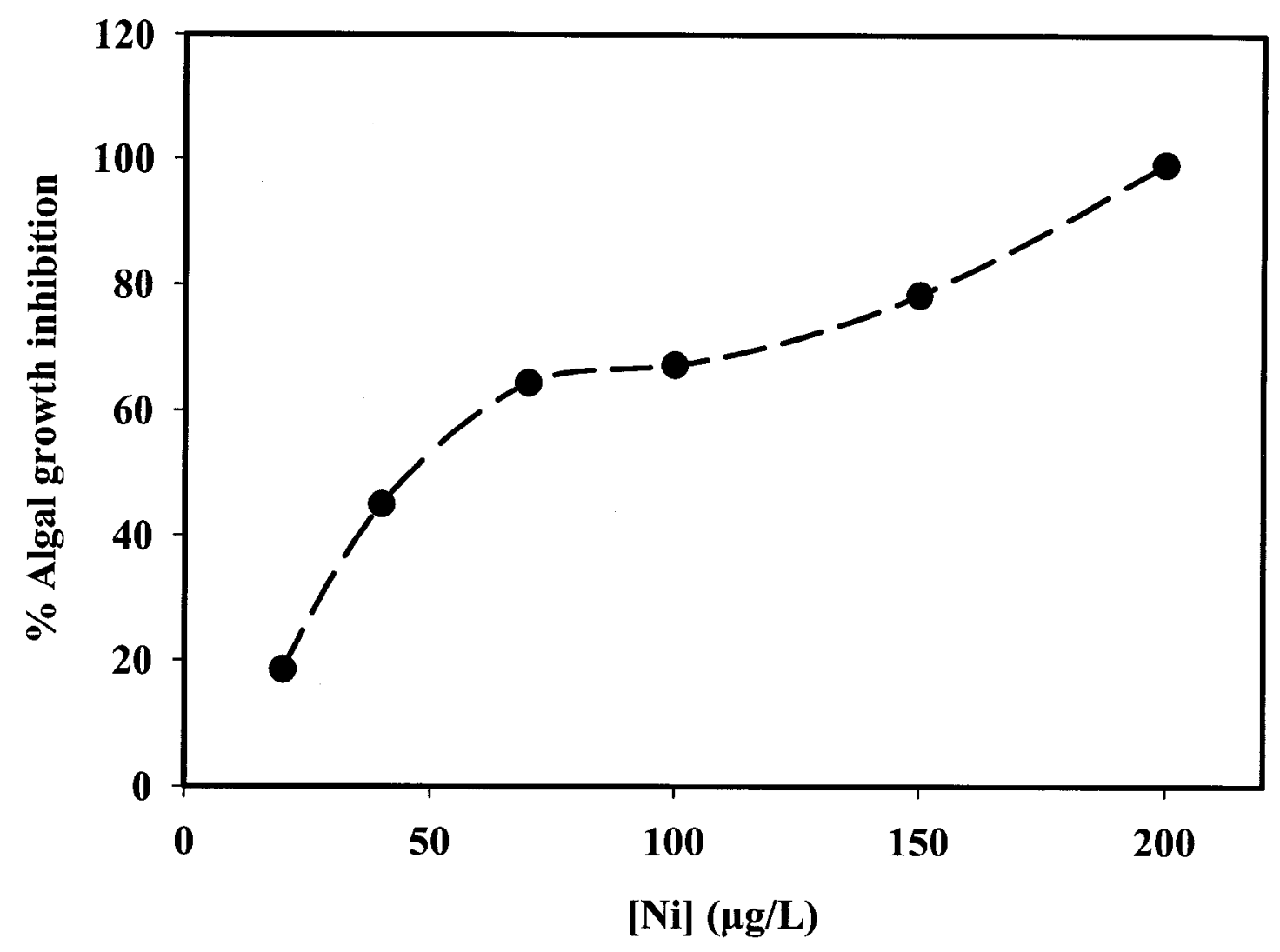

Figure 7.16 Inhibition test for standard nickel solution diluted with laboratory water. 


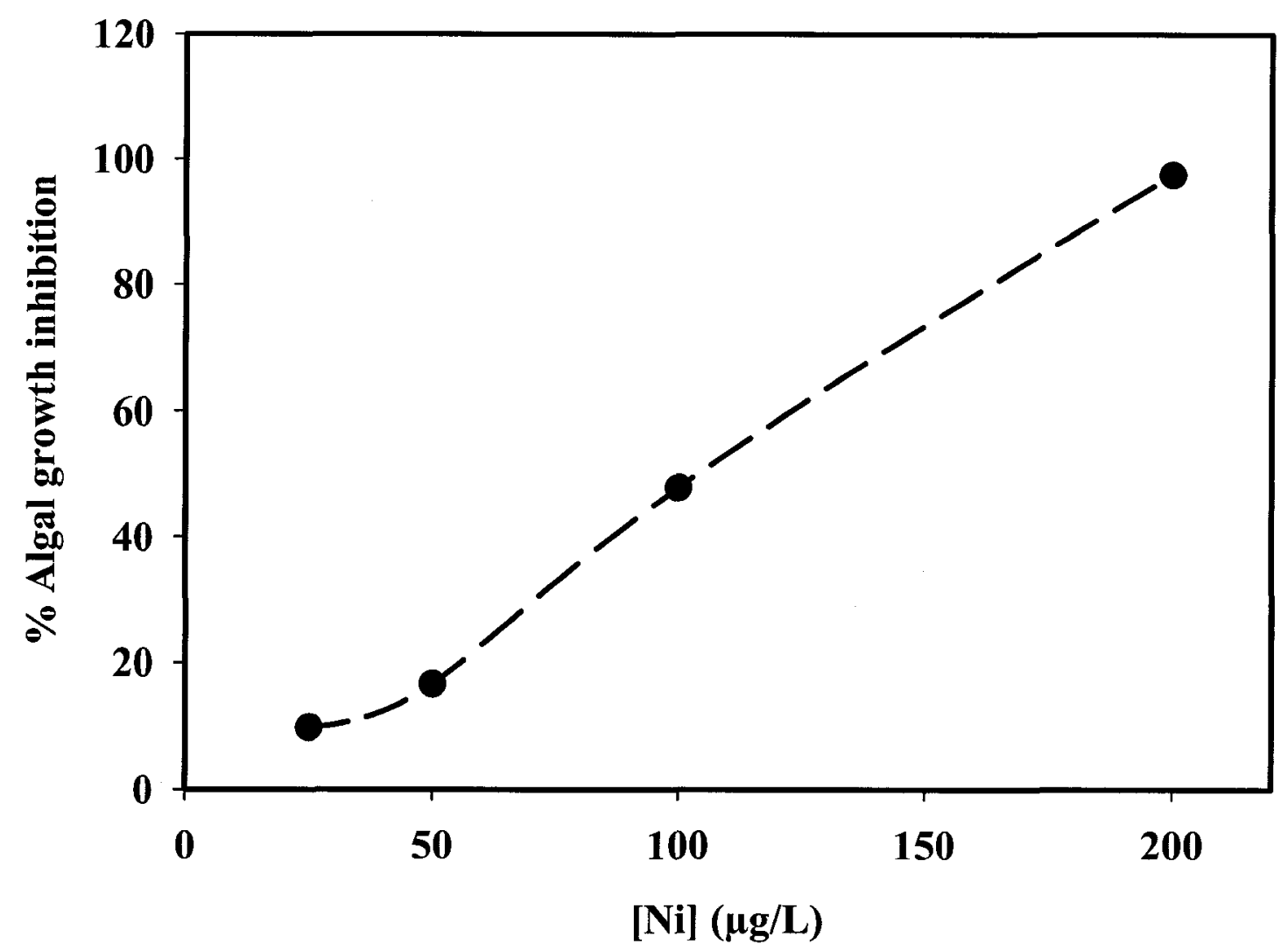

Figure 7.17 Inhibition test for standard nickel solution diluted with Reference River water. 


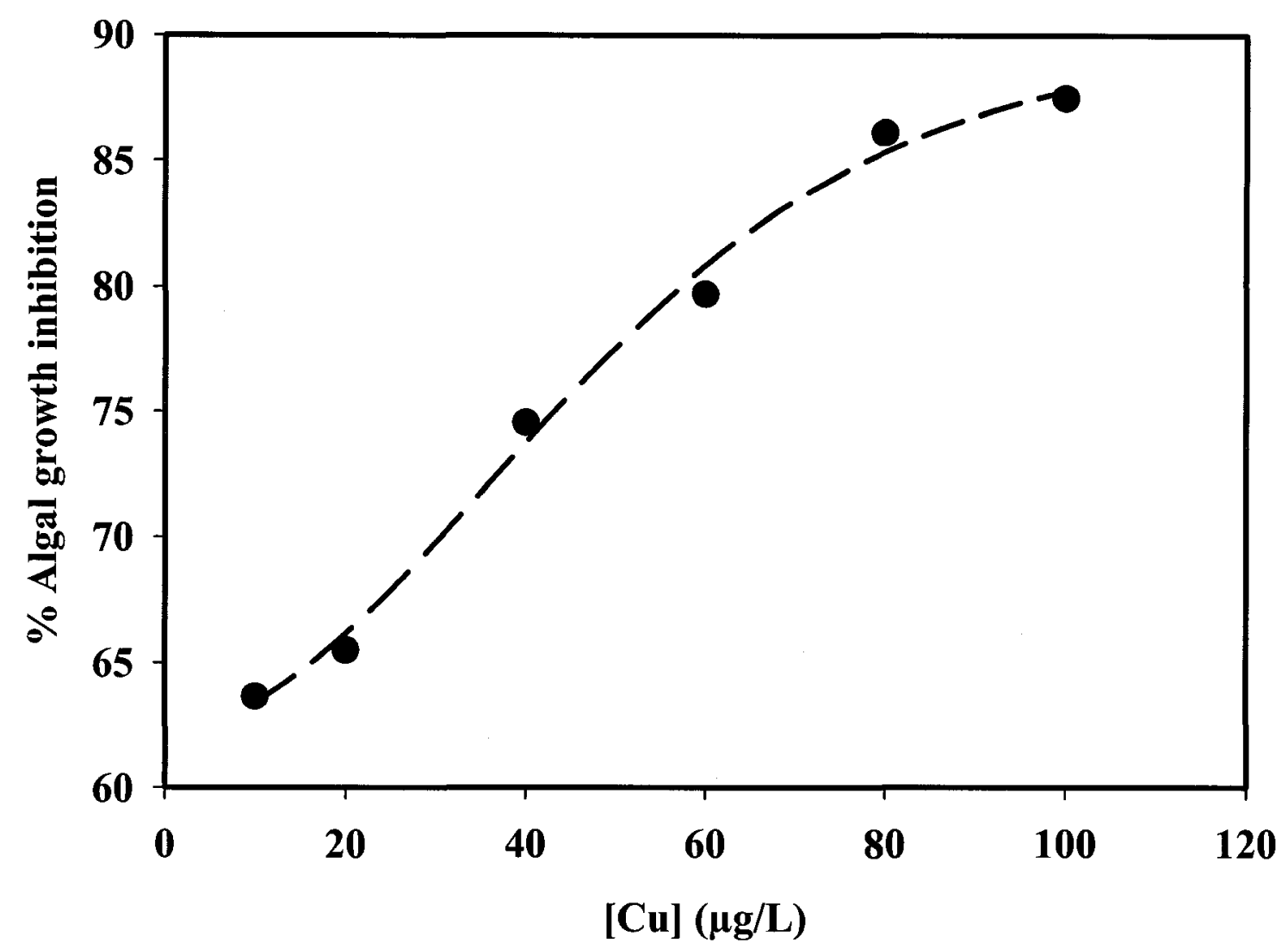

Figure 7.18 Inhibition test for standard copper solution diluted with laboratory water. 


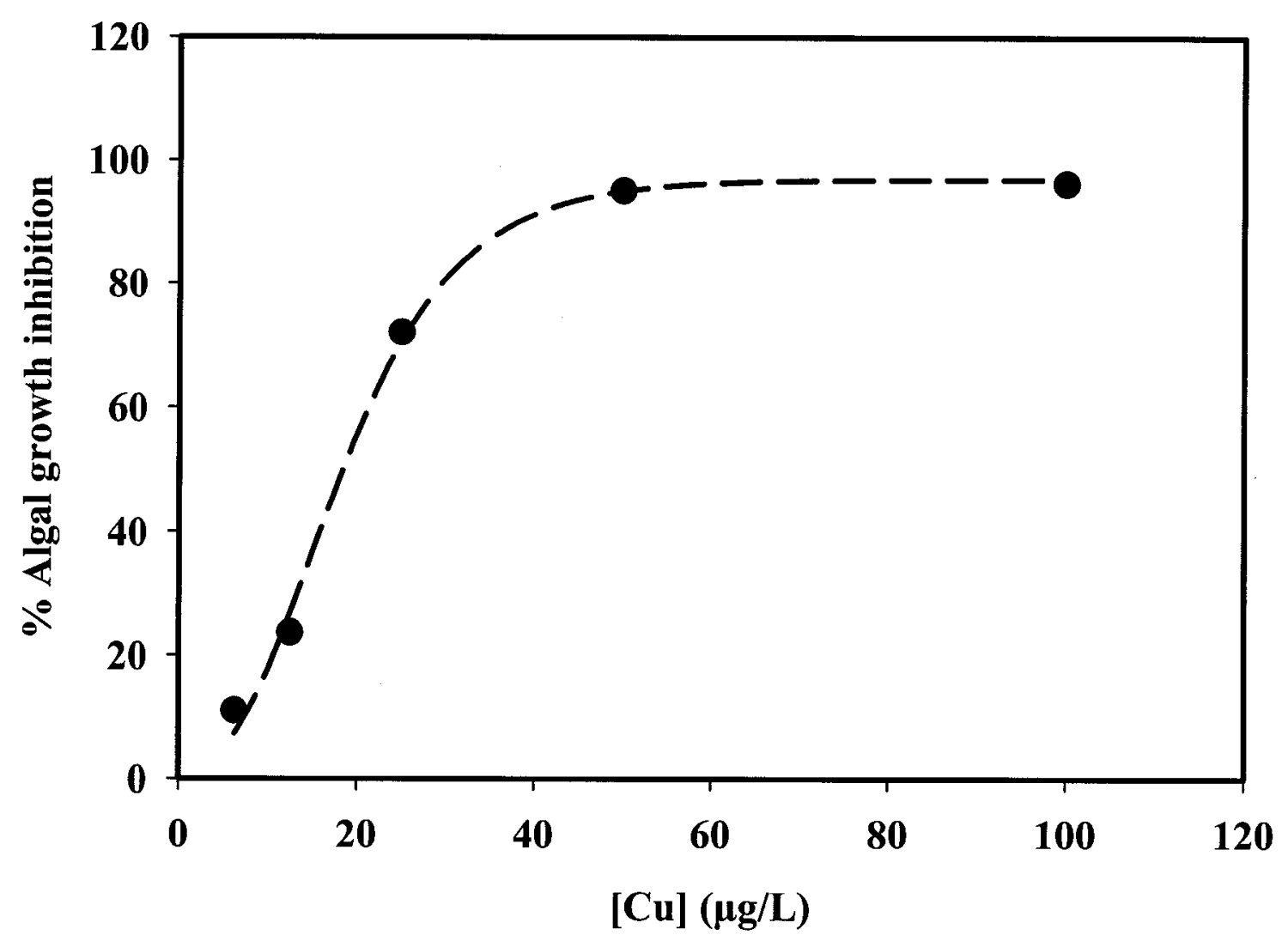

Figure 7.19 Inhibition test for standard copper solution diluted with Reference River water. 